NUREG/CR- -5447

TI9I 002467

\title{
Depressurization as an Accident Management Strategy to Minimize the Consequences of Direct Containment Heating
}

Manuscript Completed: September 1990

Date Published: October 1990

Prepared by

D. J. Hanson, D. W. Golden, R. Chambers, J. D. Miller, B. P. Hallbert, C. A. Dobbe

Idaho National Engineering Laboratory

M. Minaged by the U.S. Department of Energy

EG\&G Idaho, Inc.

Idaho Falls, ID 83415

Prepared for

Division of Engineering

Ofifice of Nuclear Regulatory Research

U.S. Nuclear Regulatory Commission

Washington, DC 20555

NRC FIN A6884

Under DOE Contract No. DE-AC07-76ID01570 


\begin{abstract}
Probabilistic Risk Assessments (PRAs) have identified severe accidents for nuclear power plants that have the potential to cause failure of the containment through direct containment heating (DCH). Prevention of DCH or mitigation of its effects may be possible using accident management strategies that intentionally depressurize the reactor coolant system (RCS). The effectiveness of intentional depressurization during a station blackout TMLB' sequence was evaluated considering the phenomenological behavior, hardware performance, and operational performance. Phenomenological behavior was calculated using the SCDAP/ RELAP5 severe accident analysis code. Two strategies to mitigate DCH by depressurization of the RCS were considered. One strategy, called early depressurization, assumed that the reactor head vent and pressurizer power-operated relief valves (PORVs) were latched open at steam generator dryout. The second strategy, called late depressurization, assumed that the head vent and PORVs were latched open at a core exit temperature of $\sim 922 \mathrm{~K}\left(1200^{\circ} \mathrm{F}\right)$. Depressurization of the RCS to a low value that may mitigate $\mathrm{DCH}$ was predicted prior to reactor pressure vessel breach for both early and late depressurization. The strategy of late depressurization is preferred over early depressurization because there are greater opportunities to recover plant functions prior to core damage and because failure uncertainties are lessened.
\end{abstract}

FIN No. A6884-Depressurization as an Accident Management Straiegy to minimize the consequences of $\mathrm{DCH}$. 


\section{EXECUTIVE SUMMARY}

Probabilistic Risk Assessments (PRAs) for some pressurized water reactors (PWRs) have identified severe accidents where portions of a damaged reactor core can relocate to the lower head of the reactor vessel while the pressure in the reactor coolant system (RCS) remains high. If the reactor vessel fails at high pressure there is a potential for ejection of molten corium and for the dispersal of this corium into the containment atmosphere. The energy released from the dispersed corium, oxidation of the metallic components in the corium, and potentially from hydrogen combustion or detonation in the containment atmosphere could cause direct containment heating (DCH). The resultant rapid rise in temperature and pressure of the containment atmosphere during DCH could cause early containment failure which could significantly increase public risk.

Accident management strategies have been identified that have the potential to either prevent or mitigate the high pressure severe accident sequences that can result in DCH. Examples of preventive strategies include (a) the feed and bleed of the steam generators using normal or alternate feedwater injection methods or water sources, and (b) the feed and bleed of the primary system using normal or alternate high pressure injection methods or sources of water. Strategies for mitigating $\mathrm{DCH}$ have also been identified in the event that preventative strategies are not effective. These strategies are generally aimed at minimizing the containment pressure rise by modifying the conditions controlling how extensively the core material is dispersed into the containment atmosphere. The basis for some of these strategies involves intentional depressurization of the reactor coolant system (RCS) prior to the failure of the lower head. These strategies would mitigate $\mathrm{DCH}$ by reducing the driving force for ejection and dispersal of the core melt.

A coordinated research program is currently being sponsored by the Nuclear Regulatory Commission to determine whether an accident management strategy that depressurizes the reactor coolant system of a PWR would be effective in reducing public risk by mitigating the effects of direct containment heating. This determination is being accomplished in two phases:

Phase 1-The objective of this phase is to determine whether the reactor coolant system pressure of a PWR can be effectively reduced to a sufficiently low value that the effects of $D C H$ will be mitigated.

Phase 2-The objective of this phase is to estimate the risk to the public resulting from DCH both with and without the strategy of RCS depressurization and to compare the change in risk with the benefits that can be identified from the use of this strategy.

This report describes the results from Phase 1. The probabilistic and phenomenological analyses necessary to produce the estimates for accomplishing Phase 2 are currently being performed.

The evaluations necessary to accomplish Phase 1 require integration of several different types of analyses including:

\section{Phenomenological behavio. \\ 2. Human performance \\ 3. Equipment performance \\ 4. Uncertainty effects.}

The analysis of phenomenological behavior provides information on whether a strategy will reduce the pressure to a sufficiently low level that the effects of direct containment heating will be mitigated and whether there may ; serious downside consequences such as excessive hydrogen generation or steam explosions that may occur during depressurization. The analysis of human performance provides information on the capability of the operator to implement RCS depressurization using plant procedures and estimates the likelihood that depressurization will be successfully implemented based on the timing of 
events and performance shaping factors such as stress levels. Analysis of equipment issues provides information on the operation of the equipment necessary for depressurization and identifies possible changes in the equipment or support systems that are needed for successful operation of the equipment. Uncertainties are discussed for each of these three areas.

The basic approach used for evaluating the effectiveness of intentional depressurization strategies includes three steps: (1) identify a typical plant and a risk important severe accident sequence suitable for analysis purposes, (2) identify and select depressurization strategies for evaluation, and (3) evaluate the effectiveness of the strategies for depressurizing the RCS and mitigating the effects of DCH using severe accident calculational tools. Step 3 includes evaluation of the the phenomenological behavior, human performance, and hardware performance of the strategies. Evaluation of the effectiveness of depressurization requires a judgement on how low RCS pressure must be for the effects of DCH to be mitigated. Based on currently available information, it was assumed that an RCS pressure that is within about $1 \mathrm{MPa}(145 \mathrm{psi})$ of the containment pressure will mitigate $\mathrm{DCH}$.

The major emphasis of this report is on strategies that involve opening the pressurizer power operated relief valves (PORVs) and upper head vent to force RCS depressurization. Both the positive and negative effects of these strategies are considered. The effectiveness of intentional depressurization is measured through comparisons with the case where the plant personnel do not successfully implement either prevention or mitigation strategies.

The Surry nuclear power plant was selected for the DCH evaluations based on the availability of pertinent information and on the potential for risk reduction through mitigating the effects of $\mathrm{DCH}$. Selection of a severe accident sequence for use in evaluation of intentional depressurization was based on risk results presented in the initial draft NUREG-1150. (The initial NUREG-1150 draft was used because it represented the most up- to-date information published at the time the depressurization evaluations were initiated.) The draft NUREG-1150 results indicated that for Surry about $74 \%$ of the total core damage frequency can be attributed to sequences involving high pressure core melt ejection where there is equipment available that could be used to depressurize the RCS. Because station blackout was the dominant contributor to this total (about 64 of the 74\%), a station blackout secpuence (TMLB') was selected for the evaluation of intentional depressurization. The TMLB' sequence is initiated by the loss of offsite power. Onsite ac power is also unavailable because the diesel generators fail supply power and all steam generator auxiliary feedwater fails.

If a TMLB' sequence occurs and the recovery actions taken by the plant personnel are ineffective, there is the potential that the reactor coolant system will fail and the system will depressurize. Initial analysis indicates that the pump seals, surge line, and hot leg are the most likely points of failure. Analysis is currently being performed to assess both the likelihood and effect of these failures. The results will be used to better estimate the risk associated with the direct containment heating for a TMLB' sequence. 'This estimate will serve as a baseline that can be used to determine the reduction in risk that is possible if the reactor coolant system is intentionally depressurized.

Accident management strategies involving intentional depressurization of the reactor coolant system have the potential to reduce the risk associated with DCH. Two depressurization strategies using the PORVs and upper head vent were selected for evaluation. The first strategy, called early depressurization, assumed that the PORVs and head vents are opened at the time the steam generators dry out. The second strategy, called late depressurization, assumed that the PORVs and head vents are opened at core uncovery, as defined by a core exit temperature of about $922 \mathrm{~K}$ $\left(1200^{\circ} \mathrm{F}\right)$. To assess relative effectiveness, these strategies were compared to each other and to a previous TMLB' calculation in which there was no depressurization. 
The intentional depressurization phenomenological analysis was performed using the SCDAP/RELAP5 integrated thermal-hydraulic and severe core damage analysis computer code. Because uncertainties in the calculated results may be large for the latter stages of severe damage sequences (formation of molten pools, relocation of corium to the reactor pressure vessel (RPV) lower head, and failure of the RPV lower head), an approach was developed to systematically bound uncertainties judged to be important to the calculation of pressure. This approach used a series of sensitivity calculations to vary certain core damage parameters within their uncertainty ranges. Based on these sensitivity studies, severe core damage parameters were selectud for use in the bounding calculations.

Based on the phenomenological behavior, human performance, and equipment performance for the two strategies, conclusions and recommendations concerning intentional depressurization have been formulated. These conclusions and recommendations are specific to the Surry Plant but their applicability to other nuclear power plants is discussed as a final conclusion.

1. Intentional depressurization using the PORVs and upper head vent has the potential to mitigate $\mathrm{DCH}$ by reducing the RCS pressure to within about $1 \mathrm{MPa}$ (145 psi) of the containment pressure.

Phenomenological analyses for both the early and late depressurization strategies indicated that the RCS pressure could be reduced to within about $1 \mathrm{MPa}$ of containment pressure. Based on information currently available, this value for RCS pressure would be sufficiently low that DCH could be mitigated. However, there are human factor and equipment issues that could affect the capability to successfully implement intentional depressurization. Several of the following conclusions discuss these issues.
2. Current Surry Emergency Operating Procedures would not initiate RCS depressurization for the TMLB' sequence. A human factors evaluation indicates that if modifications were made to the procedures, there is a high lik slihood that the plant personnel could successfully initiate depressurization strategies.

During a TMLB' sequence, the current Surry Emergency Operating Procedures would not provide an entry point into the Functional Restoration Procedure that initiates RCS depressurization using the PORVs. Because the Surry procedures are consistent with the Westinghouse Emergency Procedure Guidelines (EPGs), other Westinghouse plants that followed the EPGs would also be expected to lack guidance in their EOPs to depressurize during a TMLB' sequence.

A human factors evaluation identified two important factors that could affect the performance of the plant personnel in implementing depressurization strategies: (1) the capability of plant personnel to recognize that a depressurization strategy should be implemented and (2) the capability of the personnel to implement the necessary depressurization actions in the available time. A review of existing instrumentation indicates there would be adequate information for plant personnel to recognize initiation conditions for either the early depressurization strategy (initiated when the steam dry out) or the late depressurization strategy [initiated when the core exit thermocouples reach $922 \mathrm{~K}\left(1200^{\circ} \mathrm{F}\right)$ ].

A human reliability analysis (HRA) was performed to estimate the likelihood that personnel could implement depressurization based on possible changes that could be made to the EOPs. Implementation was separated 
into two components: diagnosis of the need to depressurize and the actions necessary to complete system depressurization. Because specific procedures were not available, the time required to diagnose the need to depressurize was difficult to determine and its effect on the failure probabilities was evaluated using a sensitivity study. The HRA results estimate that the probability of the failure to depressurize is $<0.08$ ( $>0.92$ probability of success) if there is more than twenty minutes available to perform diagnosis. This result would indicate that there is a relatively high lik slihood of proper implementation of early depressurization because there is adequate time for implementation. However, for late depressurization, the results indicate that cautions would need to be included in the procedures to alert the operator that the conditions for implementation of late depressurizaticn were being approached. The objective of these cautions would be to ensure a high likelihood of successful implementation of late depressurization in a minimum amount of time after the $922 \mathrm{~K}$ $\left(1200^{\circ} \mathrm{F}\right)$ initiation point is reached. Minimizing this time is important because significant delays in implementation would allow core temperatures to reach unacceptably high values.

3. Modifications to plant equipment at Surry would be necessary to ensure that intentional depressurization would be successful.

Based on draft NUREG-1150 results, there is a relatively high probability (0.3 conditional probability per demand) that a block valve on one of the PORV lines will be closed as a result of leakage. Because these block valves operate using only ac power, it would be impossible to open a closed block valve during a TMLB' sequence. The effect of a closed block valve would be to significantly slow RCS depressurization. Placing the block valves on emergency battery power would allow closed block valves to be opened during a station blackout, which would ensure that the strategies could be successfully implemented.

Both dc power and a supply of pressurized air are needed to force the PORVs to remain in an open position during RCS depressurization. At Surry, it is unlikely that the current systems could continue to supply their necessary functions over the eight to ten hour time period between when depressurization is initiated and the vessel fails for the TMLB' sequence. Additional capacity for both of these systems would be needed for intentional depressurization using the PORVs to be successful at Surry.

4. A strategy that depressurizes the RCS after the core begins to uncover (late depressurization) is preferred to the early depressurization strategy.

While the analyses predict a similar RCS pressure response for both the early and late depressurization cases, there are significant differences in the timing and the extent of core damage during the early stages of the TMLB' sequence. For early depressurization, latching open the PORVs removes large quantities water from the RCS early in the sequence which accelerates the onset of core heatup by about 46 minutes, when compared to late depressurization. By the time the pressure is sufficiently low that the emergency core cooling accumulators inject additional coolant, the temperature of some of the fuel rods have exceeded the threshold for oxidation of zircaloy. Accumulator injection therefore causes significant 
cladding oxidation and relocation and is not effective in controlling further core damage.

For late depressurization, core heatup begins at a later time because the water inventory in the RCS is not depleted as rapidly during the early portion of the sequence when the PORVs are cycling at their setpoints, rather than being latched open. When the PORVs are intentionally latched open late in the sequence, the inventory of water remaining in the RCS is relatively small and the RCS depressurizes rapidly to the pressure at which the accumulators inject. The temperatures in the core at the time of accumulator injection are generally below the threshold for rapid zircaloy oxidation. The accumulators initially discharge at higher rates than calculated for early depressurization, because of the higher initial depressurization rate and the inventory distribution in the RCS. Because temperatures are lower and the accumulator injection rates are higher, the core cooling during the period of accumulator injection is relatively effective and delays substantial core damage until the accumulators are empty. Thus, from a phenomenological standpoint, it is concluded that late depressurization is preferable to early depressurization because core heatup and significant core damage are delayed.

The only major difference in the demands on equipment needed to intentionally depressurize for the two strategies would be in the capacity of the air supply. The late depressurization strategy would use more air to operate the PORVs because they would cycle many more times at their setpoints. Cycling requires much more air than does maintaining the valve in its open position. However, this differ- ence is not considered to be significant because it is anticipated that the air supply system would require additional capacity for either strategy.

From an operational standpoint, late depressurization would maximize the time available for the operator to recover ac power and auxiliary feedwater. However, cautions and anticipatory actions should be included in the procedures to ensure immediate action when the initiation conditions were reached because some fuel rod temperatures at the upper core levels would be relatively high [ $>922 \mathrm{~K}$ $\left(1200^{\circ} \mathrm{F}\right)$ ].

5. Failure of the pressurizer surge line could cause the RCS to rapidly depressurize prior to failure of the reactor vessel lower head.

Hot steam and gases exiting the core heat the plant structures as they flow toward the PORVs. The calculation for early depressurization indicates that the pressurizer surge line would reach temperatures that are high enough to cause creep rupture failure during the time period when the accumulators are injecting. Because the temperature of the flow from a rupture would remain high, it is expected that the rupture area would be sufficiently large to rapidly depressurize the RCS. The calculation for late depressurization also indicates high surge line temperatures, but not sufficiently high to cause a failure prior to vessel failure. Surge line failure was also calculated when no operator action was taken to depressurize. Although failure of the surge line appears to be effective in depressurizing the system, strategies to intentionally depressurize are preferred because they control the accident conditions without relying on the failure of system components. 
6. The effect of in-vessel steam explosions during the relocation of molten core material on the integrity of the RCS needs to be assessed.

There is significant uncertainty in the effect on the reactor pressure vessel of a steam explosion resulting from core-coolant interactions when a molten core relocates during a severe accident. Because steam explosions are more likely at low pressures, use of an intentional depressurization strategy may increase the possibility of vessel damage from a steam explosion. To determine the influence of steam explosions on risk to the public, additional analysis will be needed to assess the potential for steam explosions at various pressure levels and to evaluate the potential for vessel failure.

7. The conclusions on the effectiveness of intentional depressurization strategies are specific to Surry and their extrapolation to other plants must $r$ considered carefully.

A detailed evaluation of the applicability of the Surry results to other plants was not within the scope of this program. However, a preliminary assessment of some important considerations was performed to provide insight as to the possible behavior of other plants under similar transients and initial conditions. Plant differences that could strongly influence the success of intentional depressurization would be associated with the plant hardware or with the plant operations.

Although the effect of plant operations can be very important, this effect was not evaluated because detailed procedures were not available for a reasonable cross section of plants and discussions with the operations staff to evaluate their use of the procedures was beyond the scope of this program. It is recognized that procedural changes could be made to ensure the success of intentional depressurization if plant specific analysis indicated that current procedures were not adequate. Hardware parameters that were considered to be important influences on intentional depressurization include: (a) PORV characteristics, (b) pressurizer, surge line, and relief valve piping characteristics, (c) plant support system capabilities, (d) accumulator setpoints, and (e) containment type. As an example, containment type may be important because the generation of large quantities of hydrogen was calculated during intentional depressurization. Some containment types may require additional equipment that is capable of recombining this hydrogen over a time frame that will prevent detonation and containment failure. It is recognized that other plant characteristics such as steam generator type and core characteristics (control rod material, power profile, etc.) may also influence depressurization. The potential effects of these diffenences will be assessed and discussed in a later report. 


\section{ACKNOWLEDGMENTS}

The authors wish to express their appreciation to Dr. Frank Odar for his guidance and support throughout this project. Additional thanks to Dr. Chris Allison for his help in developing an approach to bounding possible uncertainties for the SCDAP/RELAP5 analysis, Mr. R. Jack Dallman for his help in developing an approach for this analysis, and to Mr. Anthony N. Brown for performing MELCOR calculations. Thanks is due to Mr. Jeff Wright for his assistance in editing this report. 


\section{CONTENTS}

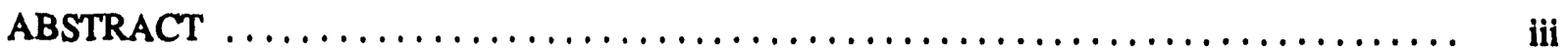

EXECUTIVE SUMMARY $\ldots \ldots \ldots \ldots \ldots \ldots \ldots \ldots \ldots \ldots \ldots \ldots \ldots \ldots \ldots \ldots \ldots \ldots \ldots \ldots$

ACKNOWLEDGMEN $\mathrm{TS} \ldots \ldots \ldots \ldots \ldots \ldots \ldots \ldots \ldots \ldots \ldots \ldots \ldots \ldots \ldots \ldots \ldots$

1. INTRODUCTION $\ldots \ldots \ldots \ldots \ldots \ldots \ldots \ldots \ldots \ldots \ldots \ldots \ldots \ldots \ldots \ldots \ldots \ldots \ldots$

2. APPROACH FOR EVALUATION OF INTENTIONAL DEPRESSURIZATION . . . . . . 3

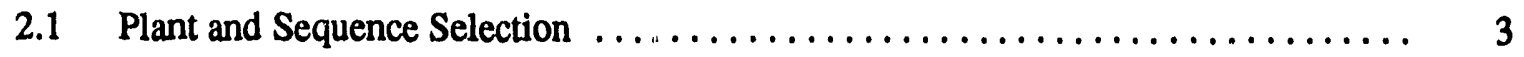

2.2 Selection of Depressurization Strategies for Evaluation $\ldots \ldots \ldots \ldots \ldots \ldots \ldots \ldots$

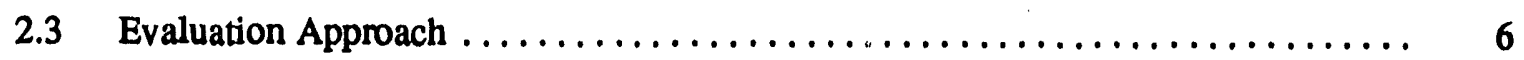

3. INTENTIONAL DEPRESSURIZATION USING THE PORV $\ldots \ldots \ldots \ldots \ldots \ldots \ldots \ldots$

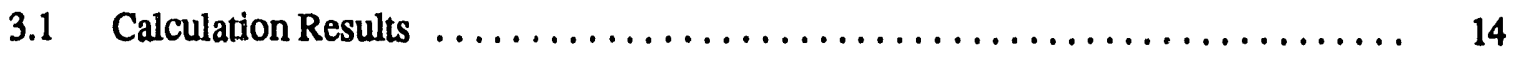

3.1.1 Calculations for Early Depressurization .................. 14

3.1.2 Late Depressurization ........................... 23

3.1.3 Comparison of Depressurization Strategies and No Operator Action .... . 32

$3.2 \quad$ PORV Capabilities and Limitations $\ldots \ldots \ldots \ldots \ldots \ldots \ldots \ldots \ldots \ldots \ldots \ldots \ldots \ldots \ldots \ldots \ldots$

3.3 Assessment of Operational Performance ..................... 37

3.3.1 Factors That Can Affect Operator Performance ............... 37

3.3.2 Human Reliability Analysis $\ldots \ldots \ldots \ldots \ldots \ldots \ldots \ldots \ldots \ldots \ldots . . \ldots$

3.4 Extension of Results to Other Plants $\ldots \ldots \ldots \ldots \ldots \ldots \ldots \ldots \ldots \ldots \ldots \ldots \ldots$

3.4.1 PORV Characteristics $\ldots \ldots \ldots \ldots \ldots \ldots \ldots \ldots \ldots \ldots \ldots \ldots . \ldots \ldots$

3.4.2 Pressurizer, Surge Line, and Relief Valve Piping Characteristics ....... 41

3.4.3 Plant Support System Capabilities ...................... 44

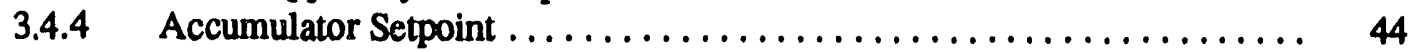

3.4.5 Containment Type $\ldots \ldots \ldots \ldots \ldots \ldots \ldots \ldots \ldots \ldots \ldots \ldots \ldots \ldots, 44$

4. CORE RECOVERY USING AUXILIARY FEEDWATER $\ldots \ldots \ldots \ldots \ldots \ldots \ldots \ldots$

4.1 Effectiveness of Feedwater Addition $\ldots \ldots \ldots \ldots \ldots \ldots \ldots \ldots \ldots \ldots \ldots$

4.2 Operational Performance for Feedwater Addition $\ldots \ldots \ldots \ldots \ldots \ldots \ldots \ldots$ 


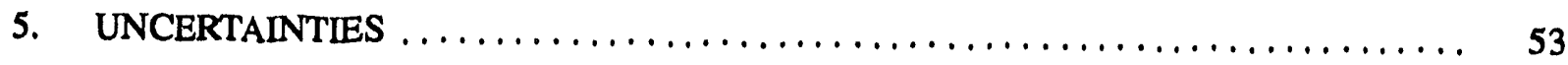

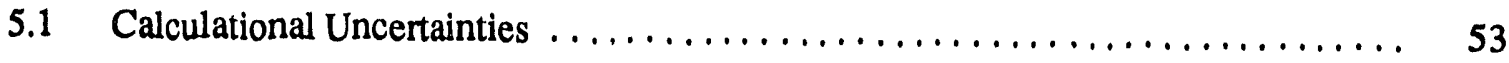

5.1 .1 Thermal-Hydraulic Uncertainties $\ldots \ldots \ldots \ldots \ldots \ldots \ldots \ldots \ldots \ldots$

5.1 .2 Core Damage Progression Uncertainties $\ldots \ldots \ldots \ldots \ldots \ldots \ldots \ldots \ldots$

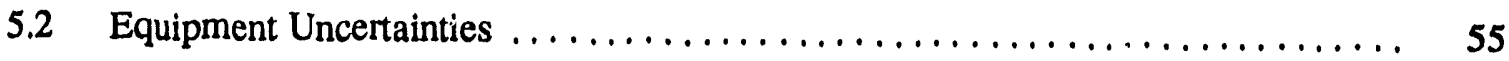

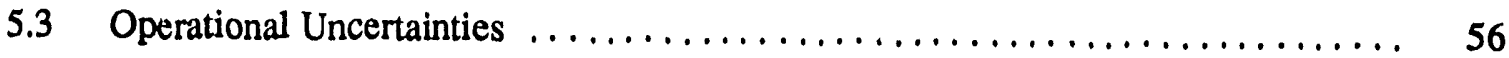

6. CONCLUSIONS AND RECOMMENDATIONS $\ldots \ldots \ldots \ldots \ldots \ldots \ldots \ldots \ldots \ldots$

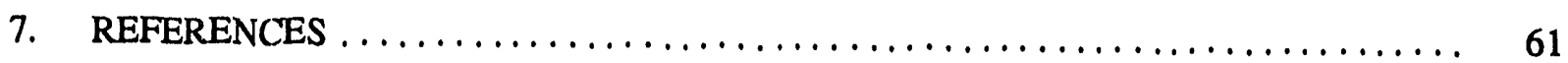

APPENDIX A-TRANSIENT SEQUENCES AND STRATEGIES $\ldots \ldots \ldots \ldots \ldots \ldots \ldots \ldots$ A-1

APPENDIX B-DEPRESSURIZATION STRATEGIES $\ldots \ldots \ldots \ldots \ldots \ldots \ldots \ldots \ldots$ B-1

APPENDIX C - SCDAP/RELAP5 CORE DESCRIPTION $\ldots \ldots \ldots \ldots \ldots \ldots \ldots \ldots, \ldots$

APPENDIX D IINPUT MODELS $\ldots \ldots \ldots \ldots \ldots \ldots \ldots \ldots \ldots \ldots \ldots \ldots \ldots \ldots \ldots$

APPENDIX E-CORE MELT PROGRESSION $\ldots \ldots \ldots \ldots \ldots \ldots \ldots \ldots \ldots \ldots \ldots \ldots$

APPENDIX F-EVALUATION OF PORV TEMPERATURE RESPONSE FOR LATE

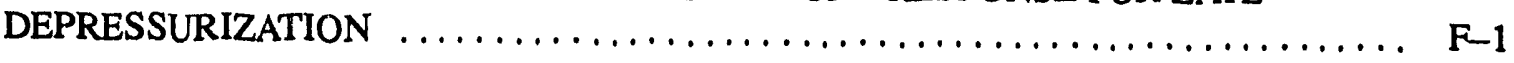

APPENDIX G-EMERGENCY OPERATING PROCEDURES $\ldots \ldots \ldots \ldots \ldots \ldots \ldots \ldots$ G-1

FIGURES

1. Plant state 1 iagram for the TMLB' sequence $\ldots \ldots \ldots \ldots \ldots \ldots \ldots \ldots \ldots \ldots$

2. Calculation paths used for core damage parameter study $\ldots \ldots \ldots \ldots \ldots \ldots \ldots$

3. Representation of fuel rod oxide shell failure $\ldots \ldots \ldots \ldots \ldots \ldots \ldots \ldots \ldots \ldots$

4. Core relocation model for maximum steam interactions $\ldots \ldots \ldots \ldots \ldots \ldots \ldots \ldots$

5. Core relocation model for minimum steam interactions $\ldots \ldots \ldots \ldots \ldots \ldots \ldots$

6. RCS pressure calculated for early depressurizatior calculations 1 and $2 \ldots \ldots \ldots$

7. Pressurizer level calculated for early depressurization calculation $1 \ldots \ldots \ldots \ldots \ldots$

8. Maximum cladding temperature for early depressurization calculation $1 \ldots \ldots \ldots \ldots$

9. Pressurizer surge line average metal temperature calculated for early depressurization 16

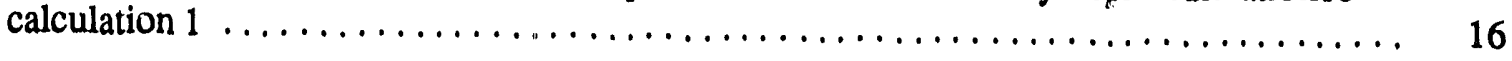

10. Effect of relocation criterion on mass of relocatid core materials $\ldots \ldots \ldots \ldots \ldots \ldots \ldots$ 
11. RCS pressure calculated for early depressurization sensitivity calculations 6 and $7 \ldots \ldots$

12. Cladding temperatures at $3.5 \mathrm{~m}$ calculated for early depressurization

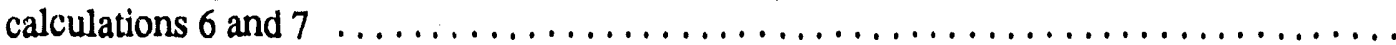

13. Total hydrogen generated during early depressurization sensitivity calculations 6 and $7 \ldots 20$

14. Comparison of calculated core geometries for calculations 6 and 7, early

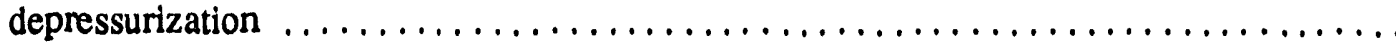

15. RCS pressure calculated following corium relocation to lower plenum, early

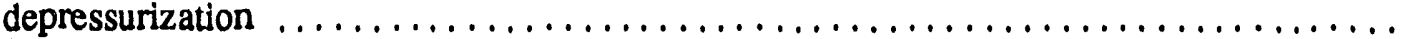

16. Maximum debris and lower head metal temperatures for maximum steam interactions ....

17. Maximum debris and wall temperatures for minimum steam interactions $\ldots \ldots \ldots \ldots \ldots 23$

18. Comparison of calculated RSC pressure for late and early depressurization . . . . . . . . 24

19. Early and late depressurization phenomenologicai sequences $\ldots \ldots \ldots \ldots \ldots \ldots \ldots \ldots$

20. Comparison of RPV downcomer liquid levels calculated for early and late

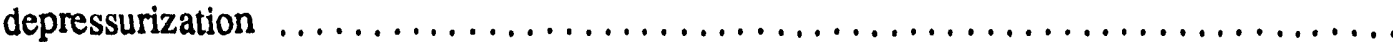

21. Cold leg mass flow rates calculated for late depressurization during first accumulator

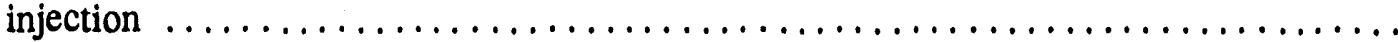

22. Cold leg mass flow rates calculated during first accumulator cycle, early depressurization calculation 6

23. Comparison of early and late depressurization cladding temperatures calculated

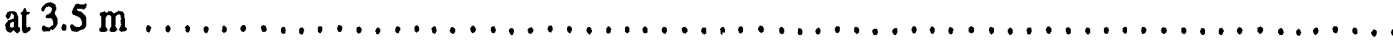

24. Total hydrogen generated compared to accumulator volume for ear'y depressurization

25. Hydrogen partial pressure in cold leg after first accumulator injection calculated for

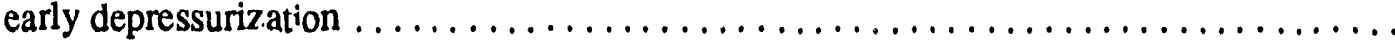

26. Total hydrogen generated compared to accumulator volume for late depressurization .... 31

27. Surge line average metal temperatures calculated for late depressurization $\ldots \ldots \ldots \ldots .32$

28. Calculated RCS pressure for various depressurization strategies $\ldots \ldots \ldots \ldots \ldots \ldots \ldots$

29. Schematic drawing of a valve typical of the Surry PORVs $\ldots \ldots \ldots \ldots \ldots \ldots \ldots \ldots$

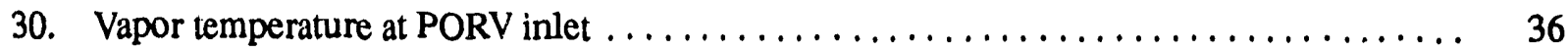

31. Power scaling of Surry relief valve size to other PWRs $\ldots \ldots \ldots \ldots \ldots \ldots \ldots \ldots \ldots \ldots$

32. Volume scaling of Surry relief valve size to other PWRs $\ldots \ldots \ldots \ldots \ldots \ldots \ldots \ldots \ldots$ 
33. Primary and secondary system pressures for calculations 1 and $2 \ldots \ldots \ldots \ldots \ldots \ldots$. 47

34. Comparison of steam generator liquid level for calculations 1 and $2 \ldots \ldots \ldots \ldots \ldots$

35. Comaprison of void fraction at top of core for calculations 1 and $2 \ldots \ldots \ldots \ldots \ldots$

36. Comparison of cladding surface temperature at top of core for calculations 1 and $2 \ldots \ldots$

37. Comparison of collapsed core liquid level for calculations 1 and $2 \ldots \ldots \ldots \ldots \ldots .49$

38. Comparison of pressurizer liquid level for calculatious 1 and $2 \ldots \ldots \ldots \ldots \ldots \ldots$

A-1. Core damage frequency shown by sequence group $\ldots \ldots \ldots \ldots \ldots \ldots \ldots \ldots \ldots$ A 6

2-1. Nodalization of the pressurizer loop for the SCDAP/RELAPS calcalations $\ldots \ldots \ldots \ldots \ldots \ldots \ldots \ldots \ldots \ldots \ldots \ldots \ldots \ldots \ldots \ldots \ldots \ldots \ldots \ldots$

D-2. Nodalization of the reactor yressure vessel for the SCDAP/RELAPS calculations ..... D-5

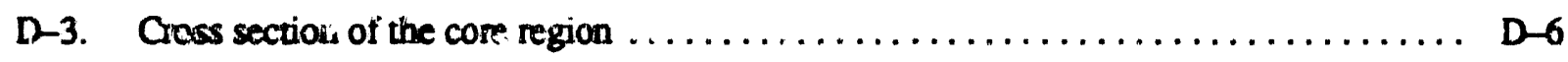

D-4. Axial peaking factors used in the SCDAP/RELAPS analysis $\ldots \ldots \ldots \ldots \ldots \ldots \ldots$

D-5. Surry cum ainment nodalization and flow path diagram $\ldots \ldots \ldots \ldots \ldots \ldots \ldots \ldots$ D 7

E-1. Calculation paths used for core damage parameter study $\ldots \ldots \ldots \ldots \ldots \ldots \ldots$ E-5

F-1. Nodalization used for the late depressurization extension calculations $\ldots \ldots \ldots \ldots \ldots$ F 4

F-2. Calculated steam temperanures in the pressurizer system for the late depressurization

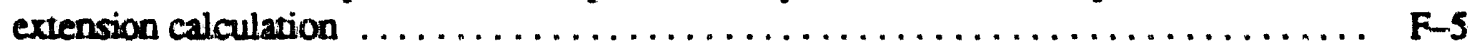

F-3. Calculated average metal temperanures in the pressurizer system for the late depressurization extension calculation ....................... F-6

\section{TABLES}

1. Depressurization calculations $\ldots \ldots \ldots \ldots \ldots \ldots \ldots \ldots \ldots \ldots \ldots \ldots \ldots \ldots \ldots \ldots \ldots \ldots \ldots \ldots$

2. Calculation matrix used for the sensitivity studies $\ldots \ldots \ldots \ldots \ldots \ldots \ldots \ldots$

3. ASEP nominal HEPs for operator actions to depressurize the RCS $\ldots \ldots \ldots \ldots \ldots$

4. Key to abbreviations for Figures 31 and $32 \ldots \ldots \ldots \ldots \ldots \ldots \ldots \ldots \ldots \ldots \ldots \ldots \ldots$

5. Feodwater addition calculations $\ldots \ldots \ldots \ldots \ldots \ldots \ldots \ldots \ldots \ldots \ldots \ldots \ldots$

6. ASEP rominal HEPs for actions to utilize emergency diesel firewater pumps to feed

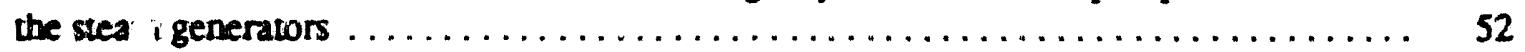

A-1. Risk dominan sequences by sequence and sequence group $\ldots \ldots \ldots \ldots \ldots \ldots \ldots$ 


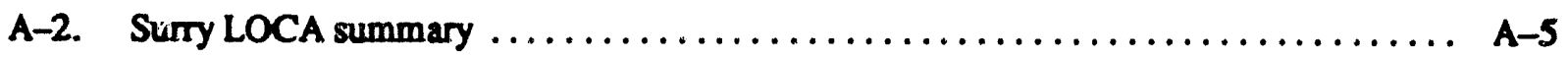

A-3. CDF for sequences subject to preventive modification or depressurization $\ldots \ldots \ldots \ldots$ A-7

B-1. Depressurization strategies $\ldots \ldots \ldots \ldots \ldots \ldots \ldots \ldots \ldots \ldots \ldots \ldots \ldots \ldots \ldots$ B $\ldots \ldots$

G-1. Operator actions required by Emergency Procedure $1.00 \ldots \ldots \ldots \ldots \ldots \ldots \ldots$ 


\section{DEPRESSURIZATION AS AN ACCIDENT MANAGEMENT STRATEGY TO MINIMIZE THE CONSEQUENCES OF DIRECT CONTAINMENT HEATING}

\section{INTRODUCTION}

Probabilistic Risk Assessments (PRAs) for some pressurized water reactors (PWRs) have identified severe accidents where portions of a damaged reactor core can relocate to the lower head of the reactor vessel while the pressure in the reactor coolant system (RCS) remains high. Failure of the lower head under these conditions could eject molten core material at sufficiently high velocities that the material would not collect in the reactor vessel cavity but would instead be dispersed into the containment atmosphere. This dispersal of core material could rapidly increase the temperature and pressure of the containment atmosphere through direct transfer of thermal energy. Additional energy could also be released rapidly to the containment atmosphere by the oxidation of metallic components in the core material and by the deflagration or detonation of hy'drogen. The process of rapid energy transfer and conversion is generally called direct containment heating (DCH).

If large quantities of molten core material are dispersed into the containment atmosphere during a severe accident, $\mathrm{DCH}$ couid rapidly pressurize the containment beyond its structural limits. The resulting containment failure could occur relatively early in the accident, reducing the time available for evacuation and sheltering and thereby increasing public risk. The risk significance of DCH was initially discussed in NUREG-0956 as one of eight areas representing major technical uncertainties. ${ }^{!}$The first draft of NUREG-1150 indicated that DCH rould change risk by up to an order of magnitude for the Surry nuclear power plant. ${ }^{2}$ In the second draft of NUREG-1150, it was concluded that the contribution of DCH to early containment failure was smaller than previously determined but was still an important contributor to risk for some PWRs. ${ }^{3}$

Accident management strategies have been ident:fied that have the potential to either prevent or mitigate the h:gh pressure severe accident sequences that can result in DCH. Exampies of preventive strategies include the following: (a) feed and bleed of the steam generators using normal or alternate feedwater injection methods or water sources, and (b) feed and bleed of the primary system using normal or alternate high pressure injection methods or sources of water. The effectiveness of these or similar preventative strategies have been, or will be, investigated during the development of current or future Individual Plant Evaluations (IPEs) or Probabilistic Risk Assessments (PRAs).

Mitigative strategies for DCH have also been identified in the event that preventative strategies are ineffective. These strategies are generally aimed at minimizing the pressure rise associated with DCH by modifying the conditions controlling how extensively the core material is dispersed into the containment atmosphere. Important contributors to dispersal include the following: the magnitude of the RCS pressure (driving force for ejecting the molten core material), the quantity of molten core material ejected, the composition of the ejected material, and the geometry of the reactor vessel cavity. Based on these contributors, strategies that intentionally depressurize the reactor coolant system (RCS) prior to the failure of the lower head have the potential to mitigate $\mathrm{DCH}$ by reducing the driving force for ejection of the core melt. 
The Nuclear Regulatory Commission (NRC) is currently conducting a coordinated research program to determine whether an accident management strategy that intentionally depressurizes the reactor coolant system of a PWR would be effective in reducing public risk by mitigating the effects of direct containment heating. This determination is being accomplished in two phases:

Phase 1-The objective of this phase is to determine whether the reactor coolant system pressure of a PWR can be effectively reduced to a sufficiently low value that the effects of DCH will be mitigated.

Phase 2-The objective of this phase is to estimate the risk to the public resulting from DCH both with and without the strategy of intentional RCS depressurization and to compare the change in risk with the benefits that can be identified from the use of this strategy.

This report describes the results from Phase 1. The phenomenological and probabilistic analyses necessary to produce the estimates for accomplishing Phase 2 are currently being performed.

The evaluations necessary to accomplish Phase 1 require integration of several different types of analyses including:

- Phenomenological behavior

- Human performance

- Equipment performance

- Uncertainty effects.

The phenomenological behavior analysis provides information to determine whether a strategy will reduce the pressure to a sufficiently low level that the effects of direct containment heating will be mitigated. It can also be used to determine whether there are serious downside consequences such as excessive hydrogen generation or steam explosions that may occur during depressurization. The human performance analysis provides information on the capability of the operator to initiate intentional depressurization using plant procedures, and provides estimates of the likellhood that depressurization will be successfully implemented based on the timing of events and the existing performance shaping factors, such as stress levels. Equipment analysis provides information on the performance of the equipment necessary for depressurization and identifies possible changes that may be needed in the equipment or support systems for successful operation.

The major emphasis of this report is on strategies that involve opening the pressurizer power operated relief valves (PORVs) and upper head vent to force RCS depressurization. Both the pos. itive and negative effects of these strategies are considered. The effectiveness of intentional depressurization is measured ihrough comparisons with the case where the plant personnel do not successfully implement either prevention or mitigation strategies.

The remainder of this report describes the approach used in the evaluation of intentional depressurization and the results obtained. Section 2 describes the approach and discusses the selection of a plant as well as a risk important sequence for evpluation. Section 3 describes the analysis performed, the results, and the applicability of the results to PWRs in general. Section 4 discusses an evaluation of the potential to recover the core using alternate methods of adding feedwater addition to the steam generator. Section 5 discusses the uncertainties in the re. sults and Section 6 presents conclusions and recommendations. 


\section{APPROACH FOR EVALUATION OF INTENTIONAL DEPRESSURIZATION}

The basic approach used for evaluating the effectiveness of intentional depressurization includes the following three steps: (1) identify a typical plant and a risk important severe accident sequence suitable for analysis purposes, (2) identify and select depressurization strategies for evaluation, and (3) evalua? the effectiveness of the strategies for depressurizing the RCS and mitigating the effects of DCH using severe accident calculational tools. Step 3 includes evaluation of the phennmenological behavior, human farformance, and hardware performance of tine strategies. Evaluation of the effectiveness of depressurization requires a judgement on how low RCS pressure must be for the effects of $\mathrm{I}, \mathrm{CH}$ to be mitigated. Based on currently available information, it was assumed that an RCS pressure that is within about $1 \mathrm{MPa}$ (145 psi) of the containment pressure will mitigate DCH. The following subsections discuss the three steps in detail.

\subsection{Plant and Sequence Selection}

The Surry nuclear power plant was selected for the DCH evaluations because of the availability of pertinent information and the potential for risk reduction through mitigating the effects of $\mathrm{DCH}$. Both significant plant and risk-related information were available because Surry was one of three PWRs being evaluated for the NUREG-1150 program. In addition, a SCDAP/ RELAP5 model of the plant was available for calculating the plant severe accident behavior. ${ }^{4}$ Surry is a Westinghouse-designed PWR with three coolant loops. Rated core thermal power is $2441 \mathrm{MW}$. Two PORVs, each with a capacity of $179,000 \mathrm{lb} / \mathrm{hr}$ of steam, can be used to relieve fluid from the top of the pressurizer. A subatmospheric dry containment building surrounds the reactor systems.

Selection of a severe accident sequence for use in evaluation of intentional depressurization was based on risk results presented in the initiai draft
NUREG-1150. ${ }^{2}$ (The initial NUREG-1150 draft was used because it representec the most up-todate published information at the time ${ }_{\text {a }}$ e depressurization evaluations were initiated.) I review of these results, presented in Appendix A, indicates that about $74 \%$ of the total core damage frequency can be nttributed to sequences involving high pressure core melt ejection where there is equipment aivailable that could be used to depressurize the RCS. Because station blackout was the dominant contributor to this total (about 64 of the 74\%), a station blackout sequence was selected for the evaluation of intentional depressurization. However, depressurization would be most difficult to implement during a station blackout sequence and would therefore represent a limiting case for evaluation purposes.

The station blackout sequence selected for evaluation is TMLB'. This sequence is initiated by the loss of offsite power. Onsite ac power is also unavailabie because the diesel generators fail to start or fail to supply power over an extended period of time. Heat removal through the steam generators cannor be maintained in the long term because there is no ac power for the electrical pumps and the steam driven auxiliary feedwater pump also fails to supply water. As the transient begins, power is lost to the control rod drives and to the pumps. The reactor scrams, and the main feedwater and reactor coolant pumps begin to coast down. Feedwater is quickly reduced to zero as the main feedwater valves close. The turbine stop valves close, and the pressure in the steam generators increases until the relief or dump valves open. Steam generator pressure is maintained fairly constant thereafter. $A_{i}$ : heat is transferred from the RCS to the steam geilerators, the liquid in the steam generators is completely vaporized and the steam generators are no longer capable of removing significani energy. Decay heat from the core then heats the RCS water causing the system to pressurize. The PORV connected to the top of the pressurizer cycles to control the pressure. After the RCS reaches saturation, a high pressure boiloff commences, 
resulting in core uncovery and heatup. Without the recovery of power or equipment, RCS pressure boundary failure, or intentional depressurization, the transient proceeds to severe core damage. Additional discussion of recovery strategies is presented in the following section.

It should be woted that the second draft of NUREG-1150 indicated that the risk posed by DCH was less than initially calculated. ${ }^{3} A$ portion of the reduction resulted from accounting for mechanisms that would cause a reduction in RCS pressure during accident sequences. Intentional depressurization by plant peisonnel was one of the mechanisms mentioned.

\subsection{Selection of Depressurization Strategies for Evaluation}

Actions taken by plant personnel can have important consequences as the TMLB' sequence progresses. Figure 1 illustrates potential progression paths for this sequence. The circles represent $s^{\text {tates }}$ of the plant and downward arrows represent the failure of strategies to stop progression toward more degraded plant conditions. The upward or horizontal arrows represent the implementation of strategies that are intended to either improve the condition of the piant (for example cool the core), or to mitigate the potential for DCH. Preventative strategies are located on the upper end of the diagram. For example, if ac power is restored within two to three hours or if plant personnel can initiate auxiliary feedwater within a relatively shorter period of time, plant operation can be recovered with no damage to the core. If these strategies cannot be implemented, additional preventative strategies would be attempted using either alternate methods to supply water for the secondary system or primary system feed and bleed. An example of a preventive strategy would be the use of fire water pumps to feed a depressurized steam generator. The poiential effectiveness of these preventative strategies is discussed further in Appendix B.

Depressurization of the RCS could occur if the recovery of ac power or the use of auxiliary feed- water is not possible, or if feed and bleed is not possible or is ineffective. The objectives of strategies involving intentional depressurization for the TMLB' sequence are: (1) to reduce the RCS pressure $w$ the accumulator setpoint so that accumulator injection can cool the core and (2) to reduce the RCS pressure below the point where $\mathrm{DCH}$ will be mitigated if other strategies are not successful in preventing core relocation and vessel failure. Although the pressure below which DCH will be mitigated is not well established, it is generally accepted that a pressure within about $1 \mathrm{MPa}$ of the containment pressure would prevent wide dispersal of the molten core and thereby prevent early containment failure for most containment conditions.

Intentional depressurization establishes a low pressure path that the sequence will follow. There is also the potential for a transition from the high pressure to low pressure paths if the RCS piping or components fail early in the sequence because of adverse pressure or mechanical conditions, or later in the sequence because they are heated to high temperatures foilowing substantial core damage. RCS failure could occur at moderate to low pressures if there is sufficient core damage to create high temperatures and if there is sufficient flow through the RCS to transport large quantities of energy to the piping or components. The transition to low pressure owing to RCS failure represents a natural evolution towards a state where DCH is mitigated irrespective of whether operator action is taken. For the TMLB' sequence, depressurization resulting from the failure of the pressurizer surge line has been predicted by SCDAP/RELAP5 calculations in the absence of accident management actions by plant personnel. ${ }^{5}$ This calculation is considered in the later sections that discuss the effectiveress of operator initiated depressurization.

Whether the sequence progresses along the high pressure or low pressure path, plant personnel will attempt to increase RCS inventory using strategies to add water by alternate injection methods or using alternate sources of water. Alternate injection methods would need to be 


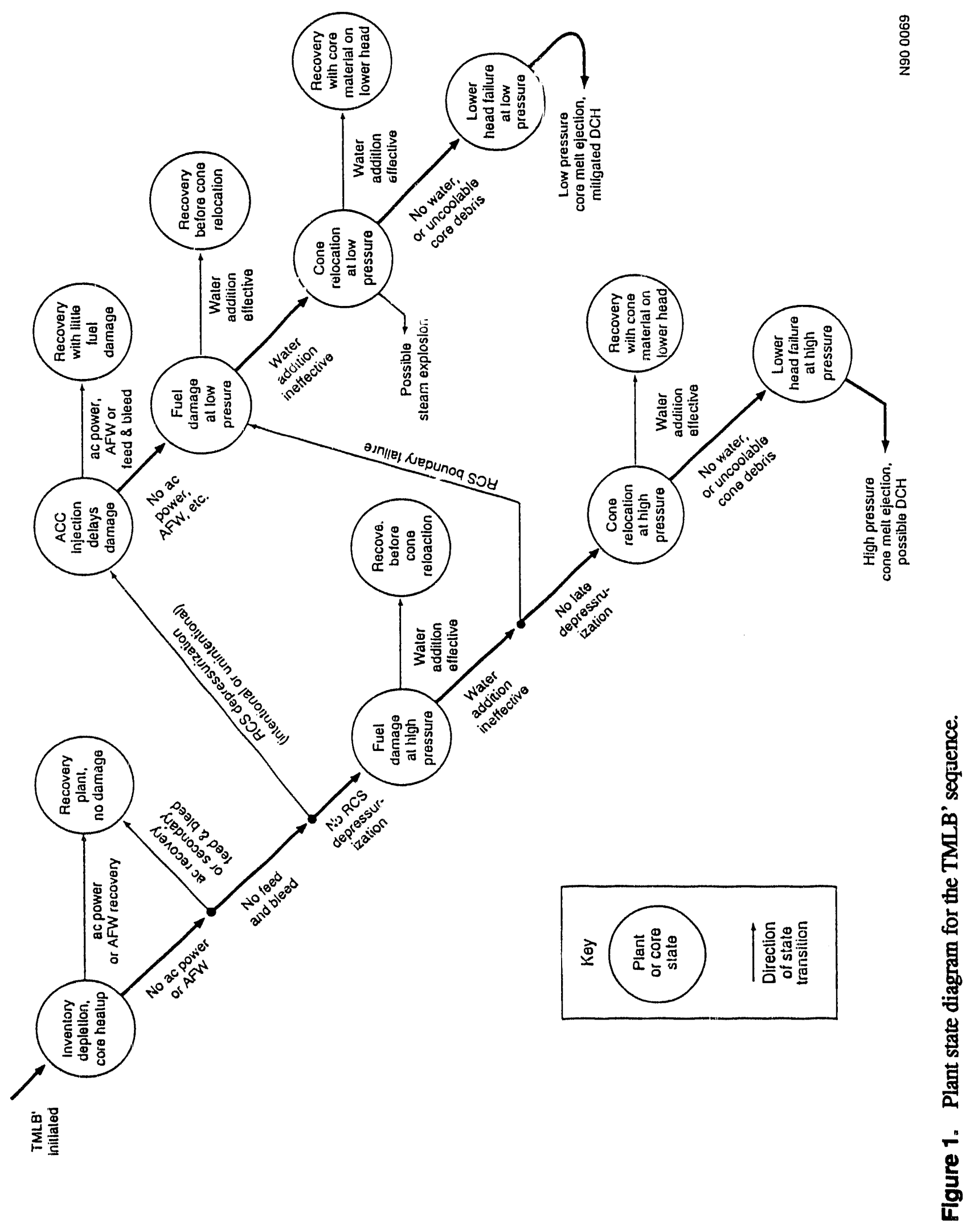


independent of ac power. These strategies are indicated by several of the horizontal arrows in Figure 1. The effectiveness of water addition in stopping the degradation of the core will depend on the amount of water that reaches the core and the condition of the core at the time when water is available. The effect of water addition on a degraded core is not addressed in this report because it is being investigated in other research sponsored by the NRC.

This report will primarily address the operating condition where preventative strategies are unavailable or have failed and depressurization must be relied upon to mitigate the effects of DCH. This report's objective is to determine whether the RCS can be depressurized to a value low enough to ensure that the potential for DCH is mitigated. Major emphasis is placed on depressurization using the PORVs and upper head vent because the loss of ac power should not disable the equipment during the early portions of the sequence.

There is some latitude at the time when depressurization must be initiated. If the PORVs are opened too early in the TMLB' sequence, there may not be sufficient time to implement preferred prevention strategies. Waiting too long, however, may allow core damage to begin before low pressure conditions are reached and may not allow sufficient time to reach low pressure conditions prior to vessel breach. For the evaluations performed in this report, two different criteria were selected for initiation of depressurization to provide a reasonable range of times for opening the PORVs during a TMLB' sequence. The first criterion would initiate depressurization when the steam generators boiled dry. This criterion was selected based on an initial assessment of seven possible methods of initiating depressurization early in the sequence. ${ }^{6}$ Strategies that are developed using this first criterion for initiating depressurization are referred to as early depressurization strategies. The second criterion would initiate depressurization when the core exit thermocouples reach $922 \mathrm{~K}\left(1200^{\circ} \mathrm{F}\right)$. This criterion would ensure that the core was in the process of uncovering and that fuel damage was imminent prior to the initiation of depressurization. Strategies that are developed using this second criterion are referred to as late depressurization strategies. For both strategies it was assumed that the upper head vent was opened at the same time as the PORVs.

A scoping evaluation of the effectiveness of steam generator feed and bleed is presented in this report to determine whether this preventative strategy would remain effective up to the time that late depressurization was initiated. This evaluation is considered to be scoping in nature because the calculations did not investigate a range of feedwater injection rates or examine different steam generator conditions or methods of control. In addition, the possible negative effects caused by injection of water into a dry steam generator were not evaluated in detail. A feedwater flowrate equivalent to that of the steam driven auxiliary feedwater pump was used for the evaluation. Two different criteria for feedwater flow initiation were considered, based on upper plenum conditions. For the first criterion, feedwater was initiated when the upper plenum vapor temperature exceeded saturation by $3 \mathrm{~K}\left(5.4^{\circ} \mathrm{F}\right)$. This deviation from saturation would correspond to the onset of core heatup as indicated by the core exit thermocouples. The second criterion used an upper plenum vapor temperature of $810 \mathrm{~K}$ $\left(1000^{\circ} \mathrm{F}\right)$. This temperature was estimated to correspond to a core exit thermocouple temperature of $922 \mathrm{~K}\left(1200^{\circ} \mathrm{F}\right)$ based on the computer codes and the plant modeling used.

\subsection{Evaluation Approach}

The approach and techniques used to evaluate the equipment performance and human performance are described in Sections 3.2 and 3.3 respectively. Evaluation of the phenomenological behavior during intentional depressurization was performed using the SCDAP/RELAP5 computer code. ${ }^{4}$ This code provides best-estimate integral calculations of the system thermal-hydraulics and core damage response. A brief description of the code is provided in Appendix C. The SCDAP/ RELAP5 model of the Surry Plant was very detailed; both the fluid volumes and metal 
structures were modeled for all three coolant loops. The piping was assumed to be adiabatic on the outer surface. The surge line and pressurizer shell were modeled as heat structures with adiabatic outer surfaces. The two PORVs were model $\mathrm{d}$ as a single valve connected to the top of the pressurizer with the valve sized to provide a steam flow of $45.1 \mathrm{~kg} / \mathrm{s}$ at $16.2 \mathrm{MPa}$, which is twice the rated capacity of one PORV. Both the steam generator primary and secondary sides were modeled for all three steam generators. The model of the steam generator included the tubes, downcomer, riser, main and auxiliary feedwater systems, steam line, main steam isolation valves, PORVs, and safety relief valves. The metal masses associated with the steam generator walls and internals were modeled with the outer surface of the steam generators assumed to be adiabatic. Three accumulators were modeled each containing $29,100 \mathrm{~kg}$ of borated water with a gas cover pressure of 4.24 MPa. The core and upper plenum volumes were divided into three radial regions and were selected so that similarly powered fuel assemblies were grouped together. Structures were used to model the fuel rods, control rods, instrument tubes, and empty control rod guide tubes in each of the three regions. The core axial core length was divided into ten vertical regions. The upper plenum volumes were extensions of the core region boundaries. The head vent and associated piping were modeled with a flow area of $0.00014 \mathrm{~m}^{2}$. Additional information on the Surry model is presented in Appendix D.

The phenomena that occur during core degradation and relocation are varied and complex. These complexities inhibit the understanding of some phenomena and in the codes capability to model them. (See Appendix $\mathrm{E}$ for a brief discussion of core melt progression and potential phenomenological uncertainties.) The early stages of core degradation with the fuel rods intact are relatively well characterized. As the core damage progresses and the control rod material, fuel rod cladding, and fuel begin to relocate, there is an increase in the degree of uncertainty in predicting some phenomena. For example, during the late phase of core melt progression the core may be in a variety of configurations ranging from highly oxidized fuel rods that are free standing, to a molten pool of fuel material contained in a metallic/ceramic crucible with adjacent beds of fuel rod rubble. The configuration is influenced by the history of the accident, the core temperature, and the coolant conditions. Depending on the amount of cooling available, the configuration may remain stable or may melt and relocate. Whether the core is in the configuration of a rod like geometry, a rubble bed, or a molten pool can influence the capability to depressurize because the configuration strongly influences the rate of energy transfer to the coolant.

The Three Mile Island, Unit 2 (TMI-2) accident provides important information for sequences leading to late-phase core melt progression (formation of a molten pool in the core region and relocation of molten material to the lower plenum). This accident was a smallbreak loss-of-coolant accident (LOCA) through a stuck-open PORV without adequate safety injection. (The operators bypassed safety injection early in the accident.) Eventually, the core uncovered and approximately $50 \%$ of the core melted. About 20 tons of the molten material relocated to the lower plenum. The reactor pressure vessel (RPV) did not fail, and the molten material in the reactor vessel was cooled after safety injection was reestablished by the operators. Because this accident embodies possible events for many potential severe accidents, a TMI-2 analysis is being conducted through sponsorship of the Committee on the Safety of Nuclear Installations (CSNI) to benchmark severe accident analysis codes. ${ }^{7}$ Users and developers of many of the severe accident analysis codes, including SCDAP/RELAP5 ${ }^{4}$ and MELPROG/TRAC, ${ }^{8}$ are participating in the analysis exercise.

Up to the time of initial core melting, most of the codes participating in the CSNI program match the recorded TMI-2 plant data-such as RCS pressure-reasonably well. Results from the various codes tend to deviate most from the measured parameters after the onset of core melt. There are also variations from one code to another for some parameters. The calculation of total hydrogen generation is an example of this 
variation. The calculated total hydrogen at $174 \mathrm{~min}$ (the end time of the first two phases of the analysis exercise) varies from about 100 to $460 \mathrm{~kg}$. This compares to an estimated release of about $300 \mathrm{~kg}^{9,10}$ at $174 \mathrm{~min}$. Similar variances occurred for other calculated quantities. It is noted that some of the boundary conditions, particularly the high-pressure injection rate, may have large uncertainties due to the lack of recorded flow measurements. Because an effort has been made to compare the codes using a common set of boundary conditions, the variations noted are the result of both uncertainties in the capabilities of the models and the application of the models. It is therefore concluded that provisions should be made to bound uncertainties in the core damage progression models that are important for the analysis of intentional depressurization.

Uncertainties considered to have important effects on intentional depressurization include the following: (1) the potential for RCS boundary failure during a severe accident and the consequences of this failure, (2) the configuration of the core during core degradation, and (3) the quantity of material that relocates to the lower plenum and the energy transfer from this material to water in the lower plenum. The approach used was to perform a series of SCDAP/RELAP5 calculations to systematically bound the uncertainties and evaluate their effect on depressurization. Table 1 identifies the calculations and summarizes the purpose for performing each one. The criteria for initiation of depressurization and the phenomena at the time each calculation was terminated are also presented. Table 2 presents input parameters that v/ere varied to influence fuel relocation and fragmentation during reflood for each calculation. A discussion of the individual calculations and the potential influence of these parameters follows.

Calculation 1 was performed to assess system behavior when the fuel rods remained essentially intact during the period when intentional depressurization had actuated the accumulators and they had emptied. The intact fuel rods maxi- mized cladding $0 \%$ Jation and heat transfer to the coolant and served as a baseline for comparing the resulis from the second calculation. Calculation 2 simulated the system response to a failure of the RCS pressure boundary at the surge line. This failure was based on the calculation of creep rupture failure of the piping. Other potential RCS failure locations such as reactor coolant pump seals were not examined in these analyses. Calculations 1 and 2 were performed early in the program and did not include improved code models in SCDAP/RELAP5 for $\mathrm{UO}_{2}$ dissolution and fragmentation of oxidized cladding by quenching. Consequently, the core configuration results for these two calculations may not be representative based on current phenomenological knowledge. The remainder of the calculations were performed with the improved models.

A methodology using sensitivity calculations was developed to assess the influence of uncertainties dealing with core degradation and relocation. This methodology (illustrated in Figure 2) relies on performing calculations to first bound core damage states that may affect system pressure (paths 1 and 2) and then to bound the effect of relocation to the lower plenum (paths 3 and 4). This parametric assessment starts at the point of core uncovery. Calculations 3,4 , and 5 are not shown in Figure 2 because they are sensitivity calculations used to establish the values of parameters to be used for calculations representing paths 1 and 2 .

Following path 1 (the upper bound path), on Figure 2 would result in the maximum transfer of encrgy from the core to the coolant causing the system pressure to be highest and the time from accident initiation to molten pool formation and relocation to be longest. Calculation 6 was performed to investigate this path. Following path 2 minimizes the energy input to the coolant thereby maximizing the energy that goes into heating the core material. As a result, more core material melts allowing larger quantities of core material to relocate to the lower plenum. Calculation 7 was performed to irvestigate this path. 
Table 1. Depressurization calculations

\begin{tabular}{|c|c|c|c|}
\hline Calculation & $\begin{array}{c}\text { Depressurization } \\
\text { Initiation } \\
\end{array}$ & $\begin{array}{l}\text { Calculation } \\
\text { Termination } \\
\end{array}$ & Purpose \\
\hline 1 & $\begin{array}{l}\text { Steam generator } \\
\text { secondary dry }\end{array}$ & $\begin{array}{l}\text { Accumulators } \\
\text { empty }\end{array}$ & $\begin{array}{l}\text { Assess system behavior when } \\
\text { fuel rods remained intact }\end{array}$ \\
\hline $2^{b}$ & $\begin{array}{l}\text { Steam generator } \\
\text { secondary drya }\end{array}$ & $\begin{array}{l}\text { Accumulators } \\
\text { empty }\end{array}$ & $\begin{array}{l}\text { Investigate sensitivity of } \\
\text { system pressure to failure } \\
\text { of RCS pressure boundary }\end{array}$ \\
\hline $3,4,5^{b}$ & $\begin{array}{l}\text { Steam generator } \\
\text { secondary dry }\end{array}$ & $\begin{array}{l}\text { After in-core } \\
\text { melting and } \\
\text { relocation }\end{array}$ & $\begin{array}{l}\text { Determine input parameters } \\
\text { that maximize in-core } \\
\text { metallic relocation }\end{array}$ \\
\hline $5,7^{b}$ & $\begin{array}{l}\text { Steam generator } \\
\text { secondary dry }\end{array}$ & $\begin{array}{l}\text { Relocation } \\
\text { to lower } \\
\text { plenum }\end{array}$ & $\begin{array}{l}\text { Bound pressure and timing of } \\
\text { events before relocation of } \\
\text { molten material to lower } \\
\text { plenum }\end{array}$ \\
\hline 8,9 & Not applicable & $\begin{array}{l}\text { Lower head } \\
\text { failure }\end{array}$ & $\begin{array}{l}\text { Bound the pressure prior to } \\
\text { lower head failure and } \\
\text { estimate time of failure }\end{array}$ \\
\hline 10 & $\begin{array}{l}\text { Core exit TCs } \\
\text { read } 922 \mathrm{~K}^{\mathrm{c}} \\
\left(1200^{\circ} \mathrm{F}\right)\end{array}$ & $\begin{array}{l}\text { Relocation } \\
\text { to lower } \\
\text { plenum }\end{array}$ & $\begin{array}{l}\text { Evaluate the effects of late } \\
\text { depressurization on system } \\
\text { response }\end{array}$ \\
\hline $\begin{array}{l}\text { a. Early dep } \\
\text { b. Initial con } \\
\text { c. Late depr }\end{array}$ & $\begin{array}{l}\text { tion strategy. } \\
\text { rom calculation } 1 . \\
\text { on strategy. }\end{array}$ & & \\
\hline
\end{tabular}

Table 2. Calculation matrix used for the sensitivity studies

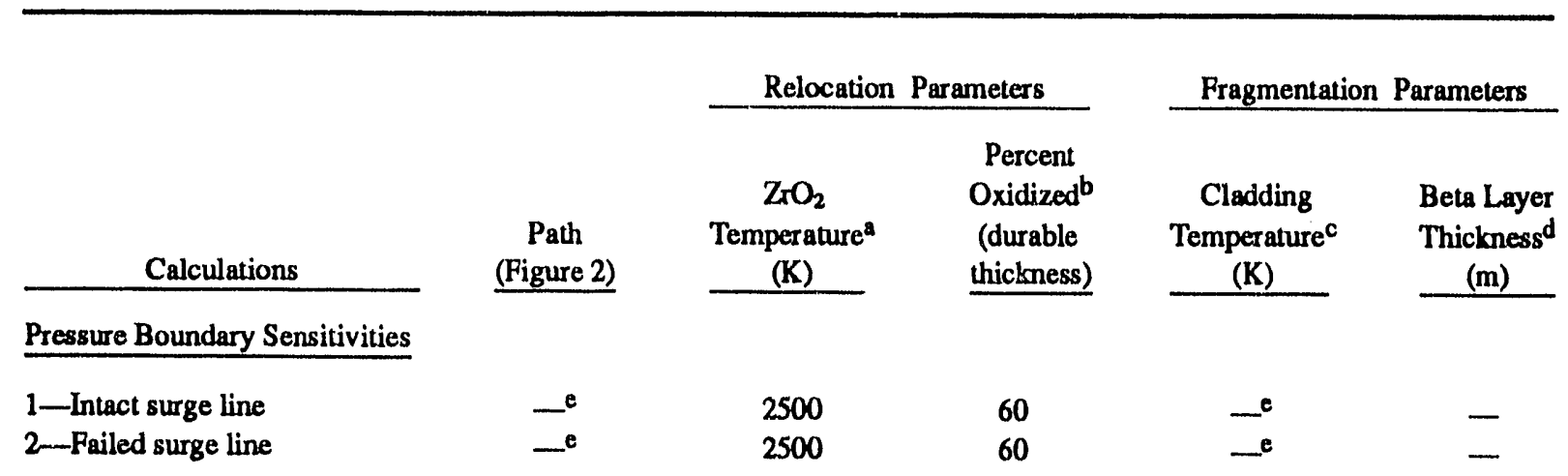


Table 2. (continued)

\begin{tabular}{l} 
Calculations \\
\cline { 3 - 5 }
\end{tabular}

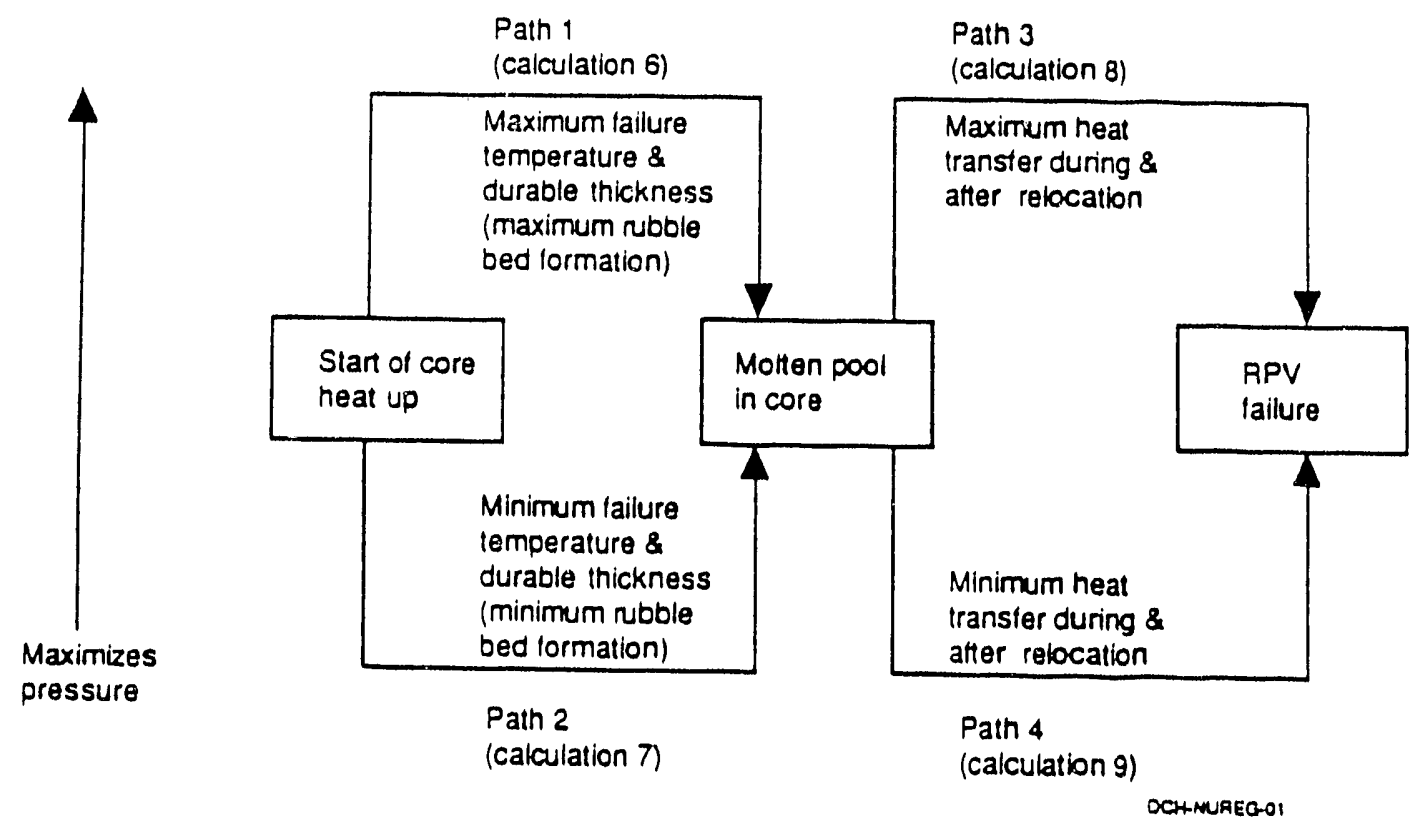

Flgure 2. Caiculation paths used for core damage parameter study. 
Parameters that affect the behavior of the fuel rod cladding were used to influence the paths taken in the calculations. Calculations 3,4 , and 5 were performed to determine the parameter values that maximize fuel dissolution and relocation. In these calculations, two input parameters were varied within their uncertainty ranges; the zircaloy dioxide $\left(\mathrm{ZrO}_{2}\right)$ fuilure temperature and the percent of zircaloy oxidation above which relocation will not take place. The $\mathrm{ZrO}_{2}$ failure temperature varies between the melting points of zircaloy $(2123 \mathrm{~K})\left(3400^{\circ} \mathrm{F}\right)$ and $\mathrm{ZrO}_{2}(2973 \mathrm{~K})$ $\left(4900^{\circ} \mathrm{F}\right)$. When this temperature is reached, the oxıde shell surrounding the fuel rod will fail (if thin enough), allowing molten zircaloy coupled with chemically dissolved $\mathrm{UO}_{2}$ to relocate downward (see Figure 3). However, if the cladding is sufficiently oxidized, the $\mathrm{ZrO}_{2}$ shell is thicker and able to contain the molten core material. In this situation, the downward relocation is delayed until the melting temperature of $\mathrm{ZrO}_{2}$ is reached. The second input parameter varied is the fraction of cladding oxidation above which the oxide shell will not fail, or durable thickness. The uncertainties in these two parameters have not been quantified, however, a failure temperature of $2680 \mathrm{~K}$ $\left(4400^{\circ} \mathrm{F}\right)$ and maximum oxide thickness for failure that corresponds to $60 \%$ cladding oxidation are typical best-estimate values. When those values arc used, code predictions are in agreement with severe accident data from the PBF SFD 1-4 experiment. " Calculation 3 was performed with these best estimate parameters. In Calcuiations 4 and 5 , temperatures of $2300 \mathrm{~K}\left(3680^{\circ} \mathrm{F}\right)$ and $2400 \mathrm{~K}\left(3860^{\circ} \mathrm{F}\right)$ were used and relocation was allowed until the zircaloy was $99 \%$ oxidized. By varying the input failure temperature, a maximum amount of $\mathrm{UO}_{2}$ that can be dissolved by the molten zircaloy before the cladding is almost completely oxidized can be determined. Fuel relocation is therefore maximized. Additional information on the reasons some parameters were selected is presented in Section 3.

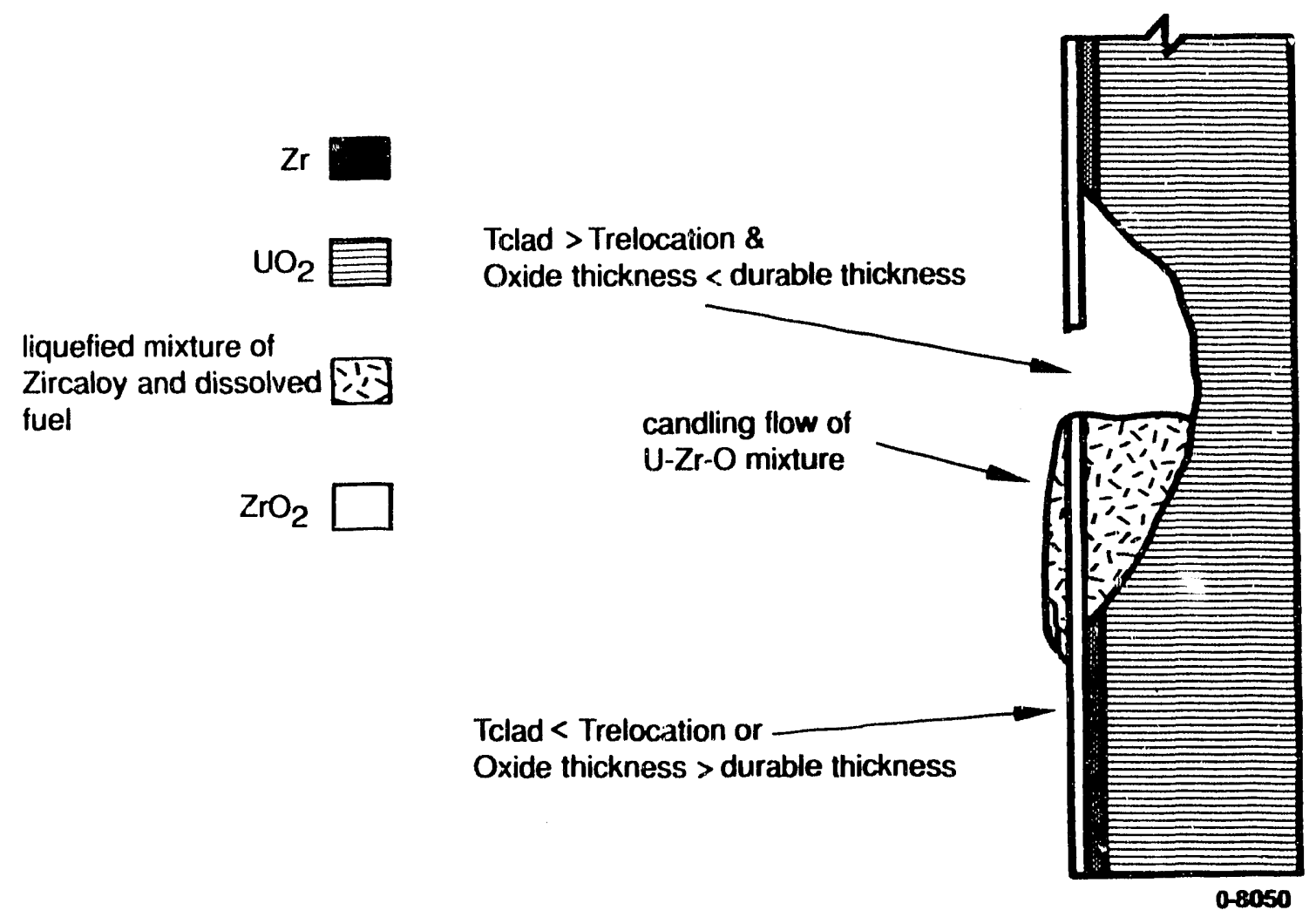

Flgure 3. Representation of fuel rod oxide shell failure. 
Two possible mechanisms for in-core fuel relocation were bounded. The first is the relocation of mostly ceramic ( $\mathrm{U}, \mathrm{Zr}) \mathrm{O}_{2}$ resulting from the melting of $\mathrm{UO}_{2}$ and $\mathrm{ZO}_{2}$. Zircaloy oxidation is allowed to proceed as far as possible prior to melt relocation. The second mechanism is the relocation of mostly metallic $U-Z r-O$ resulting from the melting of zircalloy and chemical dissolution of $\mathrm{UO}_{2}$. These mechanisms were bounded by varying the oxide failure temperature and thickness for relocation discussed above. Also, the timing and amount of cladding embrittlement and fragmentation by quenching were bounded. The fragmentation parameters are the $\mathrm{ZrO}_{2}$ temperature at which shattering occurs and the beta$\mathrm{Zr}$ layer thickness below which the oxide will shatter. The oxide temperatures are $1273 \mathrm{~K}$ $\left(1800^{\circ} \mathrm{F}\right.$ ) (the temperature of a phase change in the oxide above which the oxide is too pliable to fragment, and $\mathrm{T}_{2 \mathrm{~m}}+90 \mathrm{~K}\left(300^{\circ} \mathrm{F}\right.$ ) (a lower limit on this temperature). ${ }^{12}$ The beta- $\mathrm{Zr}$ layer is unoxidized zircaloy, so, the smaller the thickness, the more the cladding has oxidized. The uncertainty in the beta-Zr layer thickness is very small. Therefore, this parameter was not varied from the best-estimate value of $0.0001 \mathrm{~m} .{ }^{13}$

In calculation 6 (maximum rubble bed formation), relocation of metallic $\mathrm{U}-\mathrm{Zr}-\mathrm{O}$ mixtures was minimized allowing in-place oxidation of the cladding to proceed as long as possible, thus maximizing the oxidation heat generation. The criteria for rubble formation were set to ensure that a reasonable upper bound for cladding oxide embrittlement was used, resulting in the shattering of the maximum amount of $\mathrm{ZrO}_{2}$ and an increased surface area for heat transfer to the coolant. In calculation 7 (maximum metallic $\mathbf{U}-\mathbf{Z r}-\mathbf{O}$ relocation), input parameters were chosen to maximize relocation of metallic mixtures of $U-Z \mathbf{Z}-\mathbf{O}$. Because this process is highly non-linear, with the maximum mass of liquefied material occurring between the melting point of zircaloy and of $\mathrm{ZrO}_{2}$, calculations 3 through 5 were necessary to find the input parameters yielding the maximum mass relocated. The criteria for rubble bed formation were set so that a reasonable lower bound for cladding embrittlement and core quenching was used. Thus, heat transfer to the coolant was minimized.

Calculations 6 (path 1) and 7 (path 2) were p.rformed up to the time a molten pool was formed and had begun relocating to the lower plenum. These calculations therefore provide the boundary conditions for the remaining two paths. Paths 3 and 4 are upper-and lower-bound paths for the relocation of molten material in the core region to the lower plenum. On path 3, the calculation uses asslumptions that maximize the energy transfer from the relocating molten corium. On path 4 assumptions are made to minimize energy transfer. The methodology used to calculate the energy transfer to the coolant in the lower plenum is shown schematically in Figures 4 and 5 . When the calculation indicates that a failure of the crust surrounding the molten material has occurred at a specific node, the quantity of molten material to be relocated is the mass of molten material above the failure location. The rate of relocation is determined by the mass of material to be relocated and a user specified time to relocate the moiten material $\left(M / T_{n}\right.$ as shown in Figure 4)。" Because the intent is to bound the energy transfer during relocation, the code models diverge at this point, based on whether the calculation is to proceed on path 3 or path 4. For path 3, the model (Figure 4) assumes that in one time step the quantity of material relocated is cooled to the temperature of the liquid in the lower plenum $\left(\mathrm{T}_{\mathrm{sa}}\right)$, thus determining the mass of liquid vaporized. If during any time step the mass of the steam to be produced exceeds the mass of the available liquid, the eirergy transfer is limited to that necessary to vaporize the available liquid. For path 4, the model (Figure 5) assumes that there is no energy transfer from the relocating core material to the coolant in the lower plenum. After the core material has relocated, the energy transfer to the RPV lower head and structures above the debris bed are considered. On both paths, the heat transfer to and within the RPV lower head is modeled by two-dimensional, finiteelement heat transfer models.

a. In this analysis, time $\left(T_{r}\right)$ to relocate was assigned a value of $100 \mathrm{~s}$. The relocation time was based on the estimate of -60 to $120 \mathrm{~s}$ for relocation during the iMI-2 accident. 


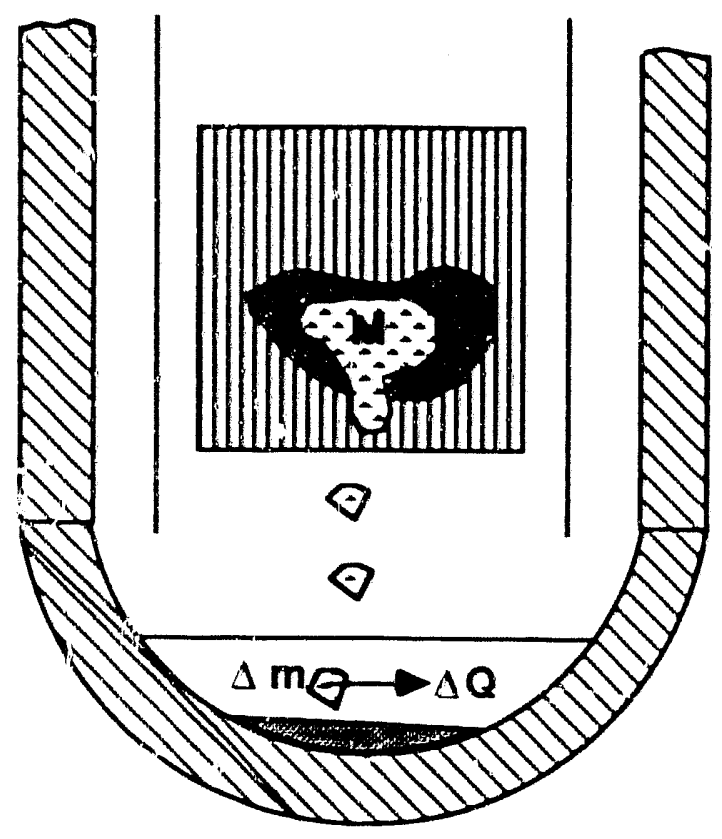

Calatarion of mass relocatid in one ino step:

$$
\Delta \sin =\frac{M}{T_{1}} \Delta s
$$

where

$$
\begin{aligned}
& M \quad=\quad \text { tot mass of molmen pool to bo relocind } \\
& T_{1}=\text { time to relocatio molten material (user } \\
& \text { inpur) } \\
& \Delta \quad=\text { arent tine stap } \\
& \Delta m \text { - molven mass relocated in cursent time }
\end{aligned}
$$

Cabakcion of liquid vaporized in one tine step:

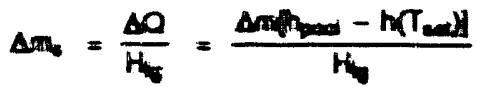

$$
\begin{aligned}
& \text { where } \\
& \Delta 0=\text { heet transtared trom rebcating molion } \\
& \text { H. = bent heat of veprization for wratar } \\
& \text { thed = spocitic enthalpy of maiten pod }
\end{aligned}
$$

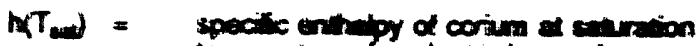

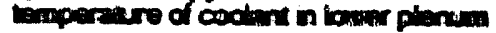

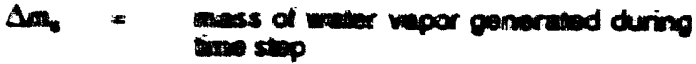

Figure 4. Core relocadion model for maximum steam interactions.

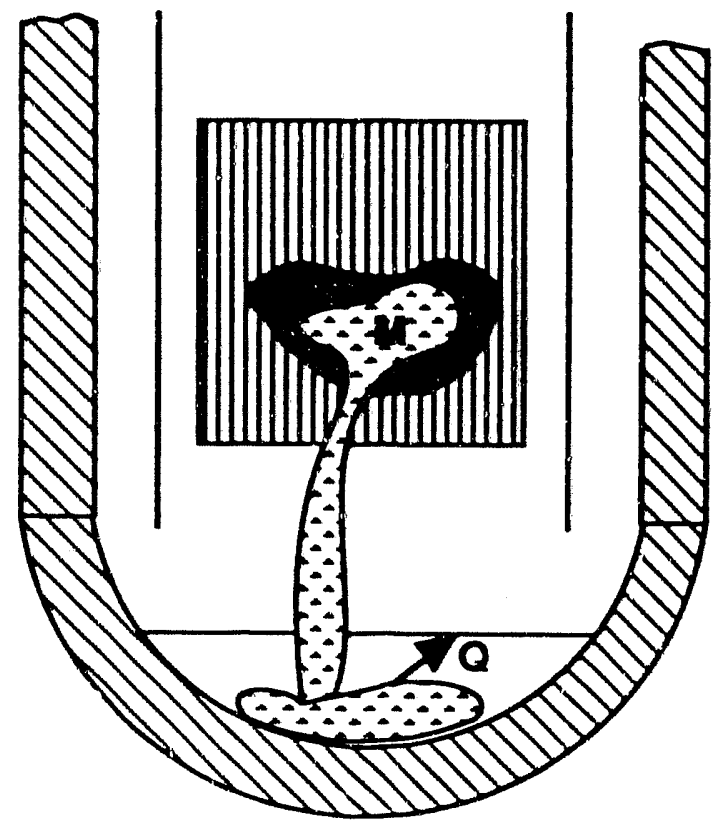

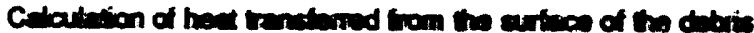

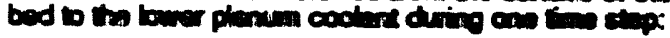

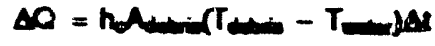

Whan

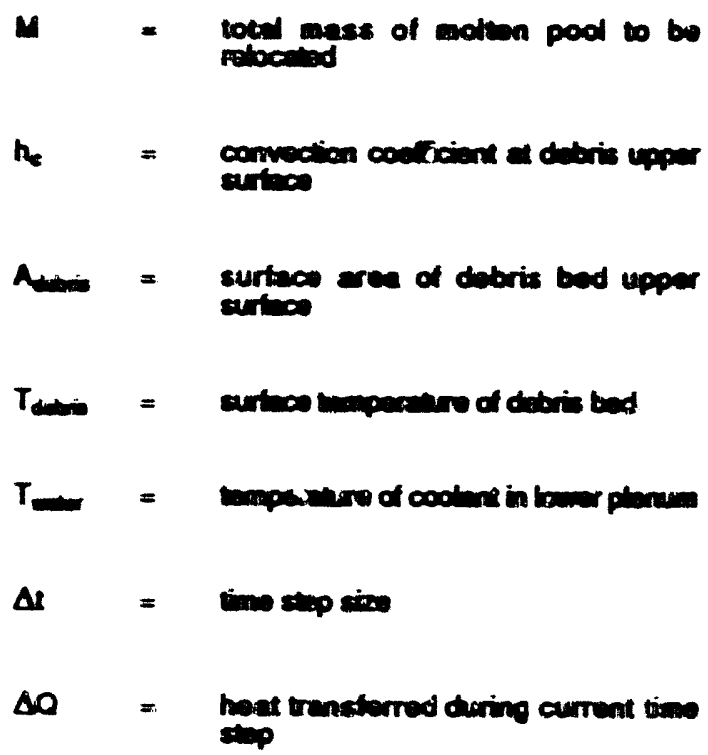

Figure 5. Core relocation model for minimum stem internctions. 


\section{MTENTIONAL DEPRESSURIZATION USING THE PORV}

This section describes results from the evaluation of intentional depressurization at Surry using the PORVs and upper head vent. In the first subection, the results of the SCDAP/RELAPS caiculations are described and explained. The results are discussed in terms of the strategies iavolving early and late depressurization (see Section 22). In the second subsection, an cvaluation is presented of the capabilities and limitations of the PORV hardware and necessary support systems for implementing intentional depressurization. The third subsection describes an evaluation of the human factors sapects of intentional depressurization and the final subexction discueses the applicability of the results to other PWRs.

\subsection{Calculation Results}

\subsubsection{Culcultions for Earty Depreasurter-} tion. As described in Section 22, calculations 1 through 7 were performed using the strategy that depressurization would be initived by the operawor when the seam genervor secondary side was dry. This struegy is referred to as early depressurimion because it was identified as the earliest reasonable time that plent personnel would be expected to initiate depressurization using the PORVs. The following paragraphs provide a discussion of results from the calculations using eady depressurizetion.

Chambers 614 performed the calculations for the eady deprescurization stritegy up to the time of molten pool relocation to the lower plenum (ace Trble 1). Calculations 1 and 2 are considered to provide bestline information and were used to provide input in determining how to perform mray of the other calculations. The RCS presoure for calcularions 1 and 2 is shown in Figure 6 and is tyrical of the early depressurization period for all calculations. The major features of the preswie plat are as follows: (a) a near constant presare region from earty in the transient to $75 \mathrm{~min}$; (b) depressurization upon opening the PORVs, followed by a short-term repressurization; and (c) a cyctic response from the start of accumulator injection to about $340 \mathrm{~min}$. Initially, bop natural circulation transports conergy to the steam genentors. The energy of decay heat is removed by heat transfer to the secondary side of the steam generators. At $75 \mathrm{~min}$, the liquid inventory in the striym generators is exhausted; the PORVs are latched open, and RCS pressure docreases to saturmion. Flasting in the RCS swells the volume of coolent it conthins. Thus, the pressurizer repidly fills (see Figure 7). The quality of the flow out the PORVs is decreased, and the vapor generation rate in the core excoeds the rate of vapor removal through the PORVs. Thus, RCS pressure increases until the pressurizer level peaks and begins to decrease.

Core heatup is calculated to start at about $114 \mathrm{~min}$. By the time RCS pressure reaches the pressure of the accumulators, signifir ant core heatup has occurred. When initial accumulator injection occurs, the maximum cladding temperature is calculated to be $-1500 \mathrm{~K}\left(2240^{\circ} \mathrm{F}\right)$ (see Figure 8). The injection of water from the accumulators forces water into the core; the additional water provides only short-term cooling. The core then continues to heatup, driven by cladding oxidation. When RCS pressure again decreases to eccumulator pressure, the inflow rate is not as great as the first cycle. Until about $200 \mathrm{~min}, \mathrm{RCS}$ pressure docreases slowly. Most regions of the core have oxidized and are starting to cool when the second major inflow cycle occurs. The inflow cycles are insufficient to maintain long-term core cooling, and the maximum cladding temperature is calculated to begin increasing again by $250 \mathrm{~min}$. By $440 \mathrm{~min}$, RCS pressure is approaching $1 \mathrm{MPa}$

The surge lire metal temperatures are calculated to exceed the melting temperature of carbon steel (about $1700 \mathrm{~K}$ ) as shown in Figure 9. Prior to reaching melting temperature, creep nupture of the surge line is predicted. Because of the large thermal mass, the calculated metal temperature at the hot leg adjacent to the surge line lags well behind the surge line. The hot leg could altemately fail by melting but is not expected to 


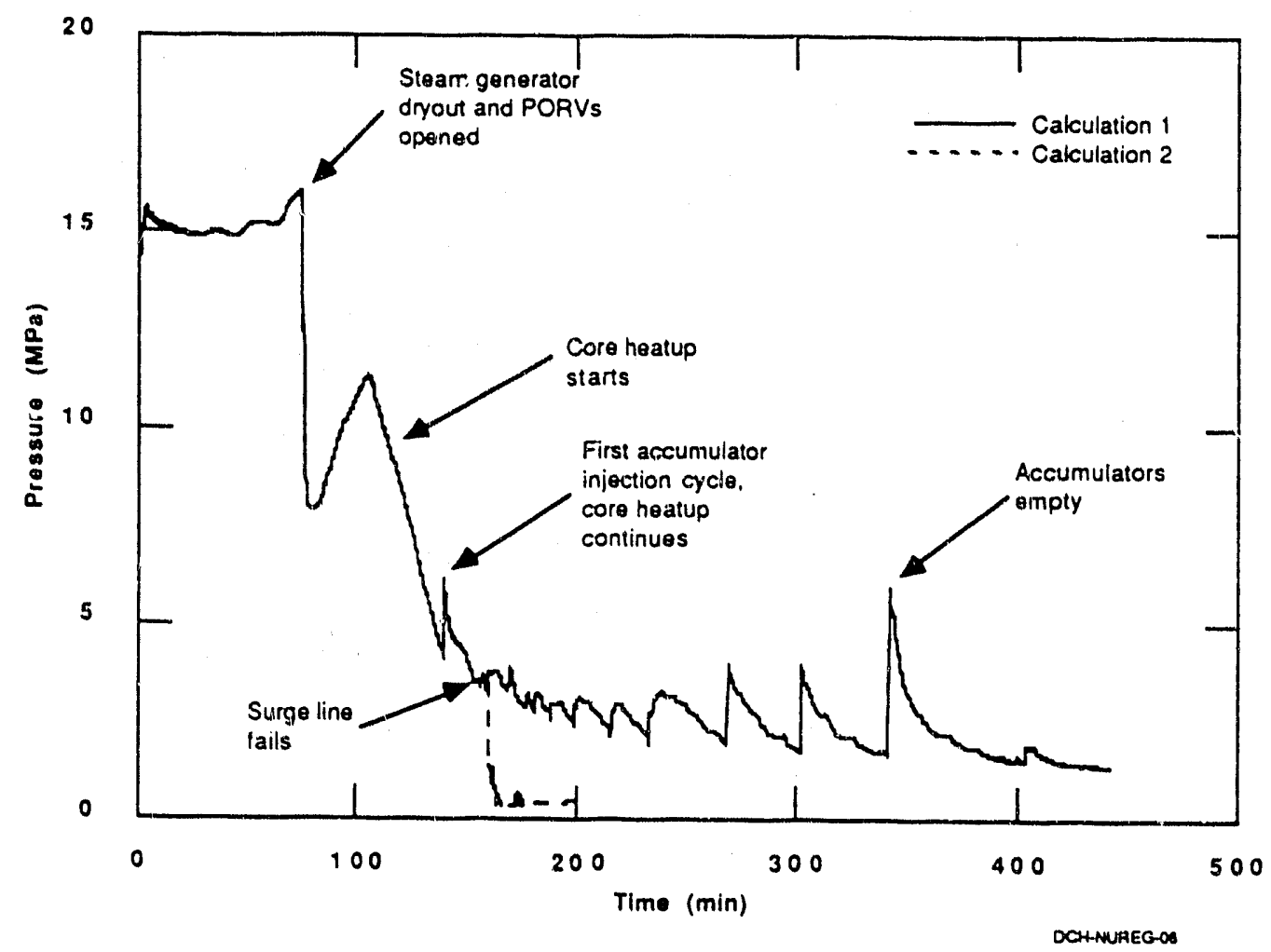

Figure 6. RCS pressure calculated for early depressurization calculations 1 and 2.

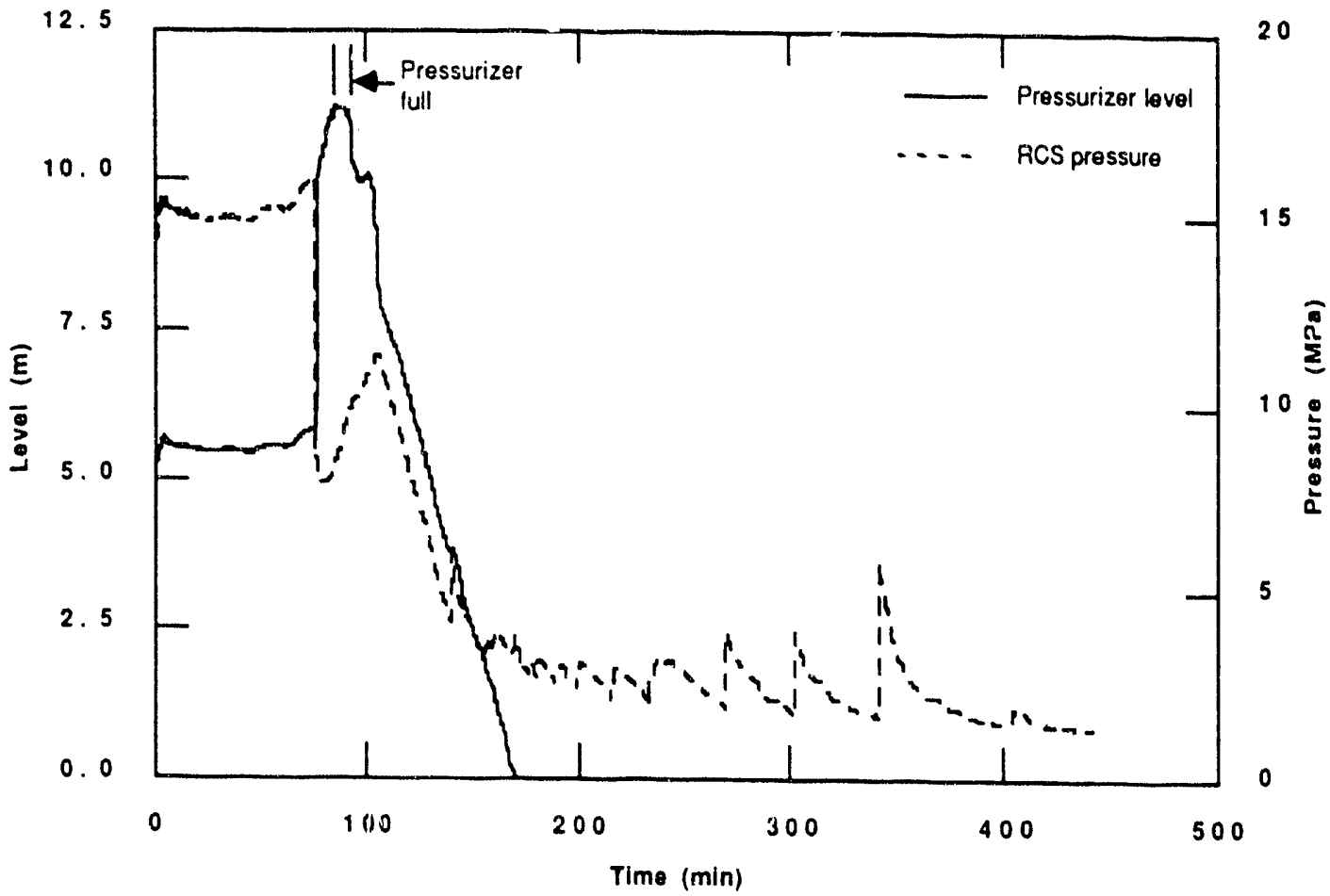

DCH.NUREG-O:

Figure 7. Pressurizer level calculated for early depressurization calculation 1. 


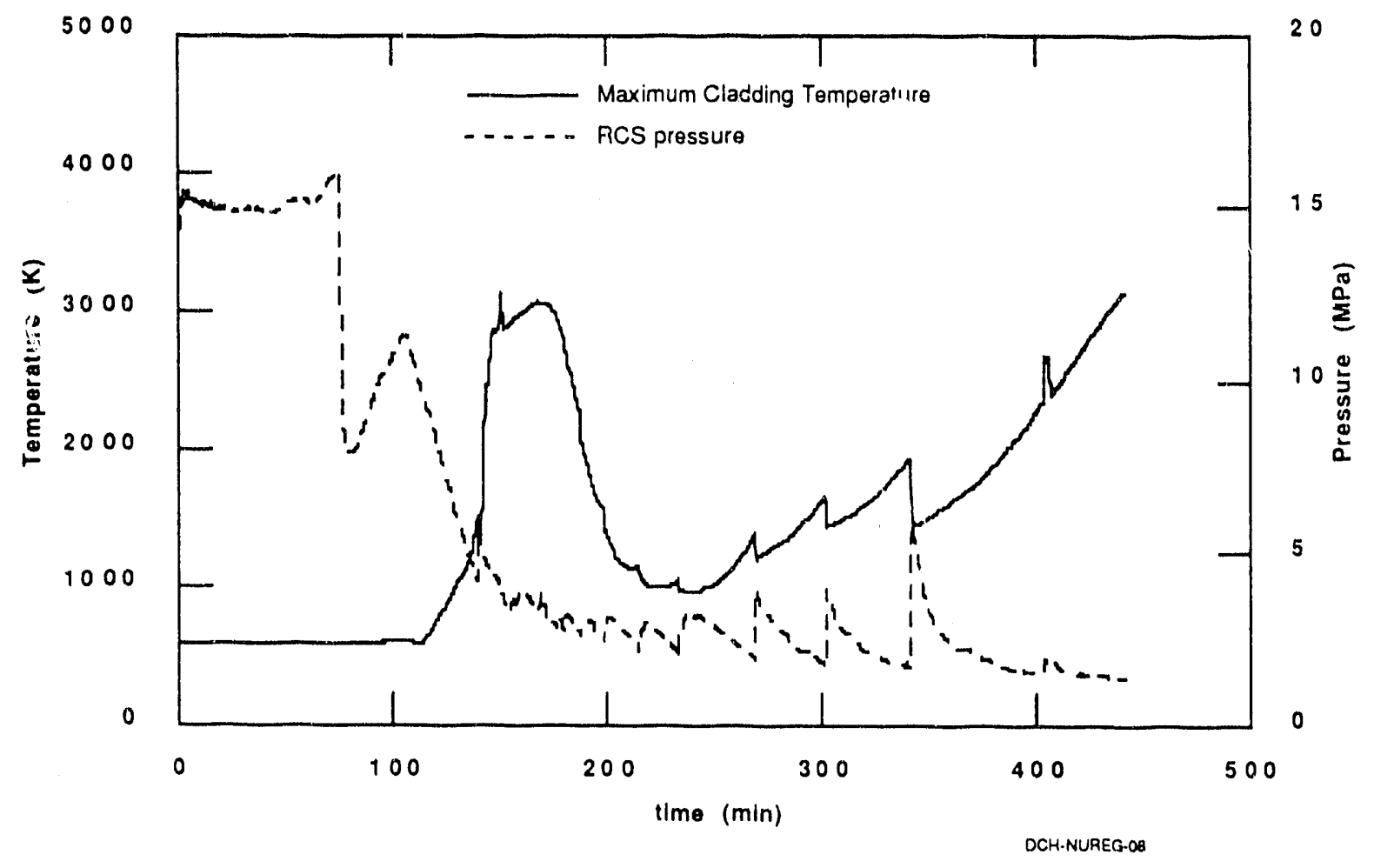

Figure 8. Maximum cladding temperature for early depressurization calculation 1.

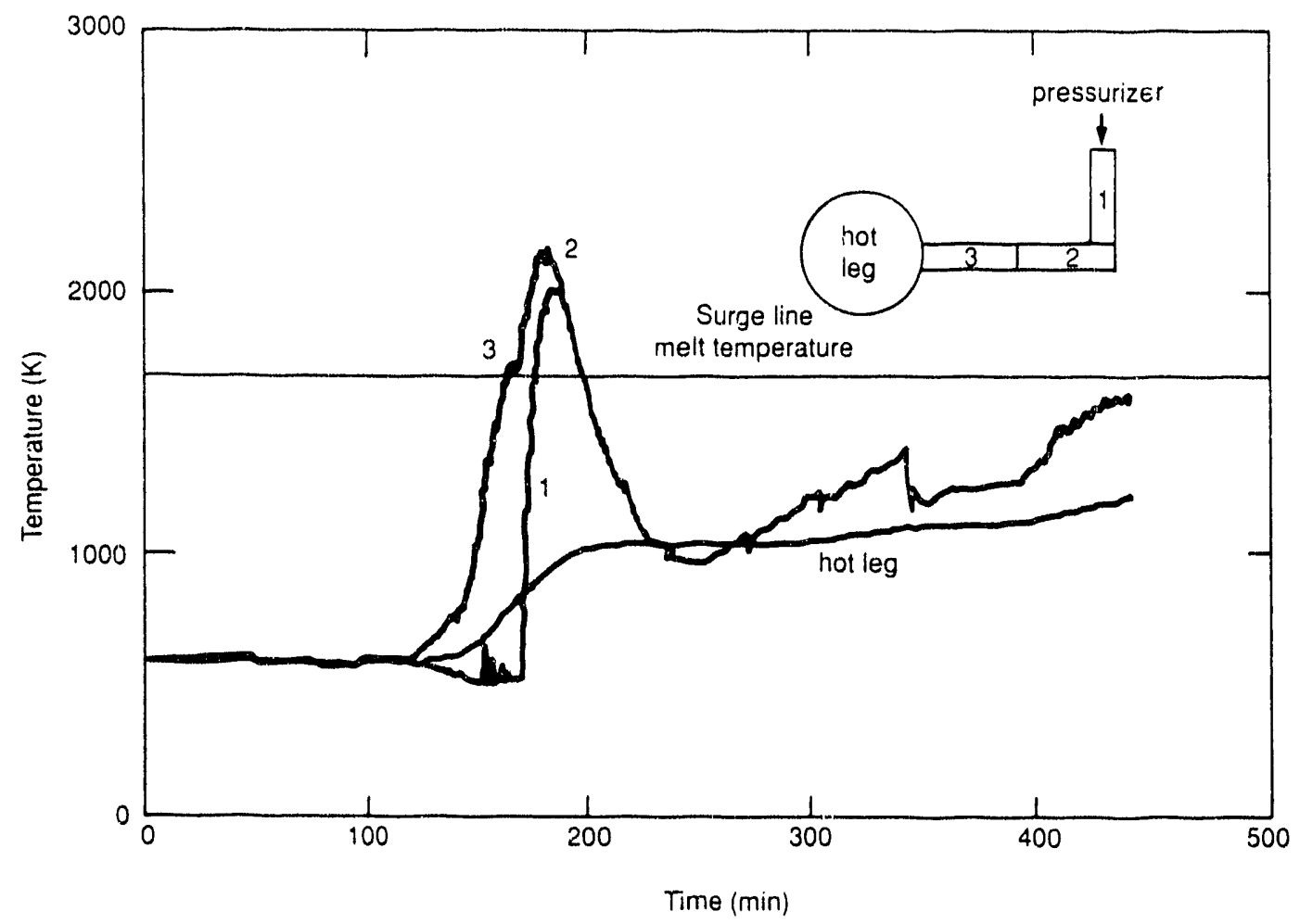

Flgure 9. Pressurizer surge line average metal temperature calculated for early depressurization calculation 1. 
fail by creep rupture. Opening the PORVs directs flow from the vessel through the hot leg, through the pressurizer surge line, and pressurizer. Because these flows are large compared to natural circulation flows, the flow of hot gases through the steam generator is diminished. Thus, the surge line is the most likely location for an RCS pressure boundary failure. Calculation 2 was made to evaluate the effect of surge line failure on the system behavior. The RCS pressure results from Figure 8 show that the surge line failure causes the RCS pressure to decrease to a smaller value than that achieved by depressurization through the PORVs. While this more rapid depressurization tends to mitigate $\mathrm{DCH}$, it also places an earlier load on the containment. However, this load would not be sufficient to cause containment failure.

Surge line failure is considered to be a likely result of intentional depressurization. However, uncertainties in the heat transfer characteristics of the core, the amount of heat transferred to the components in the flow path, and the heat transfer and structural characteristics of the surge line, could strongly affect the timing of surge line failure. Consequently, the effects of surge line failure were ignored in the remaining calculations to determine whether successful intentional depressurization could be implemented if surge line failure was significantly delayed.

As described in Section 2.3, calculations 3,4, and 5 were performed to determine the parameter settings that produce the minimum and maximum relocation of molten core materials and the minimum and maximum formation of a rubble debris bed upon injection of accumulator water. The parameters used in calculations 6 and 7 were based on the results of these three parametric calculations. The mass of relocated material calculated for the three calculations is shown in Figure 10. With the oxide shell failure temperature set at $2300 \mathrm{~K}\left(3680^{\circ} \mathrm{F}\right)$, the combination of temperature, time, and quantity of molten zircaloy does $n t$ allow for massive dissolution of $\mathrm{UO}_{2}$ before the cladding is breached and the molten mixture relocates. With the failure temperature set at $2400 \mathrm{~K}\left(3860^{\circ} \mathrm{F}\right)$, the conditions of temperature, time, and quantity of molten zircaloy appear to be optimum to cause the large amounts of $\mathrm{UO}_{2}$ to be relocated. For a failure temperature of $2680 \mathrm{~K}\left(4370^{\circ} \mathrm{F}\right)$, the hightemperature region of the core reached $100 \%$ oxidation. Under the condition of complete oxidation, $\mathrm{ZrO}_{2}$ will not dissolve any $\mathrm{UO}_{2}$ unless the temperature is at least the melting temperature of $\mathrm{ZrO}_{2}$. Thus, only the control rods contribute to the metallic relocation. As expected, the minimum cladding relocation occurs for an oxide shell failure temperature of $2680 \mathrm{~K}\left(4370^{\circ} \mathrm{F}\right)$. Therefore, for calculation 6, minimum relocation, an oxide shell failure temperature of $2680 \mathrm{~K}$ $\left(4370^{\circ} \mathrm{F}\right)$, with the durable thickness set to $60 \%$ of cladding thickness, was selected. For calculation 7 , maximum relocation, an oxide shell failure temperature of $2400 \mathrm{~K}$, with the durable thickness set to $0.99 \%$ of cladding thickness, was selected.

The RCS pressure for calculations 6 and 7 are both quite similar to the results from calculation 1 (see Figure 11). There is a period of essentially non-cyclic depressurization following the first accumulator injection cycle. This is then followed by the cyclic pressure behavior that is associated with the cyclic injection of accumulator water. It is significant that the two calculated pressures are essentially the same in peak magnitudes. These similarities would indicate that the heat transfer and energy generation from zircaloy oxidation for the differently configured cores were very similar during the injection of accumulator water. Review of the core information indicates that oxidation of the cladding was very nearly complete and did not strongly influence this process. Conclusions indicate that the interactions between heat transfer from the core material and the hydraulics of the accumulator injection cycle control the pressure.

The calculated cladding temperatures at the top of the core (3.5-m node) are also similar during the transient (see Figure 12). The temperature for calculation 6 reaches a relative maximum at about $150 \mathrm{~min}$, at that time complete oxidation of the top core (3.5-m) node has taken place. At about the same time in calculation 7 , the oxide 


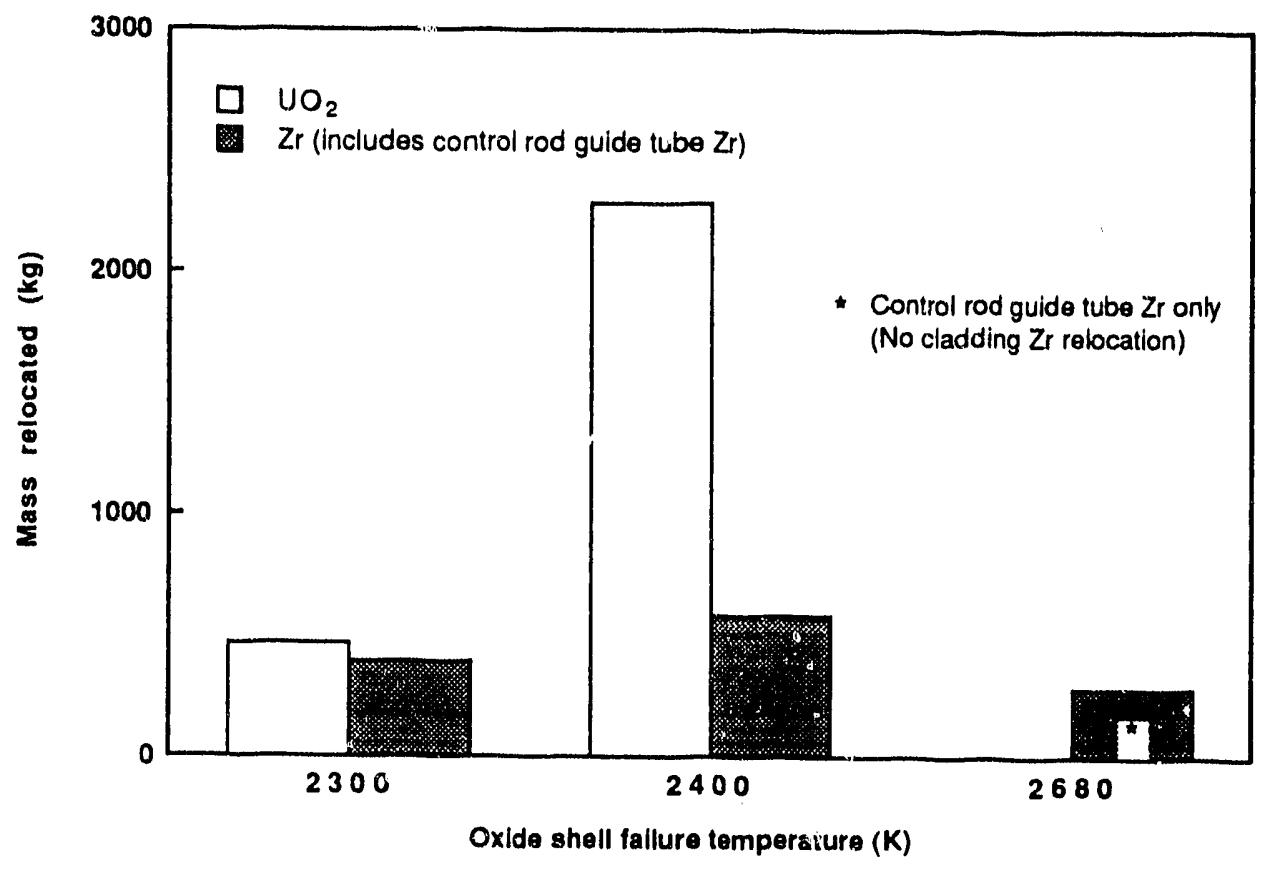

DCH.NUREQ-10

Figure 10. Effect of relocation criterion on mass of relocated core materials.

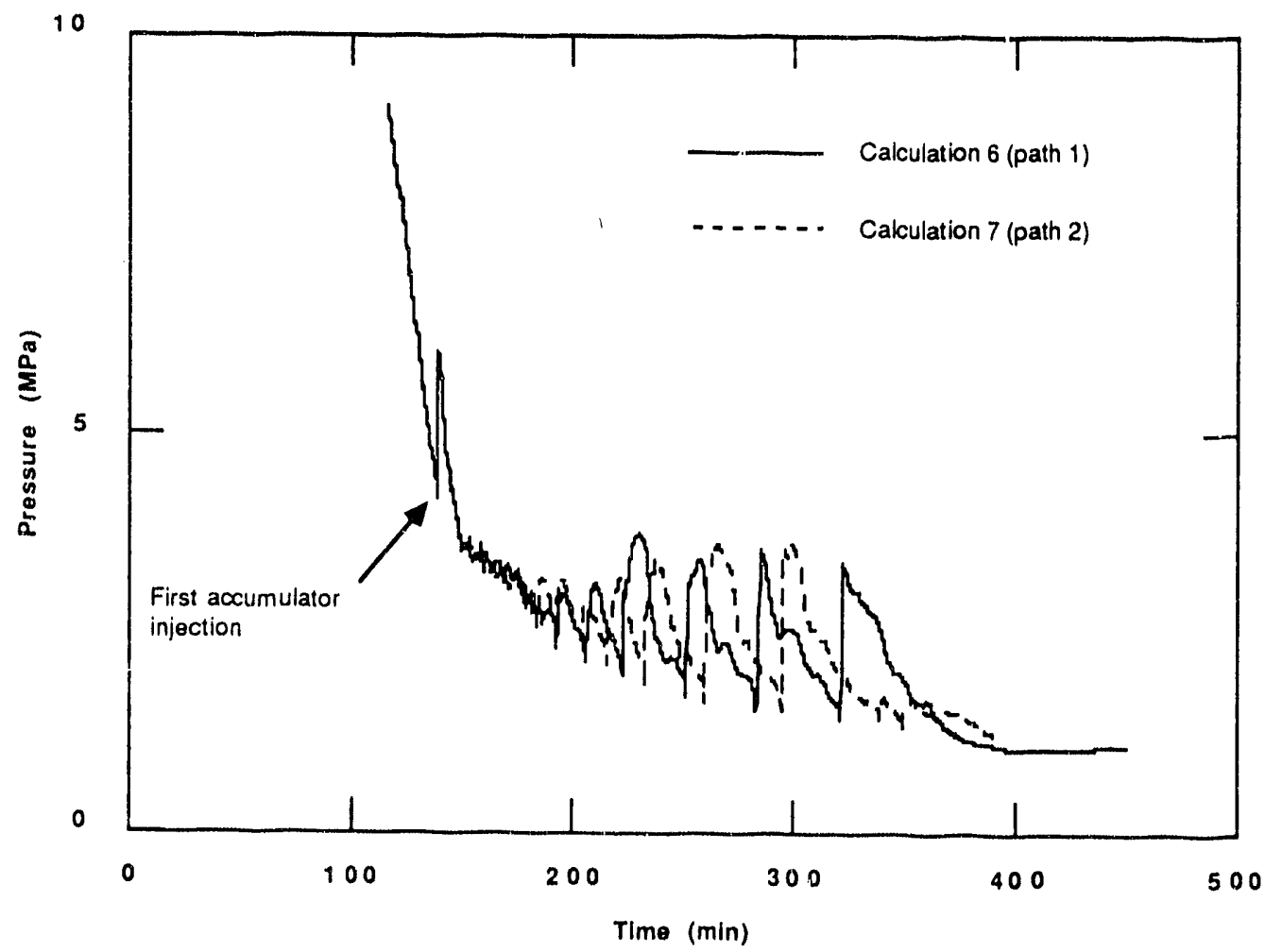

DCH-NUAEG-11

Figure 11. RCS pressure calculated for early depressurization sensitivity calculations 6 and 7 . 


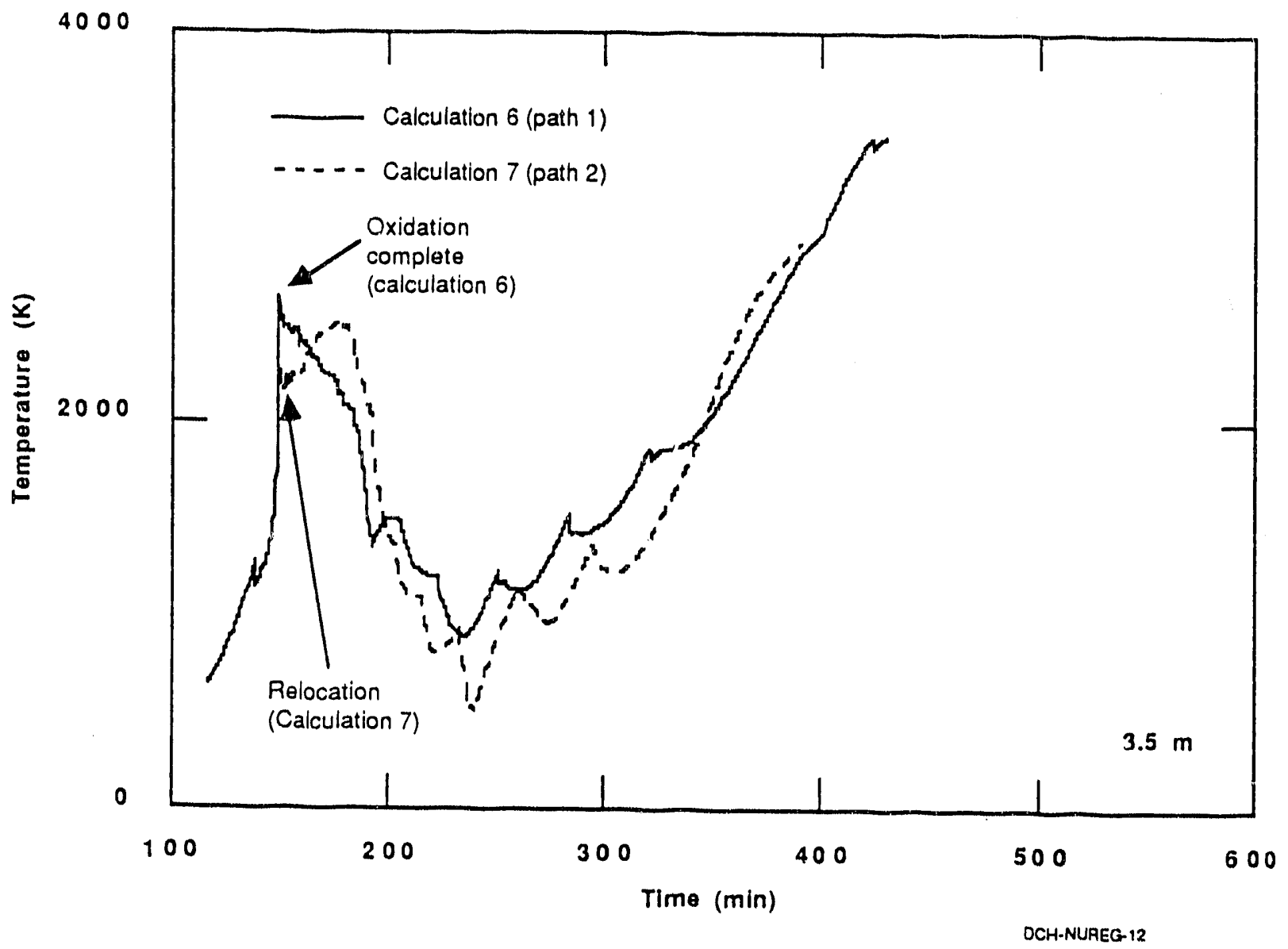

Flgure 12. Cladding temperatures at $3.5 \mathrm{~m}$ calculated for early depressurization calculations 6 and 7 .

shell fails and relocation of the liquefied $U-Z r-O$ mixture occurs. This disparity between the two calculations is reflected in the hydrogen generation (see Figure 13). Parameter settings for maximum relocation (calculation 7) produce less total hydrogen $(\sim 17 \mathrm{~kg}$ less) for periods up to $300 \mathrm{~min}$. The difference is only partially due to the difference in the amount of metallic cladding relocated $(-110 \mathrm{~kg}$ implies $\sim 5 \mathrm{~kg} \mathrm{H} 2$ generated). Calculation 7 predicts significantly greater oxidation at approximately the mid-core level than does calculation 6. However, once the accumulators are empty and the core level decreases, the total amounts of hydrogen produced are similar.

Most of the core material in the upper and xi: ddle elevations of the core were molten in calculation 6 while the molten material in calculation 7 was confined to the central region. Figure 14 shows a representation of the core region indicating the approximate location of the molten core material. About 70 tons of core material was molten for calculation 6 compared to about 20 tons for calculation 7.

To summarize, calculations 6 and 7 (early depressurization) predict that RCS pressure can be reduced to about $1 \mathrm{MPa}$ by the time core relocation to the lower plenum occurs. Although the core material was in different configurations and there were different amounts of molten material for these two bounding calculations, the overall effect of these differences on RCS pressure late in the accident sequence was not significant. The lack of sensitivity of these late pressure levels to core configuration resulted because accumulator injection, and the attendant steam generation from cooling of core debris, dominated the late RCS pressure response. Differences in the heat transfer from the injected water were not 


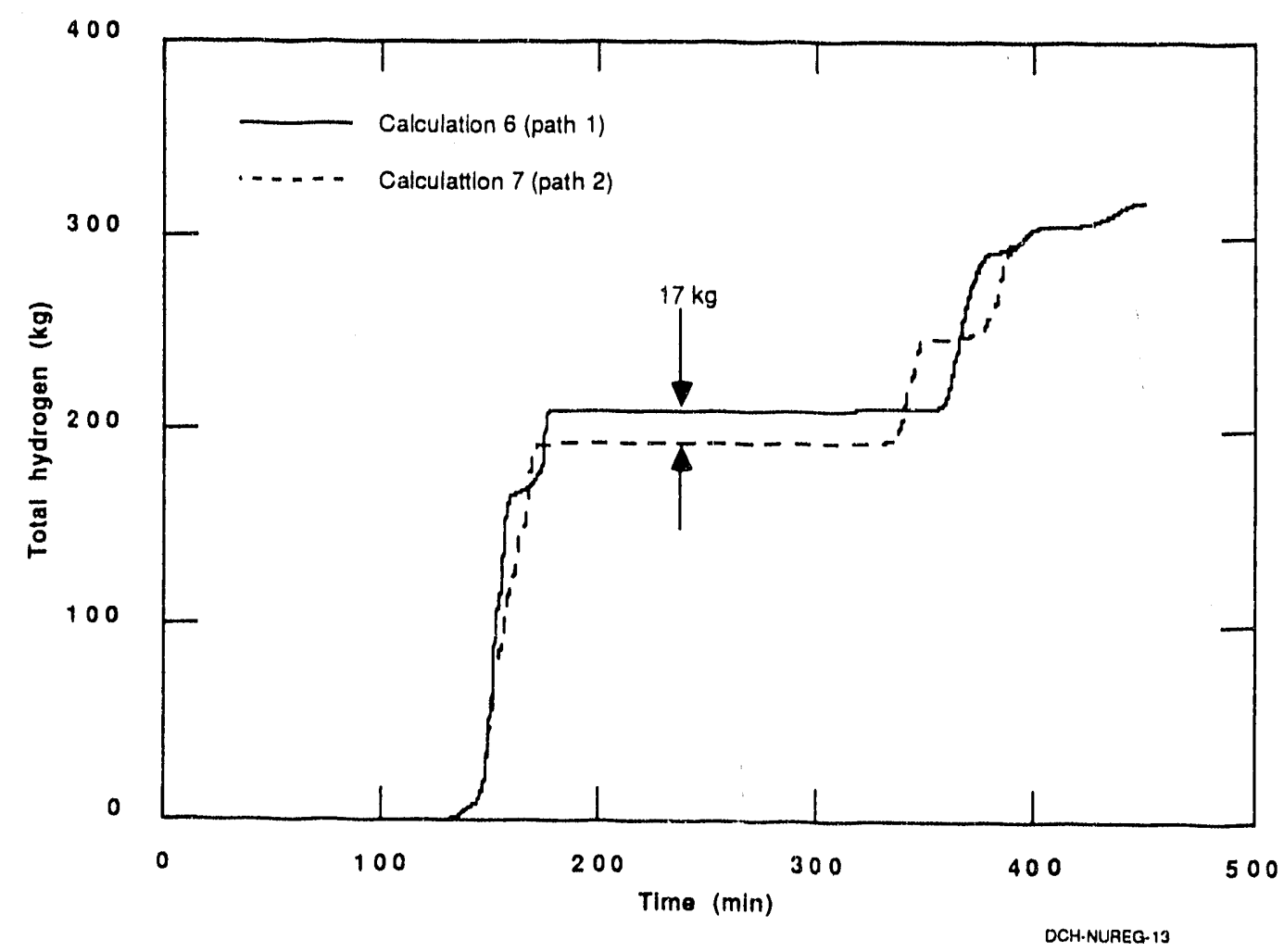

Flgure 13. Total hydrogen generated during early depressurization sensitivity calculations 6 and 7 .
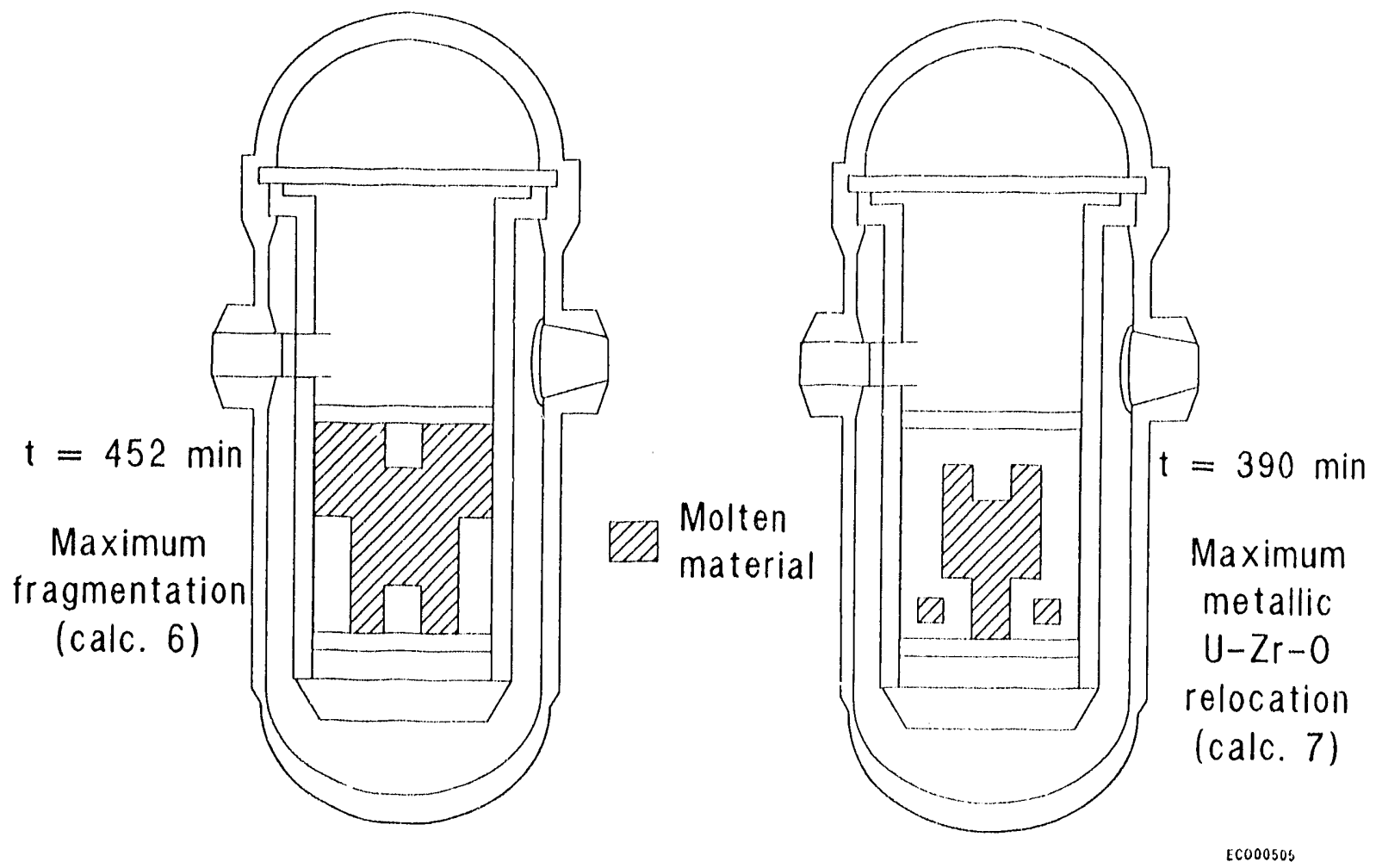

Flgure 14. Comparison of calculated core geometries for calculations 6 and 7, early depressurization. 
sufficiently influenced by the core configurations to result in significant differences in pressure levels. This pressure sensitivity may be different if steam explosions are found to be important. An analysis of the potential for steam explosions during relocation of the molten core material is currently planned using results from calculations 6 and 7 to develop appropriate initial and boundary conditions.

Calculations 8 and 9 (Table 1) were performed to estimate RCS pressure for the time period between core relocation to the lower plenum and RPV failure. a These calculations used the modeling described in Section 2.3 for maximum heat transfer during and after relocation (Path 3 ) and minimum heat transfer during and after relocation (Path 4). Calculation 6 was selected for continuation because the largest amount of core material was available for relocation when compared to calculation 7. Both calculations 8 and 9 were initiated at about $450 \mathrm{~min}(7.5 \mathrm{~h})$ and approximately 70 tons of core material were calculated to flow from the molten pool in the core through the failed crust. The flow of molten material was assumed to occur over a period of $100 \mathrm{~s}$. The time over which relocation occurred $(100 \mathrm{~s})$ was selected based on estimates of the relocation time that occurred during the TMI-2 accident. The estimates for $1 \mathrm{MI}-2$ were for a relocation time of 60 to $120 \mathrm{~s}$, with about 20 tons of corium relocated to the lower plenum.

For calculation 8 (maximum heat transfer to the lower plenum water, Path 3 ), the molten core materials were assumed to transfer sufficient energy to the water in the lower plenum to reduce the temperature of the relocating debris to the saturation temperature. When the vapor void fraction in the lower plenum was calculated to be approximately 1 , heat transfer from the molten material was then calculated to be to the lower head. The system pressure resulting from relocation under these conditions is shown in Figure 15.

a. This analysis does not consider molten fuel coolant interactions (MFCI) steam explosions. MFCIs would have to be analyzed using a code specifically designed for that purpose.
There is an immediate pressure increase of about $2 \mathrm{MPa}$ at the time of relocation followed by a decay of pressure as the rate of vaporization drops below the rate that mass is flowing through the PORVs.

When all of the water in the lower plenum is vaporized, the calculation predicts that the debris bed initially cools as energy is transferred to the lower head. As the lower head temperature increases, the rate of heat transfer from the debris decreases and ultimately the debris bed reheats. The calculated maximum lower head and debris bed temperatures are shown in Figure 16. The two temperatures are increasing in an essentially linear manner until the melting temperature of $\mathrm{ZrO}_{2}$ is reached. At that point, the debris bed is calculated to heatup at a slower, but still linear, rate. Any creep of the lower head material would not occur until the temperature exceeds about $900 \mathrm{~K}\left(1160^{\circ} \mathrm{F}\right)$. As indicated in Figure 15 , the calculated RCS pressure is essentially constant after $530 \mathrm{~min}$. At this time the RCS pressure has equalized with the containment pressure. The containment was modeled in RELAP5 as a single volume without heat structures to represent the containment walls or other structures in the containment. As discussed in Section 3.1.2, condensation of steam on the containment walls is expected to prevent the containment pressure from increasing as high as $1 \mathrm{MPa}$. The calculation was therefore terminated because it was no longer capable of accurately predicting possible creep rupture of the lower head. However, extrapolation of the lower head temperature was used to predict that melt-through would occur at a time later than $620 \mathrm{~min}$.

Calculation 9 was performed to simulate minimum heat transfer from the core relocated debris to the water in the lower plenum (Path 4 on Figure 2). Because there was no energy transfer to the coolant and consequently no vaporization of liquid, the RCS pressure was calculated to be nearly constant and approaching containment pressure. The calculated temperature of the relocated debris and the lower head wall are shown in Figure 17. A relatively linear increase, similar to that calculated for Path 3, is observed. The 


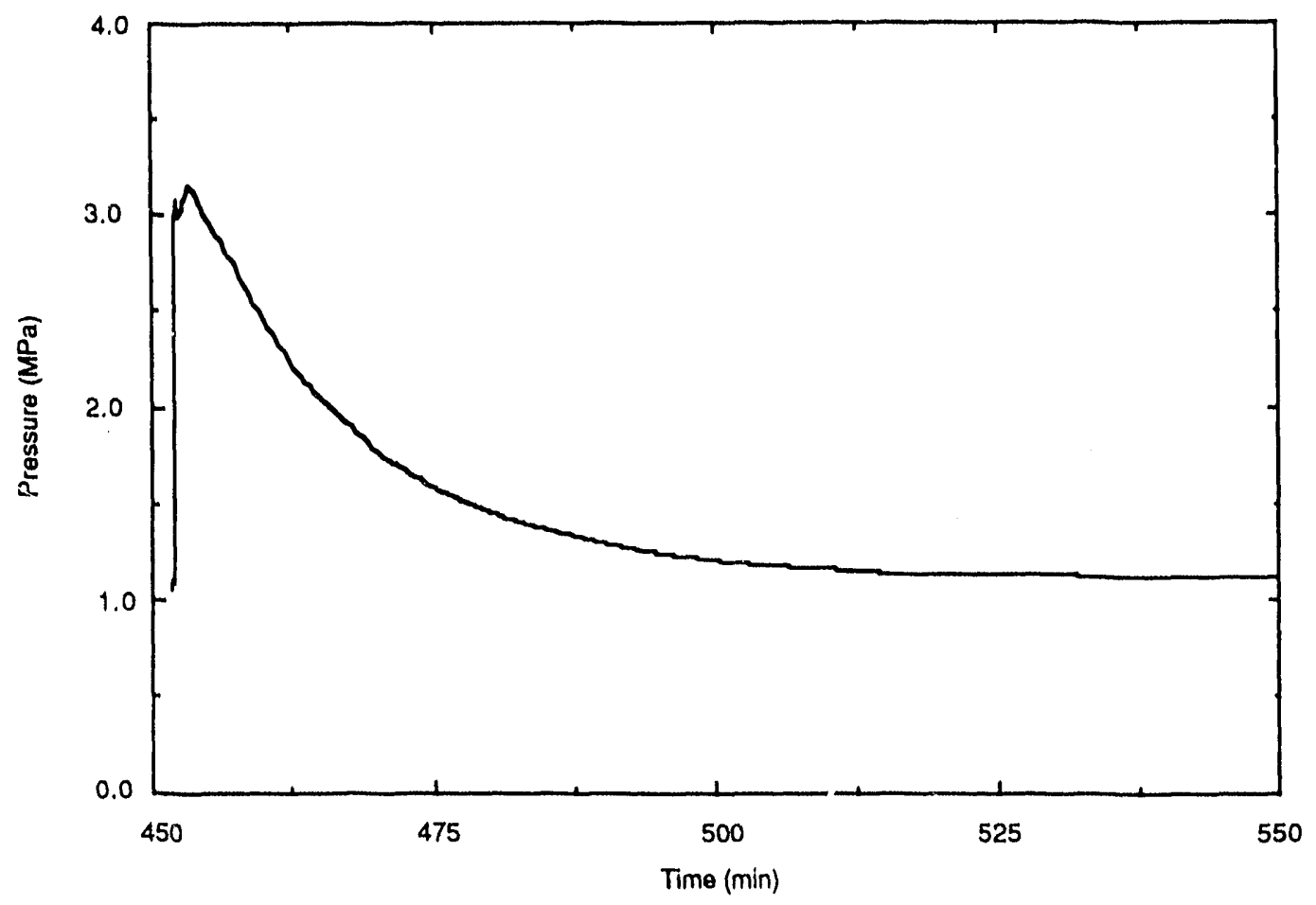

DCH-NUAEG-Z2

Figure 15. RCS pressure calculated following corium relocation to lower plenum, early depressurization.

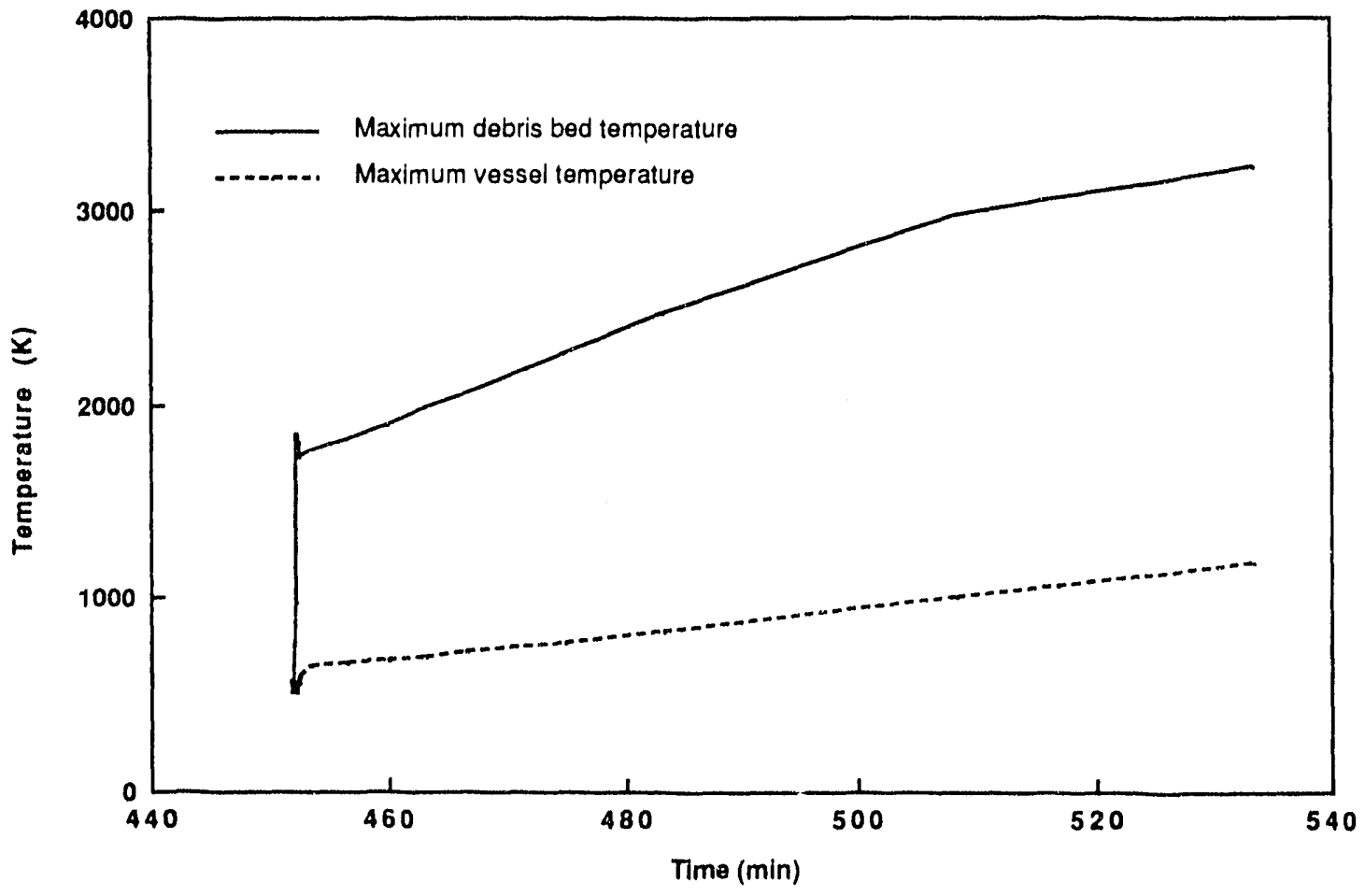

Flgure 16. Maximum debris and lower head metal temperatures for maximum steam interactions. 


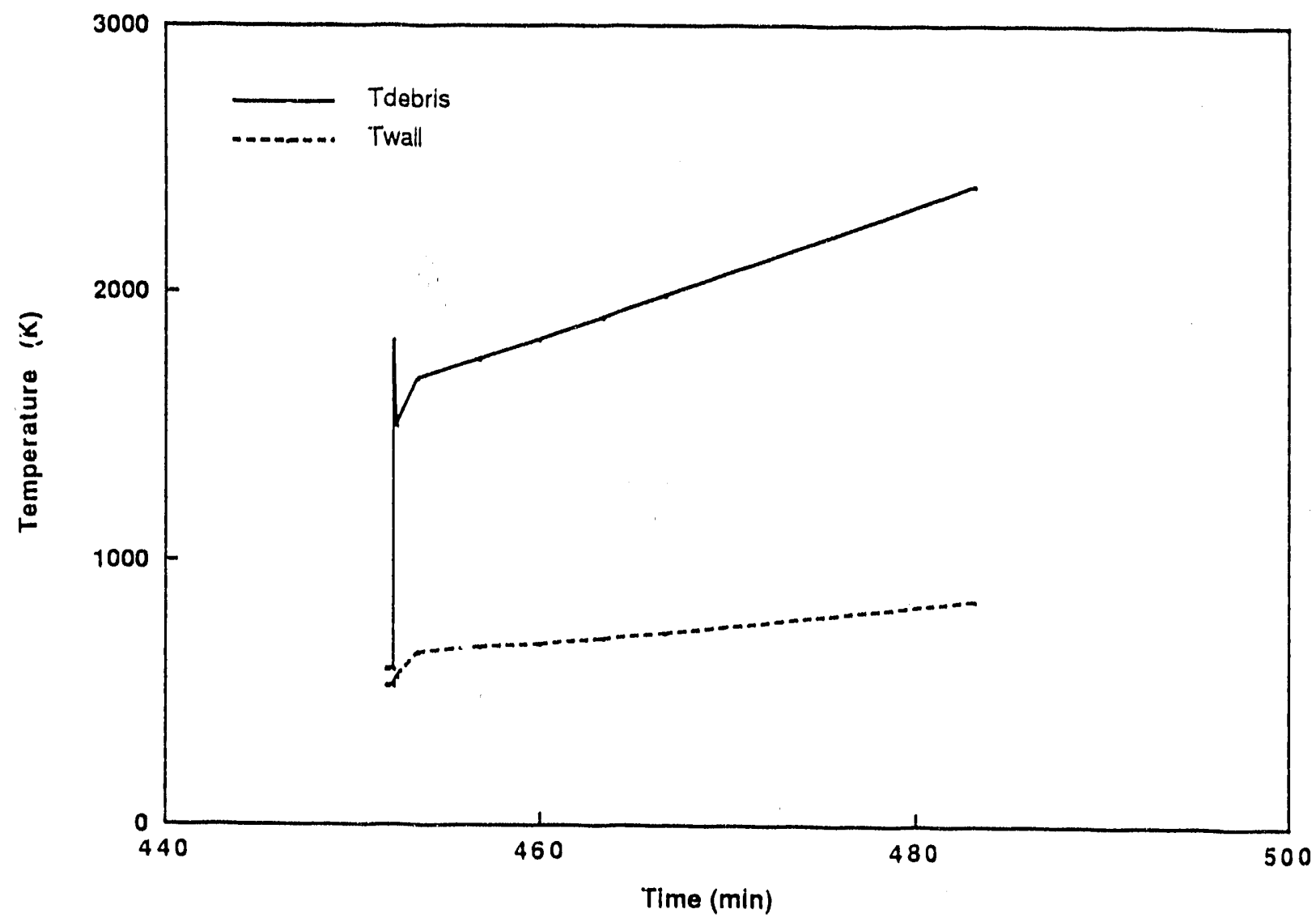

DCH.NUREG-39

Flgure 17. Maximum debris and wall temperatures for minimum steam interactions.

calculation was terminated for the same reasons as discussed for the previous calculation. Extrapolation of the lower head temperature predicts lower head melt-through to occur at a time later than $595 \mathrm{~min}$. This failure time is about $2 \mathrm{~h}$ $25 \mathrm{~min}$ after relocation occurs and should represent the minimum arnount of time between relocation and failure because there is no cooling of the debris by water.

The results of the bounding calculations to assess the effect of heat transfer from debris that relocates to the lower plenum (calculations 8 and 9) indicate that depressurization will be successful in reducing the pressure below $1 \mathrm{MPa}$ prior to lower head failure. The amount of material that relocates and the time over which reloca- tion takes place may affect these results. However, the SCDAP/RELAP5 parameters were chosen in an attempt to bound the amount of material that relocates. A more rapid relocation would be expected to affect the magnitude of the repressurization but there should be a minimum of about $21 / 2 \mathrm{~h}$ for the pressure to decrease. This amount of time should be adequate for the system to depressurize to near containment conditions.

3.1.2 Late Depressurization. The late depressurization strategy assumes that the PORVs are opened following core uncovery when the core exit thermocouples read $922 \mathrm{~K}\left(1200^{\circ} \mathrm{F}\right)$. This calculation, referred to as calculation 10 in Table 1, uses the same relocation and fragmentation parameters as calculation 6 (Path 1 on 
Figure 2). The calculated pressure response is qualitatively similar to that calculated for early depressurization, as shown in Figure 18."

a. There were code errors that affected accomplishment of the late depressurization calculation. The code on two occasions failed due to water property errors that were not alleviated by reducing the maximum time step. This is usually an indication that the energy transfer at the interface between SCDAP and RELAP5 is inconsistent. While the offending code model was being sought out, the calculation was patched. Because the core was, in general, being cooled even at its top (see Figure 23) by the accumulator flow, the PORVs were closed just prior to the water property error and held closed to allow the code to reheat the core slightly and stabilize the calculation. This is conservative with regard to the calculation of RCS pressure. The periods of closed PORV sare clearly indicated by the repressurization at about 250 and $290 \mathrm{~min}$ (see Figure 18).
However, the late depressurization calculation exhibits the following three major differences when compared to early depressurization: (1) during the early portion of the accident (from shortly after steam generator dry out until the PORVs are latched open) the PORVs cycle between their open and closed positions, (2) there is no repressurization after latching open the PORVs, until the accumulator injection cools the core, and (3) the pressure decrease at the time of accumulator injection is very rapid and consequently the initial inflow from the accumulators is rapid rather than slow. Each of these differences is discussed in more detail.

After steam generator dryout in the late depressurization calculation, the PORVs continue to cycle as steam is formed in the core as a result of decay heat. Thus, RCS coolant inventory is lost as the PORVs cycle open and closed at pressures

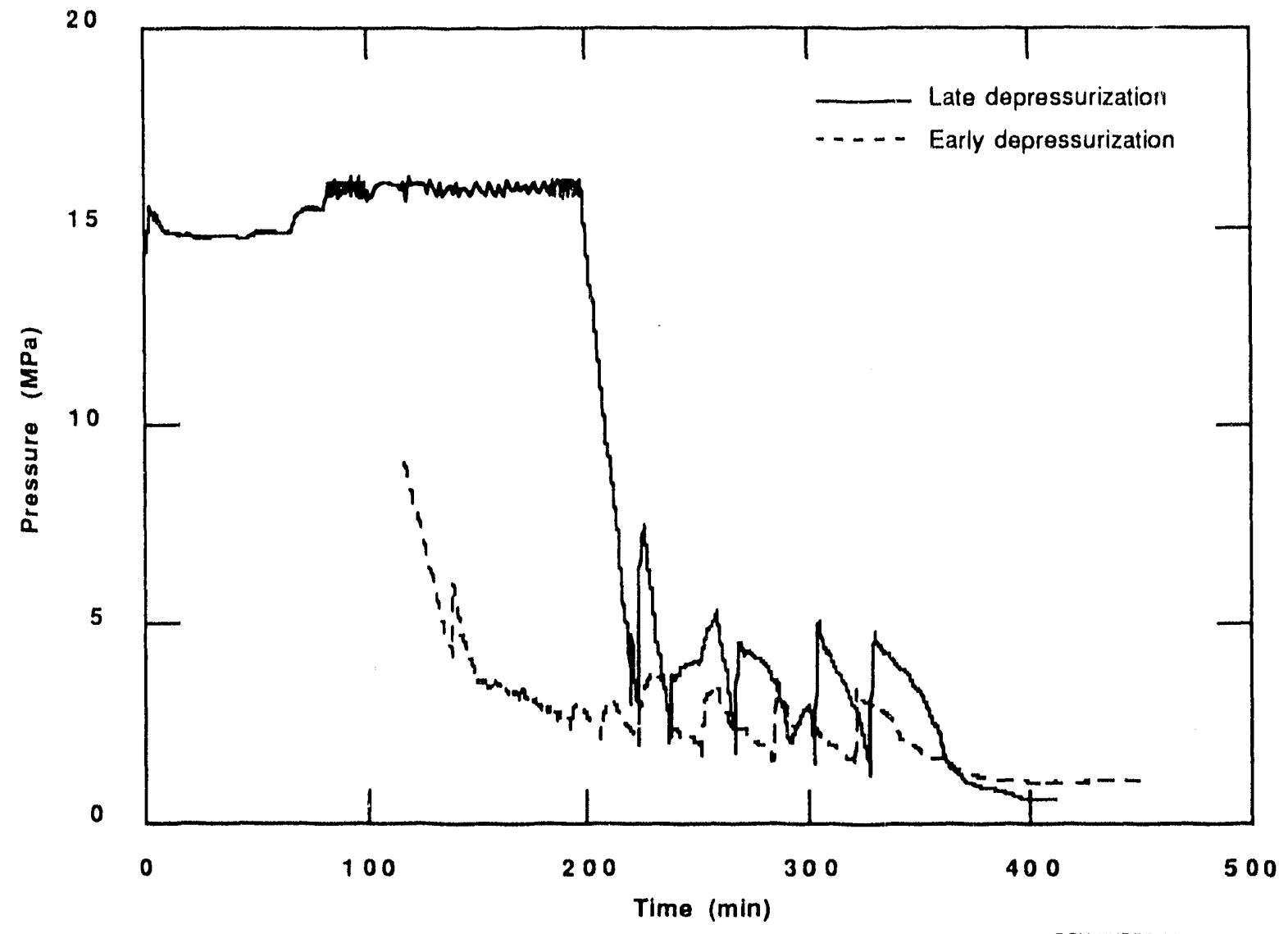

DCH-NUAEG-24

Flgure 18. Comparison of calculated RCS pressure for late and early depressurization. 
corresponding to their setpoints. After an extended period of time, sufficient inventory is lost and the core uncovers. The resulting core heatup causes the calculated core exit temperature to reach $922 \mathrm{~K}\left(1200^{\circ} \mathrm{F}\right)$ at approximately $192 \mathrm{~min}$. Based on the late depressurization strategy initiation criteria, the PORVs are latched open at this time and RCS depressurization begins. There is no repressurization, as with early depressurization, because the higher elevations of RCS are effectively steam-filled. (The only remaining liquid is in the vessel below the top of the core.) Thus, the flow at the PORVs remains essentially single-phase vapor throughout the depressurization calculation.

A difference in the RCS pressure of about $0.4 \mathrm{MPa}$ at times later than about $370 \mathrm{~min}$ between the early and late depressurization calculations is shown in Figure 18. As discussed in the preceding subsection, the pressure for the early depressurization calculation approaches a limiting value of about $1 \mathrm{MPa}$ because the SCDAP/ RELAP5 representation of the containment is not sufficiently detailed to represent the thermal, condensation, and fluid flow processes. The primary deficiency is the lack of an adequate model of the containment heat structures that allows condensation of steam. Without adequate representation of condensation the calculation overestimates the containment pressure. Because the modeling caused the final pressure to be artificially high for the early depressurization calculation, the late depressurization calculation was run with a parallel MELCOR containment analysis. ${ }^{15}$ The mass and energy flows from the RCS, as calculated by SCDAP/RELAP5, were used as input to MELCOR. The pressurizer relief tank room pressure calculated by MELCOR was then fed back to SCDAP/RELAP5 at restarts. With this technique, the pressure calculated for late depressurization was about $0.6 \mathrm{MPa}$ when the calculation was terminated, and containment pressure was about $0.2 \mathrm{MPa}$. It is expected that similar final RCS pressure results would have been calculated for the early depressurization strategy if the more detailed containment representation had been used.
The RCS inventory and fluid conditions are quite different for the two strategies when depressurization begins, as illustrated by a phenomenological time line in Figure 19. For the early depressurization strategy no mass has been lost from the RCS prior to latching the PORVs open, but for late depressurization 59\% of the RCS coolant inventory (excluding accumulator inventory) has been lost before the PORVs ane latched open. Differences in inventory during the later stages of the accident sequence are illustrated in Figure 20 using the reactor vessel collapsed liquid levels. When the collapsed liquid level reaches the bottom of the core and mass depletion in the lower plenum begins, the RCS pressure is about $5 \mathrm{MPa}$ for early depressurization and about $15 \mathrm{MPa}$ for late depressurization. This difference in pressure allows additional time for RCS mass depletion prior to the first accumulator injection cycle for the late depressurization case. As a result, when the accumulator begins injecting, the RPV collapsed liquid level is below the bottom of the core barrel for late depressurization and above the bottom of the core barrel for early depressurization.

Although the magnitude and timing of the RCS pressure response was somewhat different after the initiation of accumulator injection, similar phenomena were taking place. Cyclic pressure behavior was initiated when the pressure fell below the accumulator pressure and the accumulator began to add water to the hot core. When sufficient water had entered the core, steam generation resulting from cooling of the core exceeded the relief capacity of the PORVs and the rate of condensation of steam by the accumulator water, causing the RCS pressure to increase above the accumulator pressure thereby terminating water addition. Cooling of the core continued as water in the core region was vaporized. When the rate of vaporization of water in the core region was less than flow from the PORVs, the pressure began to decrease. The cycle started over when the accumulator pressure was reached. 


\section{Early Depressurization}

\begin{tabular}{|c|c|c|c|c|}
\hline & $\begin{array}{l}\text { am generator } \\
\text { out \& PORVs } \\
\text { tched open }\end{array}$ & $\begin{array}{l}\text { Core } \\
\text { uncovered } \\
(922 \mathrm{~K})\end{array}$ & $\overbrace{\begin{array}{c}\text { Collapsed } \\
\text { liquid level } \\
\text { below core }\end{array}}^{\mathrm{P} 5 \mathrm{MPa}}$ & $\begin{array}{c}\text { First } \\
\text { accumulator } \\
\text { injection }\end{array}$ \\
\hline Time & 75 min. & $127 \mathrm{~min}$. & $132 \mathrm{~min}$. & $138 \mathrm{~min}$. \\
\hline $\begin{array}{l}\text { RCS coolant } \\
\text { mass lost }\end{array}$ & 0 & $63 \%$ & & \\
\hline Subcooling* & $--45 K$ & 0 & 0 & 0 \\
\hline
\end{tabular}

\section{Late Depressurization}

\begin{tabular}{|c|c|c|c|c|}
\hline & $\begin{array}{l}\text { team generator } \\
\text { dry out }\end{array}$ & $\begin{array}{c}\text { Core uncovered } \\
\begin{array}{c}\text { \& PORV latched } \\
\text { open (922K) }\end{array}\end{array}$ & 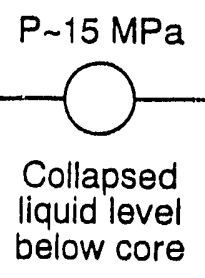 & $\overbrace{\substack{\text { First } \\
\text { accumulator } \\
\text { injection }}}^{\mathrm{P}=4.2 \mathrm{MPa}}$ \\
\hline Time & $75 \mathrm{~min}$. & $192 \mathrm{~min}$. & $199 \mathrm{~min}$. & $218 \mathrm{~min}$. \\
\hline $\begin{array}{l}\text { RCS coola: it } \\
\text { mass lost }\end{array}$ & 0 & $59 \%$ & & $88 \%$ \\
\hline Subcooling* & $\sim-45 \mathrm{~K}$ & $-3.6 K$ & 0 & 0 \\
\hline
\end{tabular}

* Cold leg fluid minus saturation temperature

Flgure 19. Early and late depressurization phenomenological sequences. 


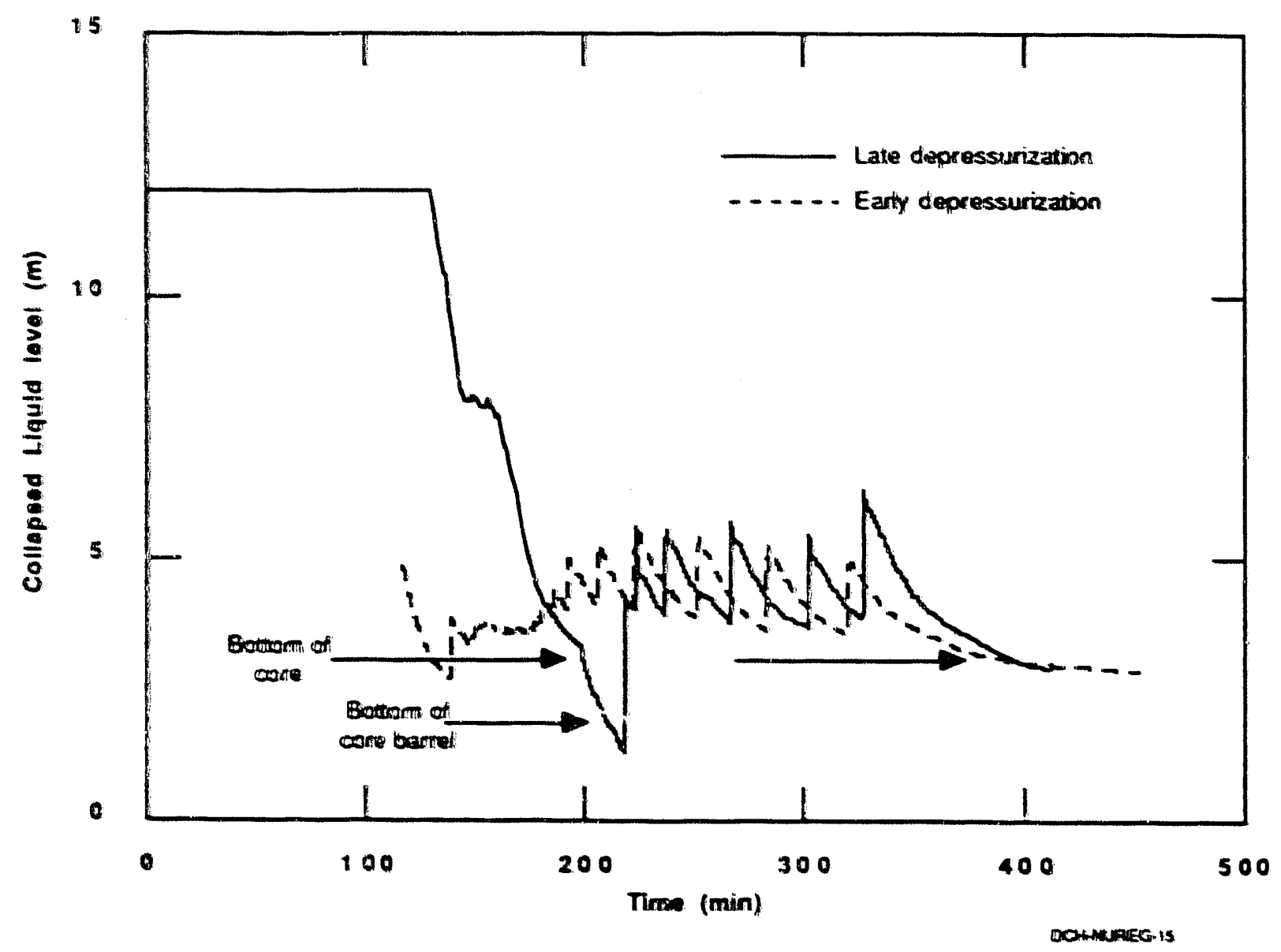

Figure 20. Comparison of RPV downcomer liquid levels calculated for early and late depressurizention.

The RCS pressure increase following the initivl accamulator injection is much larger for late depressurization as compared to early depressarisation Reasoas for this difference include the following:

- More water was required to fill the lower plenum and downcomer in the bue depressurizitio a case because more mass had been depleted. The longer initial period of accumulator now allowred higher accumulator injection rates to be extablished prior to the rime fluid began cooling the core. These higher injection rases resulted in additional cooling and steam generation, whics caused hicher presunes.
- During eariy depressurization, the cold legs are isolated by liquid in the puomp loop seaks and liquid in the lowex plenum a a level above the boutom of the core barrel. This isolation results in less availability of vapor to be condensed by the liquid inflow from the accumulators during early depressurization's first accumulator cycle. Thus, the pressure decrease in the cold les caused by condensation on the first inflow cycle is less for early depressurization.

The cold leg loop seals clear on the pressure difference between the loop seals and the pump discharge during accumulator injection. This liquid flows into the reactor vessed for both cases, 
adding to the inventory. The early depressurization flow rate into the vessel on the first injection cycle is less than one-third the flow rate calculated for late depressurization (see Figures 21 and 22).

Figure 23 illustrates a comparison between the calculated cladding temperatures at the top of the core for early and late depressurization. During early depressurization, the accumulator injection does not terminate cladding heatup until complete oxidation of the cladding at the 3.5-m node has taken place. During late depressurization, the accumulator inflow is calculated to be sufficient to control cladding temperatures to $<2000 \mathrm{~K}$ $\left(3140^{\circ} \mathrm{F}\right)$ at the $3.5-\mathrm{m}$ node until the accumulators are emptied. Once the accumulators are emptied, the temperature excursion is restarted for both early and late depressurization.

The inflow on the first accumulator injection cycle for the early depressurization strategy is insufficient to provide more than momentary cooling to the core (Figure 23). Thus, for early depressurization, hydrogen is generated during accumulator injection as a result of cladding oxidation (see Figure 24). This hydrogen generation effects the system thermal-hydraulic response. The most significant effect is on the syscem pressure because large amounts of energy are released during cladding oxidation and the volume of the hydrogen generated is relatively large. In addition, during this time period, there would be flow from the upper plenum to the cold leg via a 'sakage path from the upper plenum to the downcomer thereby transporting hydrogen to the cold leg. By $150 \mathrm{~min}$, the ratio of the hydrogen partial pressure and the steam partial pressure exceeds $50 \%$ (see Figure 25). The combination of the hydrogen with the steam in the cold le; affects the condensation rates in the cold leg, which intluences the accumulator injection rate together with the RCS pressure.

The initial inflow from the accumulator calculated for late depressurization provides sufficient liquid to significantly cool the core and the second cycle of the accumulator reduces the core temperature enough to terminate cladding oxidation as illustrated by the termination of hydrogen generation in Figure 26. The results show that once cooling is established, hydrogen generation is terminated until the accumulators are emptied. Because little hydrogen is generated during accumulator injection, back flow of hydrogen from the upper plenum to the cold leg is not significant and condensation in the cold leg is not affected during the period of accumulator injection.

The effects of the hydrogen generation on containment response during both the late and early depressurization strategies were evaluated based on the results of the MELCOR calculation. The MELCOR model was comprised of sixtien control volumes that represent the compartments within the containment. The amount of hydrogen entering the containment, through the pressurizer surge tank, was based on the SCDAP/RELAP5 calculation of the hydrogen mass exiting the RCS through the PORVs. Dispersion of hydrogen from the pressurizer surge tank to the remainder of the containment was calculated using the hydrogen dispersion models within the MELCOR code. The results of the calculations show that for both early and late depressurization, no hyilrogen detonations or deflagrations were predic ed and the pressure remained within the design pressure limits of the containument.

Because there is minimal oxidation of the cladding prior to emptying the accumulators for the late depressurization calculation, the fluid (primarily steam and hydrogen) exiting the core is at a relatively low temperature. Consequently, the structures along the flow path to the PORVs remain at relatively low temperatures, including the pressurizer surge line (see Figure 27). The volume average surge line metal temperature is estimated to be $<900 \mathrm{~K}\left(1160^{\circ} \mathrm{F}\right)$ until the accumulators are empty. Based on the models used in SCDAP/RELAP5, these temperatures are too low to cause creep rupture prior to emptying of the accumulators. After the accumulators are empty, the pressure difference between the RCS and containment is relatively small; it is expected that the surge line is more likely to fail by melting. 


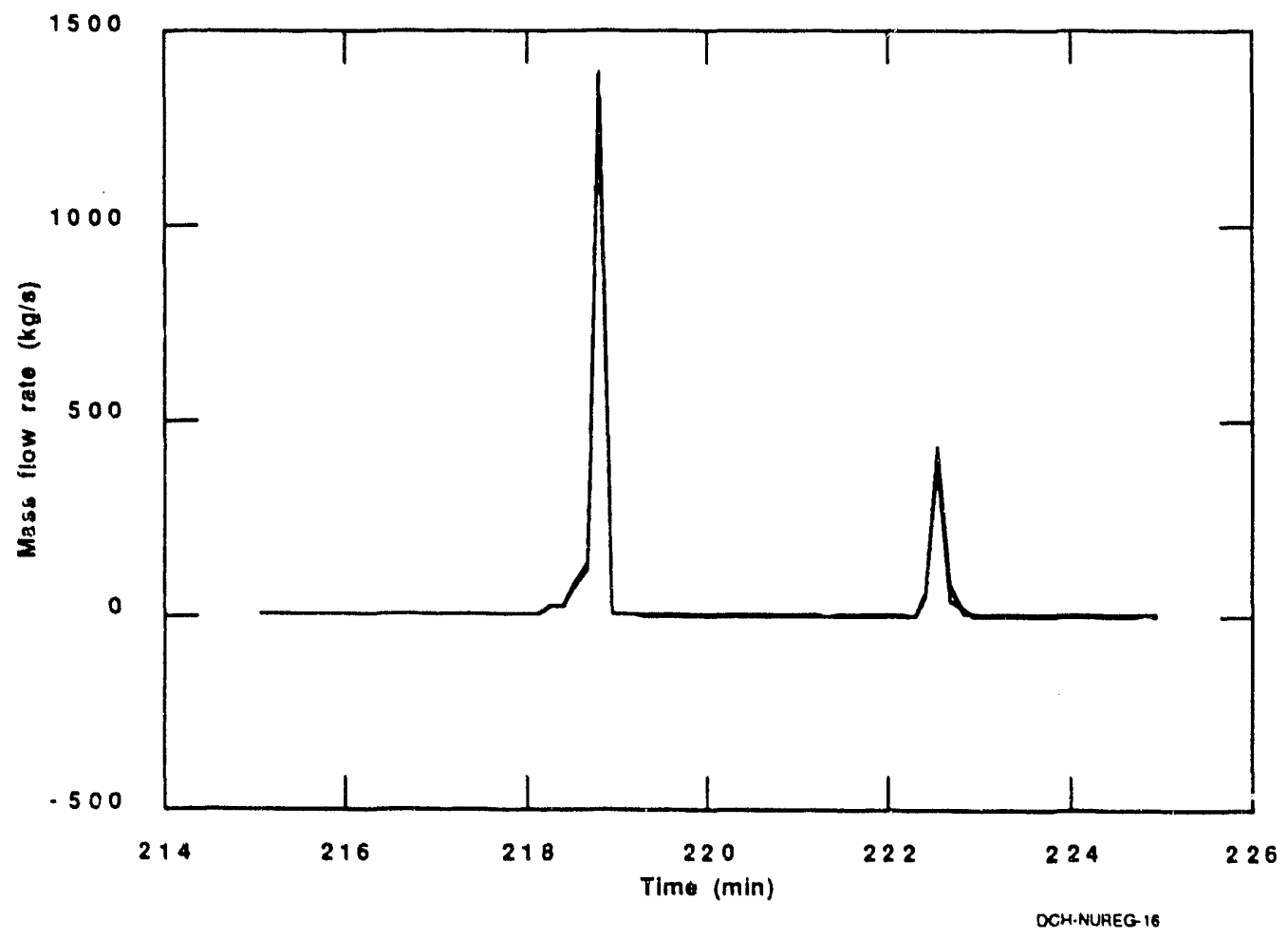

Flgure 21. Cold leg mass flow rates calculated for late depressurization during first accumulator injection.

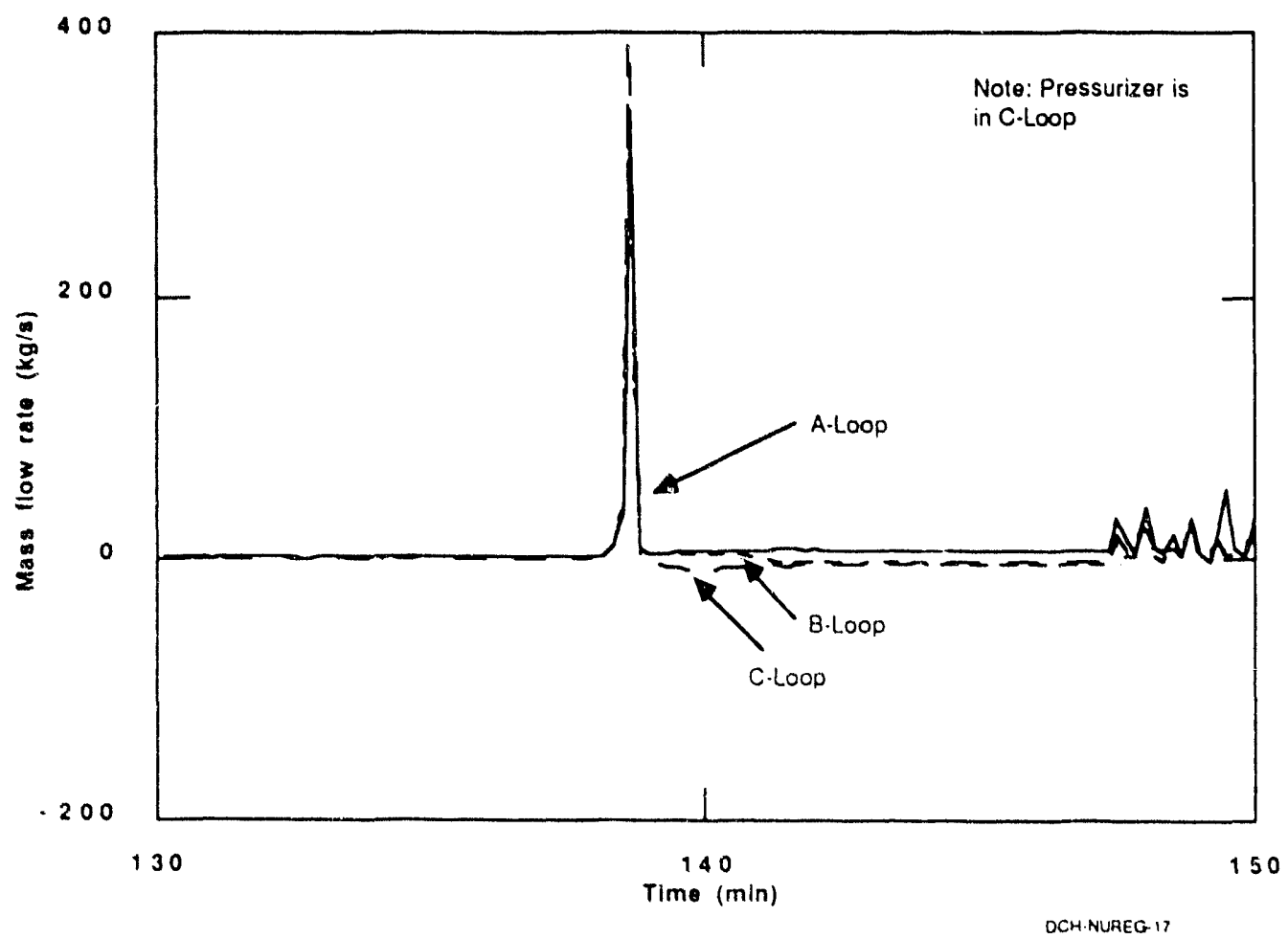

Figure 22. Cold leg mass flow rates calculated during first accumulator cycle, early depressurization calculation 6. 


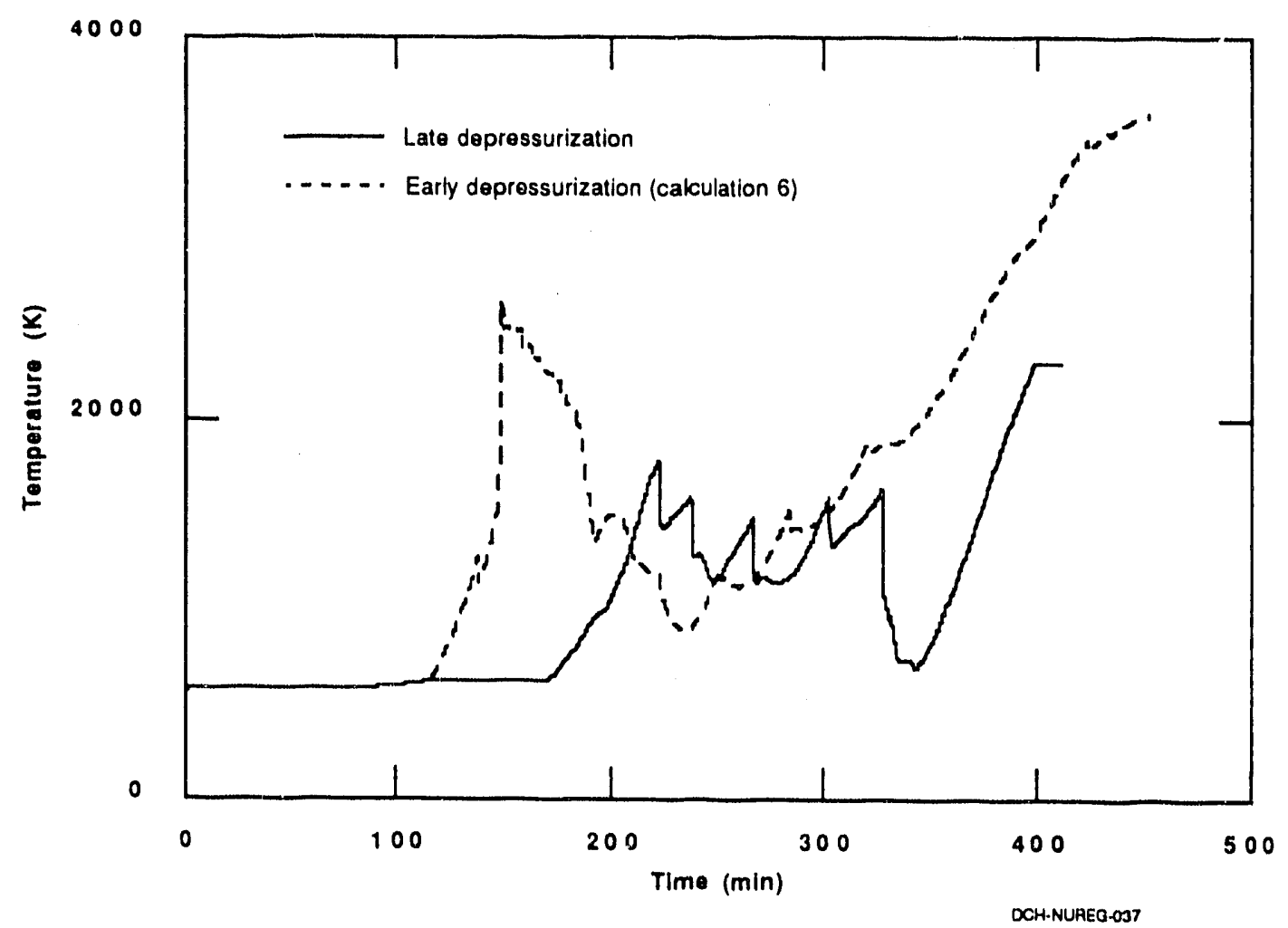

Figure 23. Comparison of early and late depressurization cladding temperatures calculated at $3.5 \mathrm{~m}$.

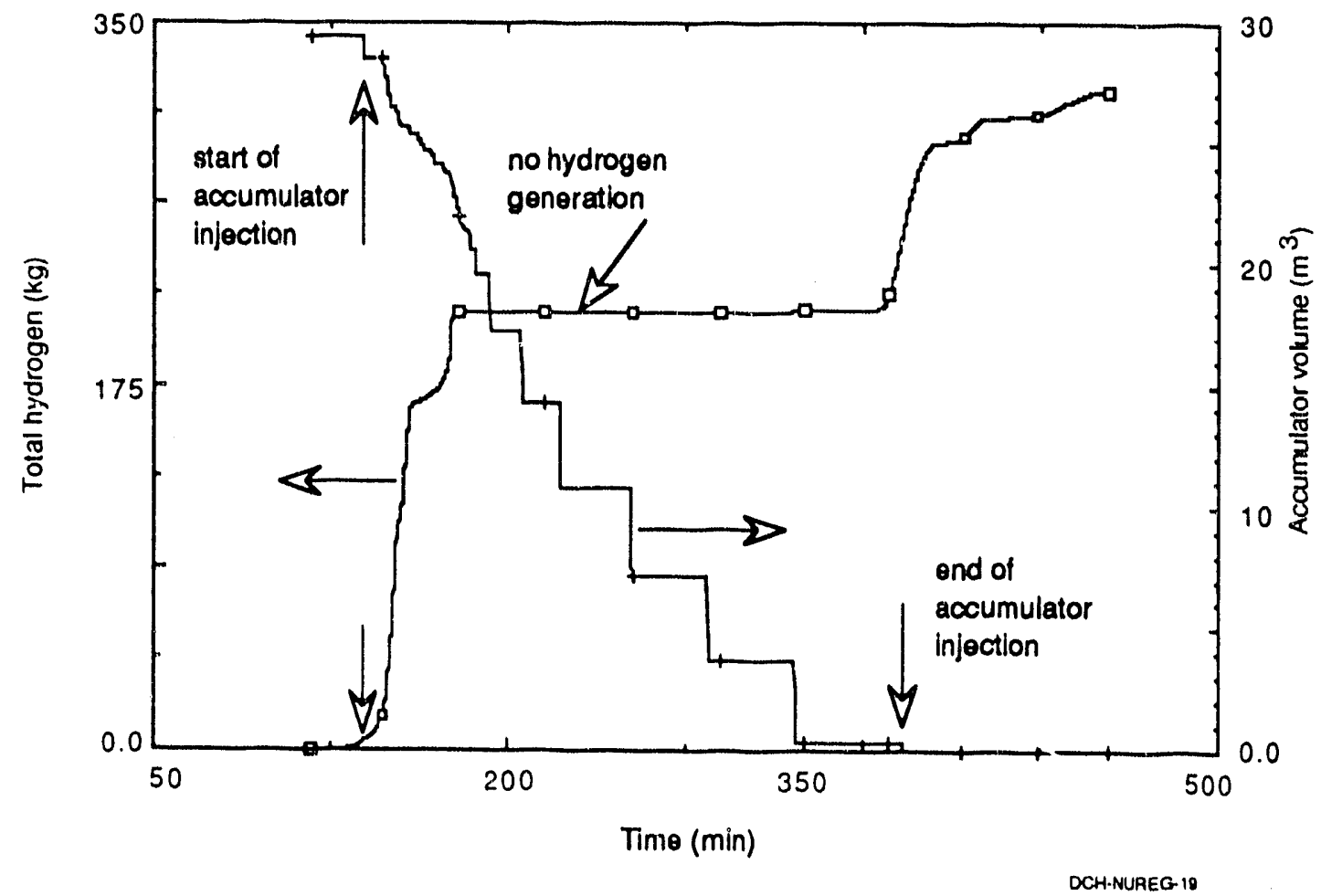

Figure 24. Total hydrogen generated compared to accumulator volume for early depressurization. 


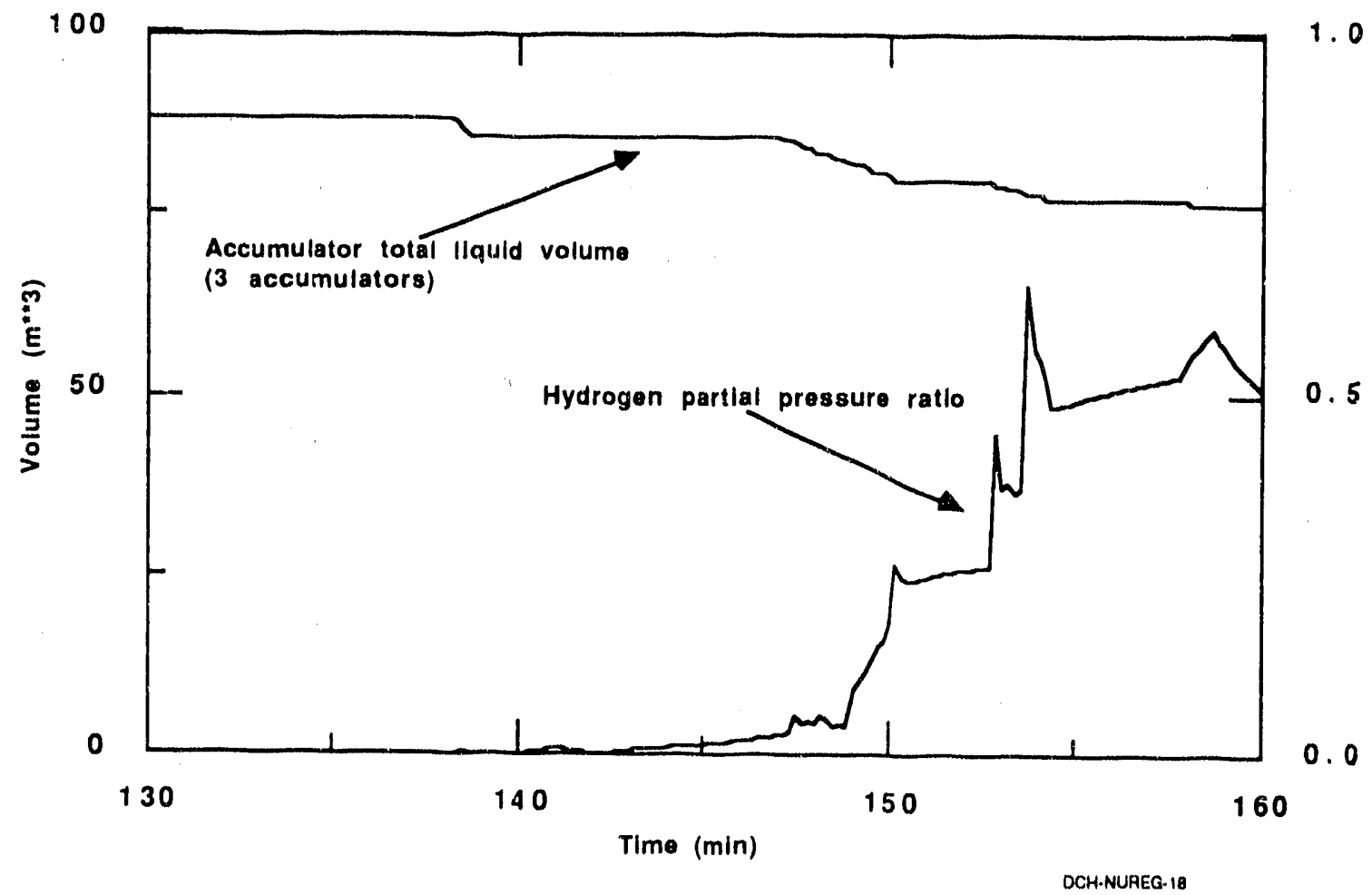

Flgure 25. Hydrogen partial pressure in cold leg after first accumulator injection calculated for early depressurization.

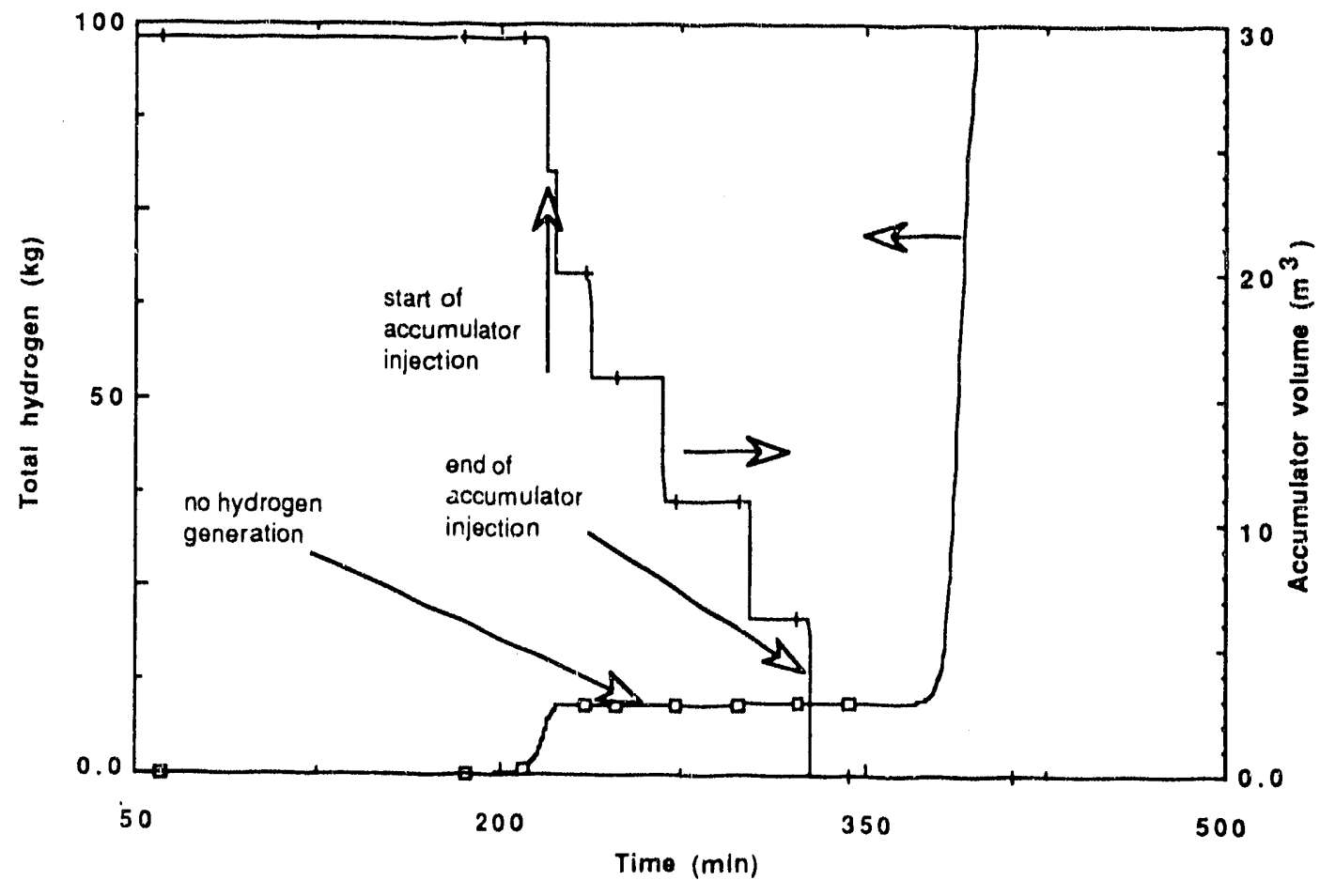

DCH.NUAEG-20

Figure 26. Total hydrogen generated compared to accumulator volume for late depressurization. 


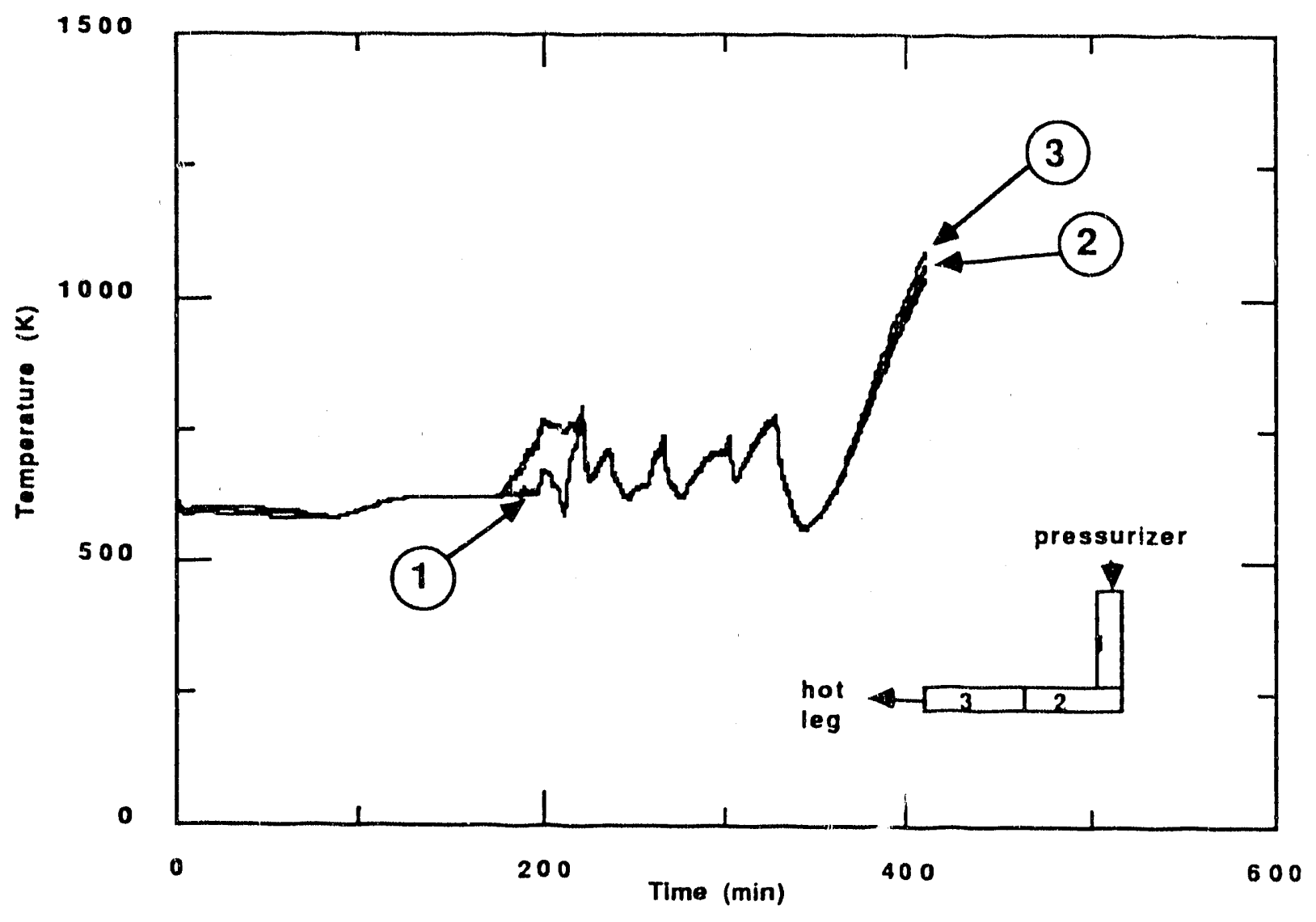

DCH-MUAEG-21

Figure 27. Surge line average metal temperatures calculated for late depressurization.

Calculations to determine pressure at the time of lower head failure were not made for late depressurization. The late depressurization analysis was terminated at approximately $420 \mathrm{~min}$. The results were, at that point, closely following the early depressurization calculations; a similar temperature excursion, a progression toward core melting, and RCS pressure slowly decreasing toward containment pressure. Based on these similarities, it is estimated that the code would predict a similar RCS pressure response as occurred for the early depressurization calculation, only delayed in time. Hence, depressurization of the RCS to a value near containment pressure, prior to breach of the RPV, is expected.

3.1.3 Comparison of Depressurization Strategles and No Operator Action. A SCDAP/RELAP5 analysis of the TMLB' sequence at Surry to study hot leg countercurrent and in-vessel natural circulation by Bayless ${ }^{5}$ provides a means of comparing the results of early and late depressurization with the results of no-operator action. Bayless performed sensitivity studies over a wide range of parameters that control energy transport within the RCS.

Comparison of the pressures for the three calculations-early depressurization, late depressurization, and no operator action-are shown in Figure 28. The results show that all three calculations provide some means for accomplishing depressurization. For the no action calculation, core damage is predicted to begin at about the same time as the late depressurization strategy. The system is predicted to depressurize at about $246 \mathrm{~min}$ for the no action case as a result of surge line failure. The pressure responses for the 


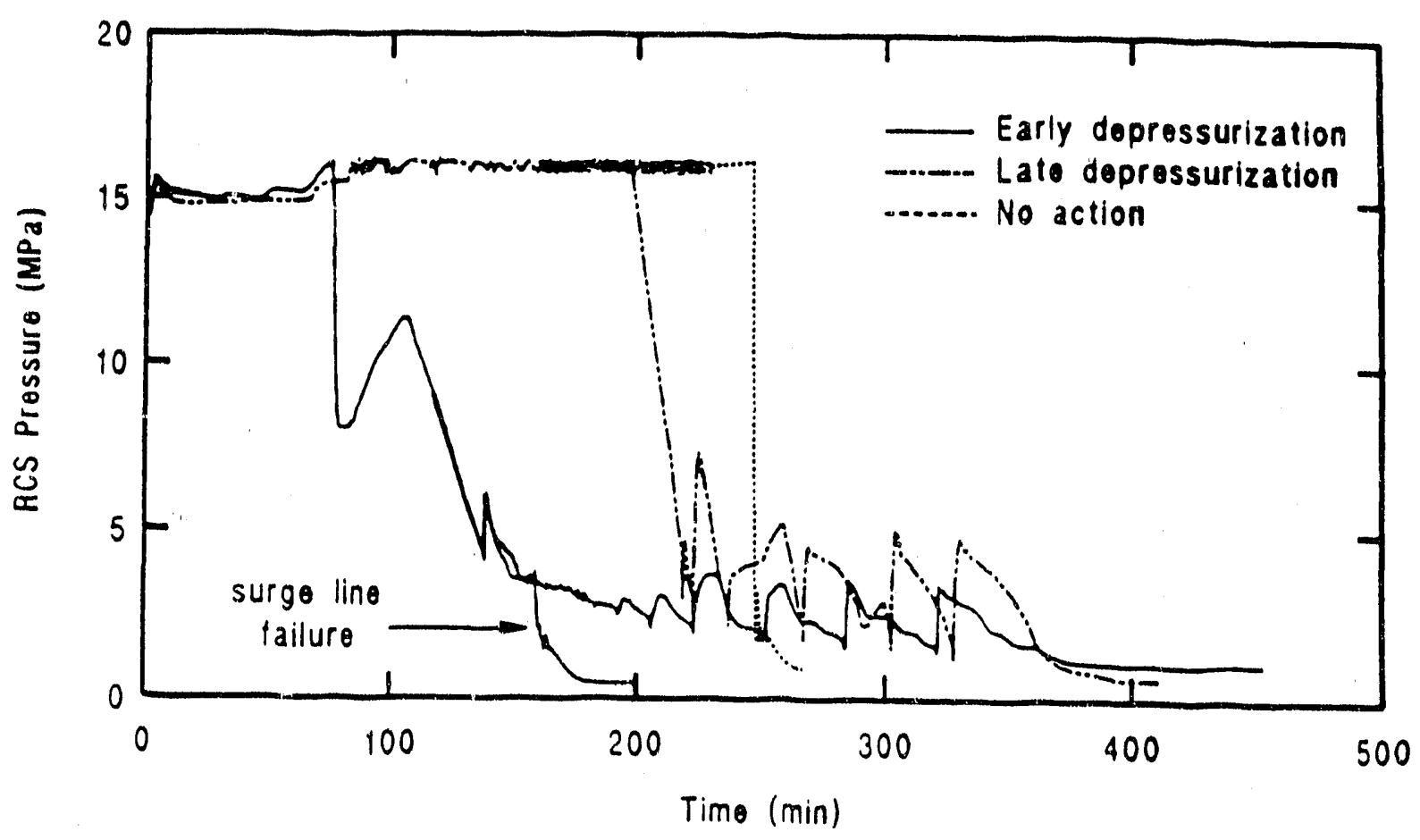

DCH-NUREG-3O

Figure 28. Calculated RCS pressure for various depressurization strategies.

three cases show that the pressure can be reduced to levels that would have a high likelihood of mitigating the effects of $\mathrm{DCH}$.

Results presented in the previous subsections indicate that early depressurization culminates in an early initiation of core damage. In comparison, late depressurization delays the time to core damage and allows more time for the operators to recover either ac power or auxiliary feedwater, or to find an emergency source of feedwater. Therefore, from a phenomenological standpoint, late depressurization is subjectively a better strategy than early depressurization. Although late depressurization does not delay core heatup relative to no action (the sequences are the same until the core has uncovered), it does initiate accumulator injection that delays substantial melting and relocation of the cladding and fuel. Thus, there is no increase or decrease in the core damage frequency associated with late depressurization. The delay in fuel rod relocation should allow additional time for plant personnel to successfully implement recovery actions. Because success for the no action case relies on an RCS pressure boundary failure, there may be some uncertainty in the likelihood of depressurization. A probabilistic assessment of depressurization is currently being conducted by the NRC to reduce this uncertainty.

\subsection{PORV Capabilities and Limitations}

Reliable operation of the PORV under severe accident conditions must be possible for extended periods of time to ensure that early and late depressurization strategies described in the previous section are successful. A limited evaluation of potential failure mechanisms for relief through the PORVs was conducted to answer the following questions:

- What is the potential for the PORVs to fail as a result of high temperatures that the valves are exposed to? 
- Can the valves be initially opened and maintained in an open position for the time required to accomplish intentional depressurization?

- Will the block valves be in the open position to enable sufficient flow through the PORVs?

The Surry RCS pressure relief system incorporates two PORVs and three code safety relief valves (SRVs). The PORVs provide pressure relief at a setpoint below the SRVs. All of these valves discharge into the pressurizer relief tank (PRT) and, upon rupture of the PRT burst diaphragm, into the containment. The PORVs are Copes-Vulcan Model D-100-160 air-operated globe valves, 2 in. NPS, 17-4PH plug and cage, with an opening pressure of $16.1 \mathrm{MPa}$ (2335 psig) and a nominal flow capacity of $45 \mathrm{~kg} / \mathrm{s}$ $(179,000 \mathrm{lb} / \mathrm{h})$ of saturated steam each. They are spring-closed, air-operated and utilize dc-powered solenoids. ${ }^{16}$ Figure 29 shows a schematic drawing of a PORV typical of those used at Surry.

Three-inch versions of the same valves were tested for operability and flow in a test program conducted by EPRI ${ }^{17}$ to respond to NRC recommendations documented in Section 2.1.2 of "Performance Testing on BWR and PWR Safety and Relief Valves,"18 and as clarified in Item II.D. 1.A. ${ }^{19}$ Testing was conducted over a wide range of fluid conditions for expected normal and accident operation. Valve performance was satisfactory except for (a) some failures to

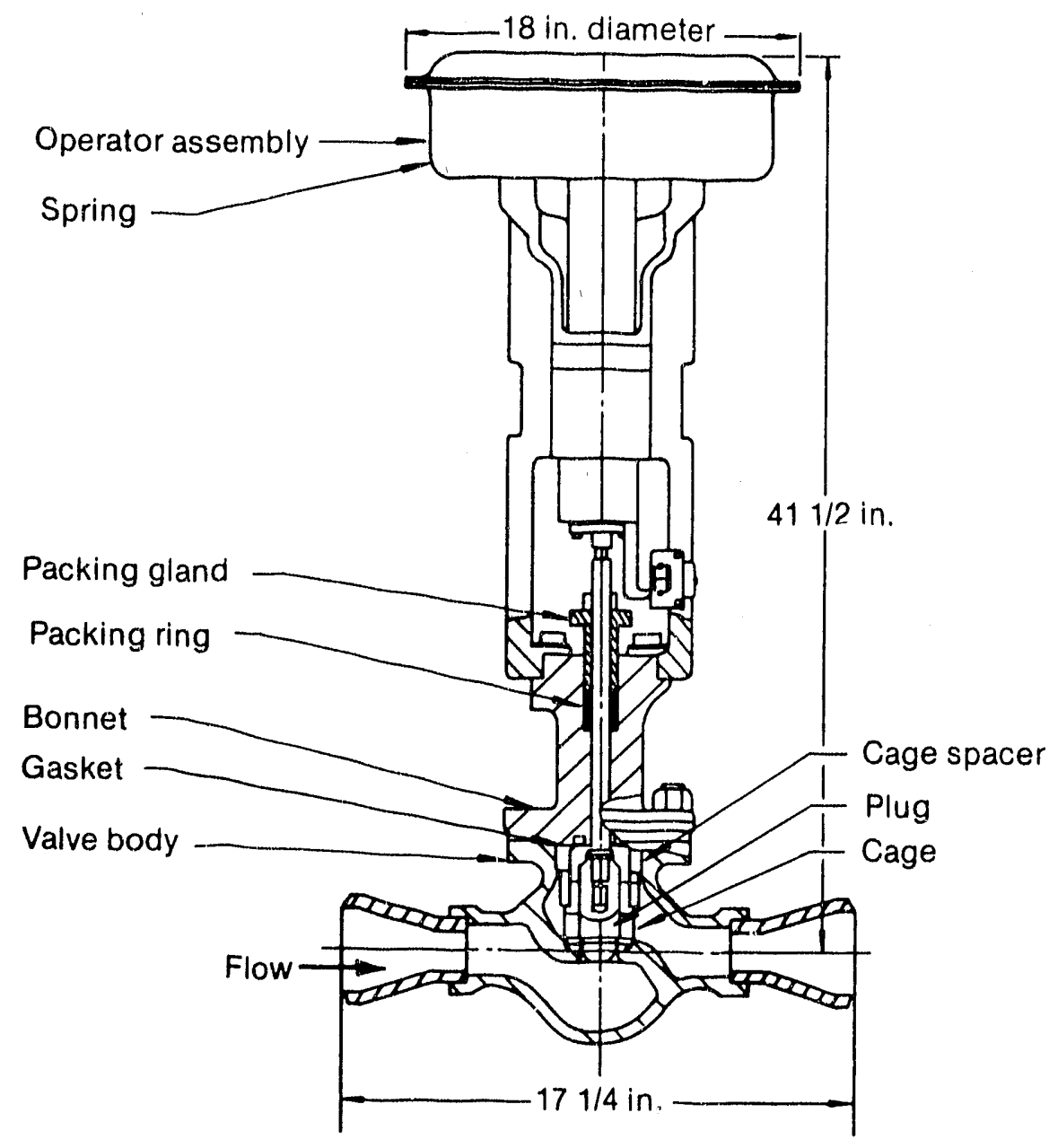

0.0502

Figure 29. Schematic drawing of a valve typical of the Surry PORVs. 
fully close were observed after several cycles when flowing steam, due to galling of the cage and plug guiding surfaces (the valve always closed to within $13 \%$ of fully-closed position), and (b) some partial washing out of the cageto-body gasket when water was used in the testing. These tests were conducted with the fluid at saturation temperature. Figure 30 shows that the calculated fluid temperature at the outlet of the pressurizer greatly exceeds the saturation temperature. Fluid temperatures at the valves would be about $55 \mathrm{~K}\left(100^{\circ} \mathrm{F}\right)$ less than these temperatures because of heat transfer to the piping leading to the PORVs. An estimate of the fluid temperatures up to the time of vessel failure was made for the late depressurization strategy and is documented in Appendix F. These results show that the fluid temperature at the PORVs for late depressurization does not exceed $900 \mathrm{~K}\left(1160^{\circ} \mathrm{F}\right)$. Temperatures in the piping and valve material would lag these temperatures significantly, although detailed heat transfer calculations for the valve body were not performed. The calculated fluid temperatures are substantially above the valve design temperature $\left[616 \mathrm{~K}\left(650^{\circ} \mathrm{F}\right)\right]$.

Potential high-temperature failure modes with the valve in the open position were examined and included: seizure of the valve in the position due to uneven expansion between the stem and body, failure of the bonnet nuts or bolts due to thermal stresses, failure of the valve body due to thermal/ pressure stresses, and significant erosion or deformation of the valve seat or the plug assembly. A valve stem-to-disk separation could cause the plug to drop; however, any significant pressure upstream of the valve would likely prevent the plug from fully seating. Further, because the valve plug is caged, it is unlikely that the plug could escape to cause an obstruction in the downstream piping. Failure of the valve in the open position and erosion to the valve seat would not be significant problems for intentional depressurization since reclosing the valve would only be necessary if other methods of mitigating the accident sequence became available. Failure of the valve bonnet nuts and bolts and the valve body would be unlikely for the late depressurization strategy because the metal temperatures would be low [substantially $<900 \mathrm{~K}\left(1160^{\circ} \mathrm{F}\right)$ ] and the pressure at the valve would also be low. The higher fluid temperatures for early depressurization, which occur early in the sequence could increase the likelihood of these components failing, but is expected to remain small.

Among high-temperature fallures that prevent the PORV from opening or staying open, the most credible scenario is the thermal distortion of the valve backseat causing leakage. Leakage could result in packing failure and the venting of hot gases upward, causing the valve's pneumatic operator to fail. The operator components most likely to fail would be the diaphragm or the electrical control solenoids. Because this valve iails to the closed position with spring pressure, the valve might go to the shut position if the actuator fails. Although the temperature of the fluid passing through the valve exceeds the design temperature, the valve packing would have a temperature capability of between 700 and $838 \mathrm{~K}$ (800 and $1050^{\circ} \mathrm{F}$ ) depending on the gasket material. Because the pressure is relatively low compared to the design pressure of the gasket and since the gasket material would not be expected to fail rapidly compared to the time frame of the high temperatures, it would be highly unlikely that gases from the valve would leak in sufficient quantity and at high enough velocities to cause the air actuator to fail. These results would be specific to the Surry valve for the TMLB' sequence. Specific analysis for other conditions or for other plant configurations, and valve types would be necessary to expand these results.

The air supply to the valve operator is from the containment instrument air system, with a backup system to assure operability in the event of a loss of the primary air supply and/or a loss of offsite power. Four high-pressure air bottles are provided for each valve, with each bottle capable of 31 cycles. A continual supply of air is necessary to hold the valve in the open position.

As shown in Figure 18, the late depressurization of a TMLB' sequence involves an extended period prior to the depressurization in which RCS overpressure is controlled by the PORVs through cycling at their normal setpoints. Exhaustion of 


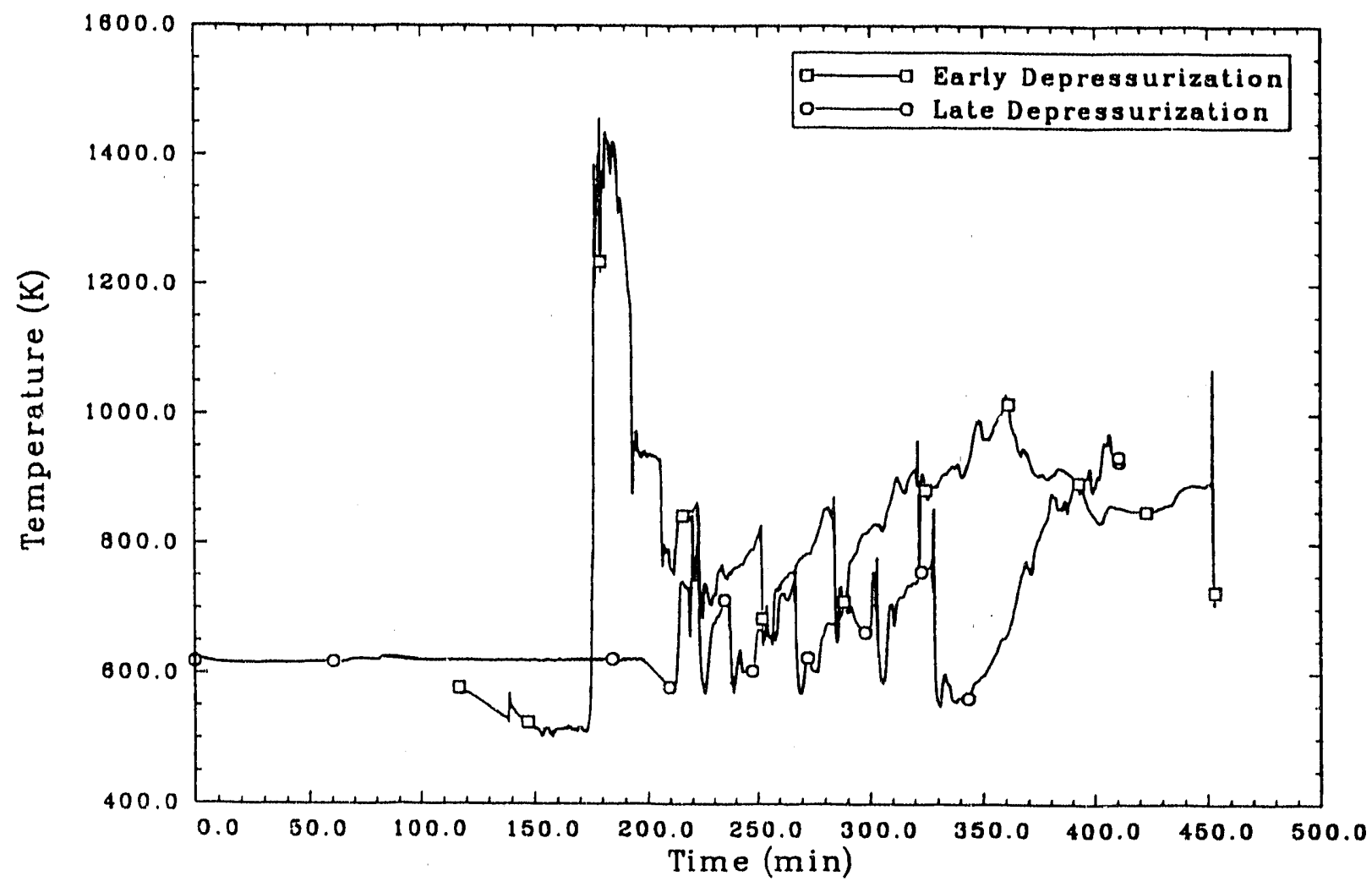

Flgure 30. Vapor temperature at PORV inlet.

the backup air supply could occur during this period because these valves cycle numerous times. Although the number of calculated cycles appears to be smaller than the capability of the existing air bottles, maintaining the PORVs in a latched position would allow additional leakage of air and detailed calculations would be necessary to evaluate the possible need for additional air bottles. An alternative to additional air bottles is that the operator control RCS pressure by a series of shallow depressurizations, which would involve fewer valve opening-closing cycles. The operator control strategy is less desirable because of high demands for operator action during this period.

Power from a dc source must be available to actuate solenoids that control the air needed to open the PORVs and to maintain them in an open position. For strategies analyzed for the TMLB' sequence, battery power must be available at the time the decision is made to open the PORVs and for the 7 hours necessary to complete depressurization. For Surry, battery life during a station blackout should be aoout 4 hours. 6 Additional battery capacity or a reliable means of charging the batteries may be required to allow the PORVs to remain open.

The final equipment consideration concerns the PORV block valves. Experience at the Surry plant led to use of draft NUREG 1150 analysis of a probability of 0.30 per demand that a PORV block valve is closed due to a leaking PORV. The PORV block valves are motor-operated and require ac motive and control power from the ac emergency power buses. In a TMLB' sequence, the block valves are therefore inoperable, leading to a $\mathbf{0 . 3 0}$ probability that one PORV is unavailable. Depressurization with one PORV was not evaluated in the previous analysis, but the amount of core damage would definitely be greater prior to accumulator injection if only one PORV was available. The effect of only one PORV would need to be evaluated on a plant specific basis. 
Equipment modifications to reduce PORV leakage and/or improve PORV block valve availability may be warranted in order to improve the likelihood of successful depressurization.

\subsection{Assessment of Operational Performance}

A human factors assessment of the capability of the operators to successfully initiate depressurization at the Surry plant was performed. This assessment was limited in its scope because during a TMLB' sequence, the current Surry Emergency Operating Procedures (EOPs) do not contain specific instructions to enter the Functional Restoration Procedure (FRP) that initiates depressurization using the PORVs. This lack of specific procedural instructions restricted the types and amount of data that were available for conducting a detailed human reliability analysis (HRA) for intentional depressurization. The intent of the operational performance assessment was to provide answers for the following questions:

- Does depressurization compete with other actions for the operators aftention?

- Is the information available to the operator at the decision point adequate?

- What is the probability that the operator will successfully execute the depressurization?

A review of the Surry EOPs was performed to evaluate their applicability for depressurization during the TMLB' sequence. This review, documented in Appendix $G$, indicated that current EOPs contain a loop that is unique to a station blackout sequence with a coincident loss of auxiliary feedwater (TMLB'). When executing the EOPs, the operations personnel encounter a step directing them to check whether ac power has been restored. Finding these conditions have not been met, the operators are directed to control RCS conditions, check the status of local actions, and return to a previous step in this same procedure. Because the conditions for exiting this loop are not met for the TMLB' sequence, the functional restoration procedure that initiates RCS depressurization using the PORV is never entered. As a result, a detailed HRA based on the procedures was not possible. However, sensitivity calculations on human reliability were performed to compensate for the lack of procedural detail and are documented in Section 3.3.2. An assessment of Seabrook EOPs for a TMLB' sequence $^{20}$ also identified this loop and proposed procedural modifications that would direct depressurization through the FRPS.

\subsubsection{Factors That Can Affect Operator} Performance. Several important factors that could affect operator performance for intentional depressurization using the PORVs were identified and evaluated. These factors include the capability of the plant personnel to use plant instrumentation to recognize that a depressurization strategy should be implemented and the capability to initiate action based on the time available.

For the early depressurization strategy, the criteria for initiating depressurization would be based on parameters indicating steam generator dryout. Current steam generator instrumentation appears to be adequate for the operators to follow procedures and determine that depressurization should be initiated. Because steam generator dryout will occur relatively early in the sequence, initiation of depressurization will restrict the amount of time available for recovery of ac power and other vital systems. Early depressurization may cause plant personnel to make an early decision to abandon other success paths due to the commitment of personnel resources to depressurization. Although the time available for diagnosing the need for action and attempting to recover resources would be limited, early depressurization would provide an extended period over which implementation actions could be taken, which would increase the likelihood of successfully carrying out these actions. If an early depressurization strategy was chosen, modifications to both procedures and training would be necessary to ensure that there would be a high 
likelihood of initiating early depressurization because existing Surry EOPs (a) do not provide guidance to depressurize for the TMLB' sequence, and (b) emphasize establishing a makeup or feed path before opening the PORVs or other RCS bleed paths.

Plint personnel would implement the late depressurization strategy using the same actions as early depressurization except the initiation condition is based on the core exit thermocouples, which must exceed $922 \mathrm{~K}\left(1200^{\circ} \mathrm{F}\right)$. The currently installed instrumentation is judged to be adequate to provide the information necessary to make this decision. This strategy would provide the operating crew with an extended amount of time for recovery of feedwater and an ac power source. It is also the most compatible with the present EOPs and the training background of the plant personnel. Because the core has reached relatively high-temperature conditions, the crew would likely be prepared to acknowledge that the remaining inventory in the RCS would not provide effective heat removal and thus be more willing to take actions to depressurize to initiate accumulator flow and to minimize later challenges to the containment.

By waiting until high-temperature core conditions have been reached, however, the time available for the operator to perform the critical actions to accomplish RCS depressurization is diminished. Consequently, errors and recovery from error states will have a greater impact on the success of operator attempts to depressurize than for the early depressurization strategy. This reduced time available for action is reflected in the results of the HRA discussed in the following section.

3.3.2 Human Rellabillty Analysis. Although the current Surry EOPs do not include specific actions to intentionally depressurize the RCS during a TMLB' sequence, an assessment of the likelihood that the plant personnel could depressurize was accomplished by making assumptions regarding the actions that would be taken and by performing sensitivity studies. Modeling the operator actions for this sequence for the HRA assumed that operators would wait as long as possible to perform RCS depressurization. Assuming the Functional Restoration Procedures are entered from the EOPs, the critical actions identified in Functional Restoration Procedure C.1 are to open both PORVs and the reactor vessel head vent. These actions can be accomplished from the control room, and adequate instrumentation is provided to assist operators in verifying that their actions are accomplished.

The Accident Sequence Evaluation Program (ASEP) HRA Procedure ${ }^{21}$ was selected as the method to be used in performing the HRA for the important operator tasks. This method was chosen because the existing procedures did not specifically implement intentional depressurization strategies for the TMLB' sequence so there was not sufficient information to support the application of more detailed HRA methods.

The ASEP HRA method separates a task as a function of two activities: diagnosis and action. Diagnosis refers to the detection and recognition of an abnormal event and includes interpretation, decision-making, and identification of systems or components whose status can be changed to reduce or eliminate the problem. Action refers to carrying out one or more activities indicated by the diagnosis, operating rules, or written or memorized procedures. Both definitions are based on the ASEP HRA definition of technical terms.

Table 3 summarizes the nominal HRA information obtained by using the postaccident tables in ASEP and applying them to the operator task of depressurizing the RCS. Because the current procedures do not implement depressurization for the TMLB' sequence, it was not possible to determine, with a high degree of confidence, the time it will take for the operator to reach the procedural steps where it will be necessary to diagnose the need to perform RCS depressurization. Consequently, a set of sensitivity calculations were performed assuming times of 5,10 , and $20 \mathrm{~min}$ were available for diagnosis. 
Table 3. ASEP nominal HEPs for operator actions to depressurize the RCS

\begin{tabular}{ccccccc}
$\begin{array}{c}\text { Time } \\
\text { Available } \\
\text { (min) for } \\
\text { Diagnosis }\end{array}$ & $\begin{array}{c}\text { Diagnosis } \\
\text { HEP }\end{array}$ & $\begin{array}{c}\text { Action } \\
\text { HEP }\end{array}$ & $\begin{array}{c}\text { Recovery } \\
\text { Factor }\end{array}$ & $\begin{array}{c}\text { Failure } \\
\text { Probability }\end{array}$ & LCB & UCB \\
\hline 5 & 0.5 & 0.05 & 0.5 & 0.54 & 0.506 & 0.642 \\
10 & 0.1 & 0.05 & 0.5 & 0.16 & 0.113 & 0.36 \\
20 & 0.01 & 0.05 & 0.5 & 0.08 & 0.025 & 0.297
\end{tabular}

a. Failure probability lower confidence bound.

b. Failure probability upper confidence bound.

In Table 3, the human error probabilities (HEPs) for diagnosis vary by one and one-half orders of magnitude for a difference of $15 \mathrm{mi}$ ' utes in the time available for diagnosis.

The nominal action HEP for this sequence was taken from Table 8-5 of ASEP (Assessment of Nominal HEPs for Postaccident, Post-Diagnosis Action) and corresponds to a step-by-step task done under extremely high stress. This level of stress in the ASEP method is assessed for situations in which more than two primary safety systems fail to function. The action HEP used in this analysis encompasses all three operator actions necessary to depressurize the RCS: open two PORVs and open the reactor vessel head vent valve. The recovery factor of 0.5 gives credit for recovery by other control room personnel if the personnel that are responsible for opening these valves fails to do so properly.

The median failure probabilities that are presented in Table 3 represent a failure of the operator to depressurize the RCS when given a specified amount of time to diagnose the need to perform the critical tasks. Upper confidence bounds (UCBs) and lower confidence bounds (LCBs) were also calculated for the failure probabilities. The ASEP procedure assigns an error factor of 5 , for the action HEP, to be used in determining UCBs and LCBs. Based on this error factor, action HEPs of 0.01 and 0.25 were used in calculating, respectively, the lower and upper confidence bounds for the failure probability. Error factors were not applied to the diagnosis HEPs because there was not sufficient transient specific information available (for example, tabletop discussions or simulator based information) to adequately determine the error factor valves.

The strong inverse relationship between the median failure probabilities and the time available for diagnosis-the less time available, the higher the probability of failure-indicates that the setpoints for initiating RCS depressurization must be clearly established to avoid any possible confusion with other conditions and provide the operating crew with a sufficiently large time window to reliably accommodate both diagnosis and action.

In terms of the strategies for depressurization, without special cautions in the procedures, it is more likely that early depressurization would be successful because the time available for diagnosis appears adequate and the time for action is relatively long. This is not to say that the operating crew could not anticipate the need for RCS depressurization (if so trained) once indications of core uncovery were received for the late depressurization strategy. However, the current approach in the EOPs (assuming a transition to 
the steps in FRP C.1, which contain the critical tasks) would not tell the operators that they should be prepared to perform depressurization until the setpoint (based on high core temperature) has been reached. In the interest of reducing the possible complications that a diagnostic error would add for late depressurization, it would be advisable to provide cautions sufficiently early in the procedures that the operators would be prepared to initiate RCS depressurization as soon as the specified high temperature setpoint was reached.

\subsection{Extension of Results to Other Plants}

Sections 3.1 through 3.3 provide results from an analysis of intentional depressurization of the Surry Plant during a TMLB' sequence. These results are specific to Surry and their extrapolation to other plants must be considered carefully. A detailed evaluation of the applicability of the results to other plants was not within the scope of this program. However, a preliminary assessment has been performed to provide insight as to the possible behavior of other plants under similar transients and initial conditions. The following section discusses where extrapolation of the results may be appropriate and where additional work would be necessary to provide improved information on other plants.

Plant differences that could strongly influence the success of intentional depressurization would be associated with the plant hardware or with the plant operations. Although the effect of plant operations can be very important, this effect was not evaluated because detailed procedures were not available for a reasonable cross-section of plants and discussions with the operations staff to evaluate their use of procedures was beyond the scope of this program. It is known that many of the plants designed by Westinghouse would be expected to have procedures with a structure similar to the Surry procedures. It is also recognized that procedural changes could be made to ensure the success of intentional depressurization if plant specific analyses indicated that current procedures were not adequate.
Hardware parameters that were considered to be important influences on intentional depressurization include the following: (a) PORV characteristics, (b) pressurizer, surge line, and relief valve piping characteristics, (c) plant support system capabilities, (d) accumulator setpoints, and (e) containment response. It is recognized that other plant characteristics such as steam generator type and core characteristics (control rod material, power profile, etc.) may each influence depressurization, but these influences were judged to be smaller than those listed above. The following sections provide a brief discussion of the potential effect of each of these parameters on depressurization at plants other than Surry.

3.4.1 PORV Characteristics. The flow capacity of the PORVs would have a major effect on the capability of a PWR to intentionally depressurize. Scaling studies for small break loss-of-coolant accident experiments have shown that power or volume scaling would be appropriate to preserve the timing of the depressurization when scaling PORV sizes between PWRs. The equation for power scaling PORV flows from Surry to other PWRs could then be written:

$\frac{\mathrm{m}_{s}}{\mathrm{~m}_{\mathrm{p}}}=\frac{\mathrm{P}_{\mathrm{s}}}{\mathrm{P}_{\mathrm{p}}}$

where

$\mathrm{m}=\begin{aligned} & \text { the mass flow rate of the fluid } \\ & \text { through the PORV }\end{aligned}$
$\mathrm{P} \quad=\quad$ plant thermal power
$\mathrm{S}=$ Surry
$\mathrm{p} \quad=\quad$ other PWRs.

A similar equation could be written for volume scaling with the ratio of system volumes replacing the power ratio. Information on the PORV capacities, power, and volumes were collected for about 25 PWRs. The results are easily visualized if the relief capacity of each plant is plotted as a function of power and an equivalent Surry relief valve size is plotted as a line that represents the relief valve capacity that would be scaled to Surry 
at the comesponding vallue of power. The equa. tion of thes: lime is:

$$
\mathbf{m}_{\mathrm{max}}=\frac{P_{\text {mate }}}{P_{S}}
$$

where

$$
\begin{aligned}
& \text { - = the rass llow rate of the fluid } \\
& \text { through the PORV } \\
& \mathrm{S}=\text { Sumy } \\
& \mathbf{P}=\text { plunt themal power } \\
& \text { Ploc = valtues gloded as a line. }
\end{aligned}
$$

The resuliss for the power sealing approsed are shown in Figure 31. A sicsilar approach was tats. en for voluxare scolling and is shown in Figure 32. Table 4 lists the pi-at aboreviations in these two figutes.

The resulas preseated in Figures 3.1 and 32 provide an indlication of the expectud : mas of depressuncistion of PWRs wher compared to that caticulated for Surry essuming equivalent plan sysuero conditicas and operations. Phants that are abrowe the Sury Power or Volumed Scaled lines would gencrally be expected to depressurize wore rapidlly than Surry It would therelone be expected that, unless there were plant differences ocher than system power or volume that woald significanty aftect plant behavior during a TML B" sequence, these planas could be depressunized prion to vessel fuilure. Because the Surry calculation represtents ondy one PORV espaciry tor one phisto there is ao way to determine the effect of a samaller PORV size on the cupability to sucotssifully depressurize prior to vessel failure. Therefore. no conalusions for the success of depressuriation eas be resched for points thas lite below the lians on Figures 31 and 32. In would be

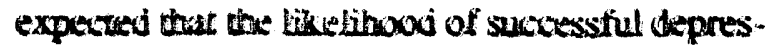
surization is less for plants that are the greatiest distance below the line, if all other conditions are sicaiber to Surry. It is incerescing wo note that the majority of the plants that tall below the line beat wo clusker in three groups: (a) large four loop Westinghouse dessigned planks, (b) Combustion
Engineering designed plants that have PORVs, and (c) Babcock and Wilcox designed plants.

In addition to the capacity of the PORV, the design of the PORV may also have an influence on the capability to depressurize to pressure levels equivalent to those calou! ated for Sumy. The PORV's for Surry are air-acanated valves. Some PORV's in use at other plants are actuated usix, $I$ an electrically-operated pilot valve to expose an intemal valve area (simillar to a piston) to the RCS pressure which essentially drives the valive open. Because all of the PORV's are spring loaded, some PORV designs rely only on the system pressure to overcome the spring force to open the valve and to hold it open If the pressure in the system falls below a certain value, the force on the piston may not be sufficiently large, and in some valve designs the spring can force the valve to close. Closing of the PORV at an elevated pressure would definitely result in a plant response than woss differeat than predicted for Surry. However, because a rise in pressure would be expected to rcopen the PORV, this feature may not significantly affect the capability to successfully depressurize. Whether depressurization was successful would olepend on the magninude of the pressure at whict the PORV reopened. This value would be dependant on the valve design and should be eva. huatied for plants with this type valve.

\subsubsection{Pressurtaer, Surge Une, and Rellef Valve PIpling Characterlstlcs. The geometry} of the pressurizer, surge line, and relief valve piping would affect the pressure drop through these components and could therefore affect the thow out the PORV's. It is expected that differences in these components would not be sufficiently lange that the success of depressurization would be signiticandly different between plants. However, the arnount of insulation on these components. particularly the surge line, may expecs to have some influence on the progression of a TMLB" sequence when compared to Surry. If the surge line was not insulated it could expect to fail at a much later cime than the calculations predict for Surny. Although surge line failure was nox relied upon to deterwine whether depressurization was successiful, the Surry resulis indicate that there is 


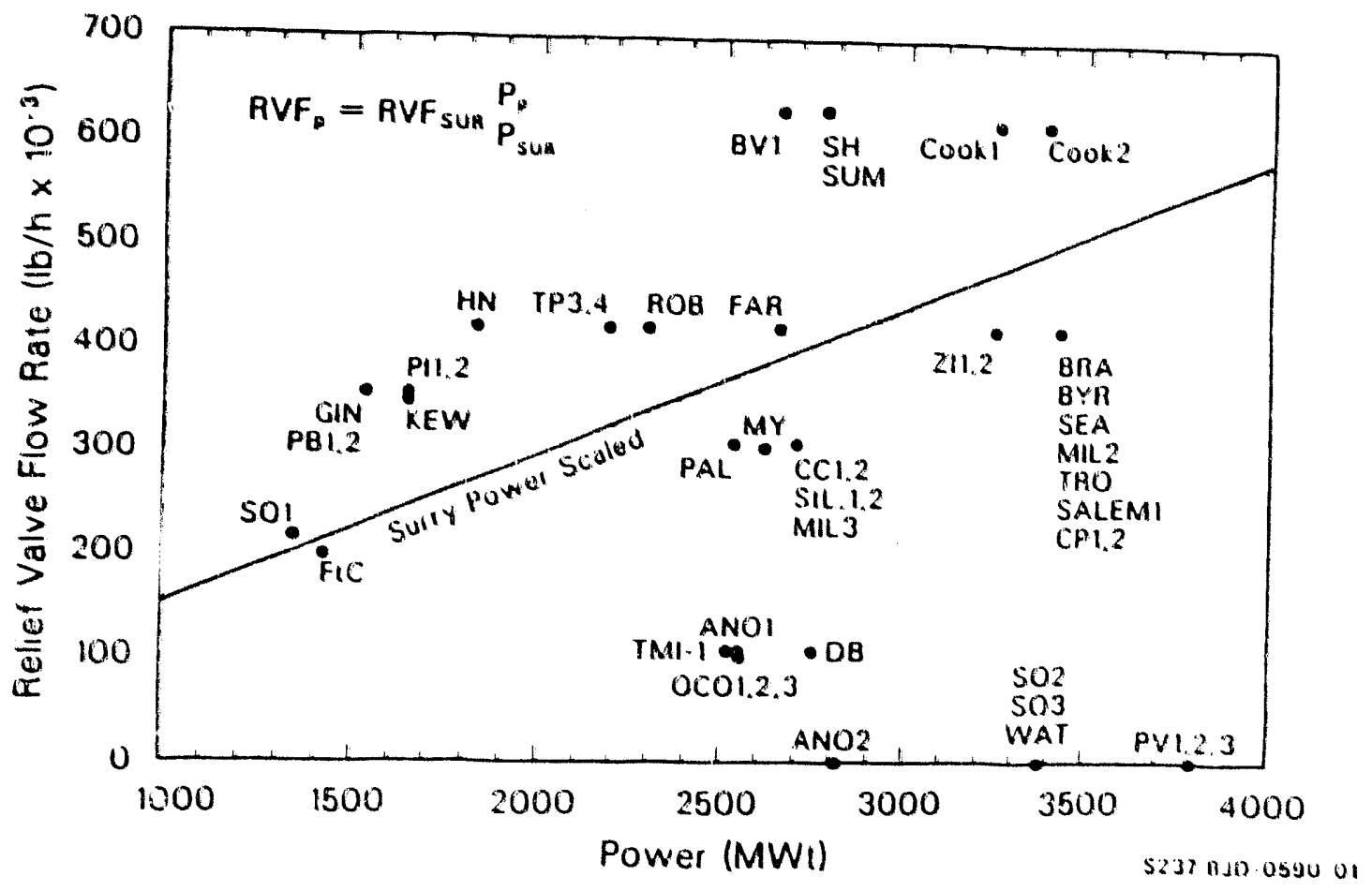

Flgure 31. Power scaling of Surry relief valve size to other PWRs.

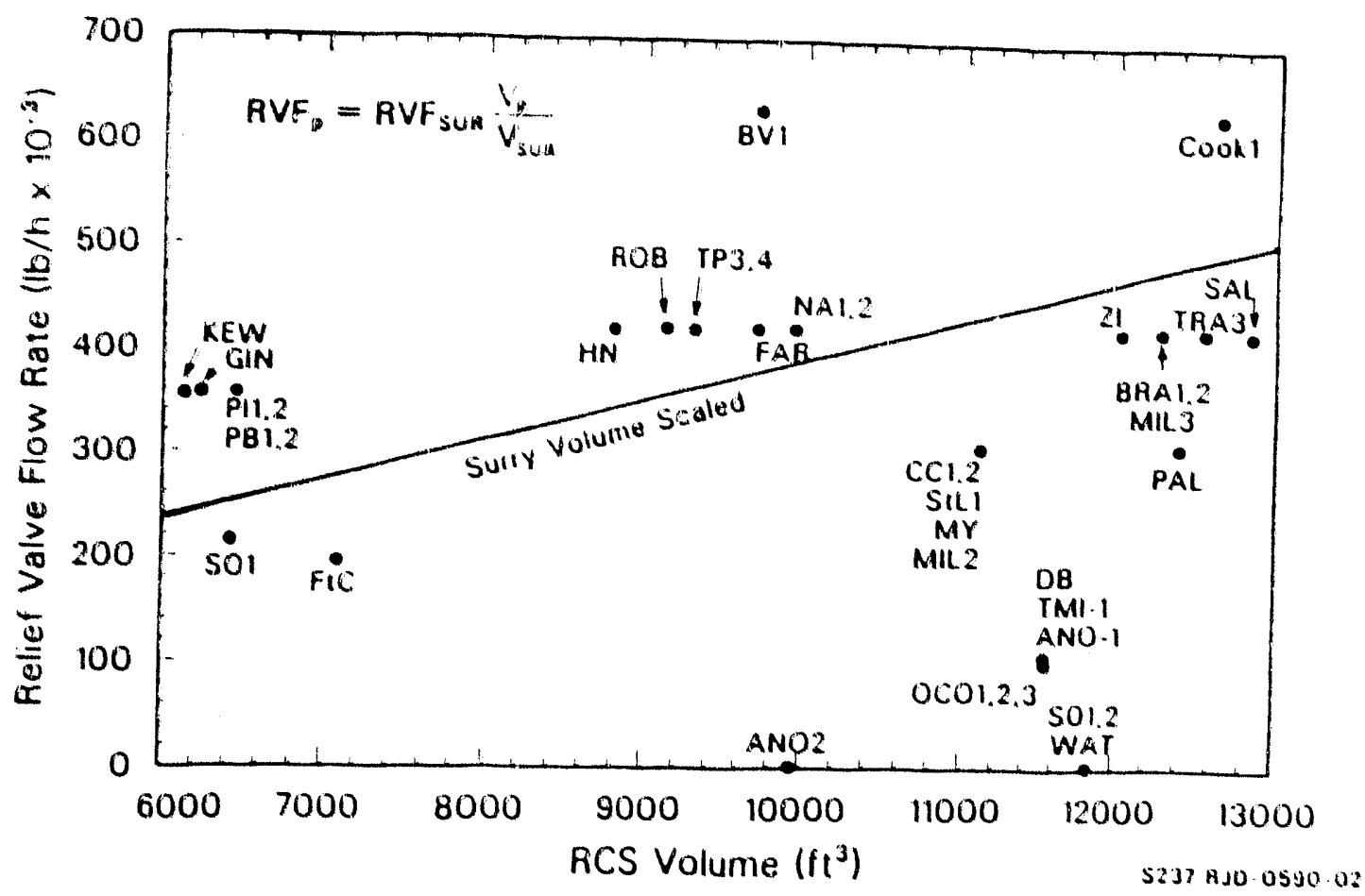

Flgure 32. Volume scaling of Surry relief valve size to other PWRs. 
Table 4. Key to abbreviations for Figures 31 and 32

\begin{tabular}{|c|c|}
\hline Abbreviation & Plant Name \\
\hline $\begin{array}{l}\text { ANO1 } \\
\text { ANO2 } \\
\text { BRA } \\
\text { BV1 } \\
\text { BYR }\end{array}$ & $\begin{array}{l}\text { Arkansas Nuclear One Unit } 1 \\
\text { Arkansas Nuclear One Unit } 2 \\
\text { Braidwood Unit } 1 \\
\text { Beaver Valley Unit 1 } \\
\text { Byron Unit } 1\end{array}$ \\
\hline $\begin{array}{l}\text { CC1,2 } \\
\text { Cook1 } \\
\text { Cook2 } \\
\text { CP1,2 } \\
\text { DB }\end{array}$ & $\begin{array}{l}\text { Calvert Cliffs Units } 1,2 \\
\text { Donald C. Cook Unit } 1 \\
\text { Donald C. Cook Unit } 2 \\
\text { Comanche Peak Units } 1,2 \\
\text { Davis-Besse }\end{array}$ \\
\hline $\begin{array}{l}\text { FAR } \\
\text { FtC } \\
\text { GIN } \\
\text { HN } \\
\text { KEW }\end{array}$ & $\begin{array}{l}\text { Joseph M. Farley Unit } 1 \\
\text { Fort Calhoun } \\
\text { Rooent E. Ginna } \\
\text { Haddam Neck } \\
\text { Kewaunee }\end{array}$ \\
\hline $\begin{array}{l}\text { MLL2 } \\
\text { MLL3 } \\
\text { MY } \\
\text { OCO1,2,3 } \\
\text { PAL }\end{array}$ & $\begin{array}{l}\text { Millstone Unit } 2 \\
\text { Millstone Unit } 3 \\
\text { Maine Yankee } \\
\text { Oconee Units 1,2,3 } \\
\text { Palisades }\end{array}$ \\
\hline $\begin{array}{l}\text { PB } 1,2 \\
\text { PI1,2 } \\
\text { PV1,2,3 } \\
\text { ROB } \\
\text { SALEM1 }\end{array}$ & $\begin{array}{l}\text { Point Beach Units } 1,2 \\
\text { Prairie Island Units 1, } 2 \\
\text { Palo Verde Units 1,2,3 } \\
\text { H. B. Robinson Unit } 2 \\
\text { Salem Unit 1 }\end{array}$ \\
\hline $\begin{array}{l}\text { SEA } \\
\text { SH } \\
\text { SO1 } \\
\text { SO2 } \\
\text { SO3 }\end{array}$ & $\begin{array}{l}\text { Seabrook } \\
\text { Sharon Harris } \\
\text { San Onofre Unit } 1 \\
\text { San Onofre Unit } 2 \\
\text { San Onofre Unit } 3\end{array}$ \\
\hline $\begin{array}{l}\text { SLL1,2 } \\
\text { SUM } \\
\text { TMI-1 } \\
\text { TP3,4 } \\
\text { TRO }\end{array}$ & $\begin{array}{l}\text { St. Lucie Units } 1,2 \\
\text { Virgil C. Summer } \\
\text { Three Mile Island Unit } 1 \\
\text { Turkey Point Units 3,4 } \\
\text { Trojan }\end{array}$ \\
\hline $\begin{array}{l}\text { WAT } \\
\mathrm{Z} \amalg 1,2\end{array}$ & $\begin{array}{l}\text { Waterford Unit } 3 \\
\text { Zion Units } 1,2\end{array}$ \\
\hline
\end{tabular}


a high likelihood that the surge line will fail prior to failure of the lower head. Similarly, if the line leading from the pressurizer to the PORVs was not insulated, the temperature of the fluid reaching the PORVs would be lower than predicted for Sury and the potential for failure of these valves could be decreased.

\subsubsection{Plant Support System Capabllities.} The capability of the plant support systems to provide long-term support to the PORVs would be highly dependent on the valve type and the design of the plant systems. Air-actuated valves similar to those used in Surry require both dc power and air to maintain the valve in the open position. More than half of the operating PWRs use these type valves. The remainder of the PORVs currently in place use a pilot valve that requires dc power, or in a few cases ac power. to open, which allows the system pressure to act over an area and open the PORV.

During a TMLB' sequence, batteries for most PWRs are generally available for at least four hours with some plant having battery power for about eight hours. In most plants, this availability time is shorter than is needed to ensure the success of intentional depressurization. Consequently, additional load shedding or the use of altemate equipment, such as dedicated batteries or portable battery chargers, may be needed.

Air supplies capable of opening the PORVs for a limited number of cycles during a TMLB' sequence are generally available for air-operated PORVs. However, the capacities of plant specific air supplies for PWRs other than Surry were not determined. If the size of the Surry bottled air supply is typical, additional capacity would be necessary to ensure success for the late depressurization case during a TMLB' sequence.

3.4.4 Accumulator Setpolnt. In Section 3.1, accumulator injection was shown to have an important influence on both the early and late depressurization sequences. However, if the pressure at which the accumulators inject was lower than 4.14 MPa (600 psi), as it is in some PWRs, differences in plant response could be significant. For example, late depressurization in a PWR with an accumulator injection pressure of $1.38 \mathrm{MPa}$ (200 psi) would be expected to result in more extensive core damage because core temperatures would be in a range where injection could result in increased oxidation and higher energy generation rates rather than the core cooling that occurred in the Surry calculation.

3.4.5 Containment Type. Surry has a subatmospheric containment with a relatively large volume. Other containment designs, particularly those with smaller volumes and with other features, such as ice beds, may be sufficiently different that the response calculated for Surry would not be typical. For example, other containment designs may cause the hydrogen concentrations to reach higher levels and may be less robust if the hydrogen concentrations reach levels where detonations or deflagrations occur. This Lehavior would be important for plants considering intentional depressurization because the Surry calculation indicated large quantities of hydrogen were released from the RCS. These containment types may require additional equipment that is capable of recombining hydrogen over a time frame that will prevent containment failure. An evaluation is currently being conducted to determine the response of ice condenser containments for hydrogen concentrations typical of those calculated for Suny. 


\section{CORE RECOVERY USING AUXILIARY FEEDWATER}

Depressurization may not be necessary if feedwater is restored at some time after steam generator dryout but before vessel failure. Addition of feedwater prior to significant mass depletion in the RCS may provide sufficient cooling to avoid significant core damage. The following two alternatives must be weighed:

1. Initiate depressurization procedures early (soon after secondary system dryout occurs).

By initiating depressurization procedures early, the time available to depressurize prior to vessel failure would be maximized. However, early depressurization of the primary system might mean that core damage is unavoidable, even if feed water is later restored. That is, if sufficient mass has already been lost from the primary system when auxiliary feedwater is restored, it may be impossible to keep the core cool.

2. Wait to start depressurization procedures until after the latest time that initiation of feedwater would be successful in preventing core heatup.

By waiting to initiate depressurization procedures, more time is available to regain offsite or onsite power or to restore operation of the turbine driven auxiliary feedwater pump or to provide feedwater using alternate sources, for example the firewater systems. However, there is the possibility that, if depressurization is delayed and feedwater is not restored quickly, it will be too late to depressurize the reactor before vessel failure.

The results of Section 3 indicate that depressurization can be delayed until late in the transient from the standpoint of the phenomena and the operations associated with initiating the depres- surization. However, it has not been demonstrated that recovery of feedwater prior to the time that depressurization was initiated would be effective in halting the progression of core damage. Consequently, an evaluation of the effectiveness of feedwater addition during the TMLB' sequence was made together with an evaluation of the likelihood that operations persomel could supply feedwater from a source other than auxiliary feedwater.

\subsection{Effectiveness of Feedwater Addition}

In order to assess the capability of feedwater added late in a TMLB' sequence to prevent a core temperature excursion at different recovery times, two calculations were performed using the RELAP5 computer code. The RELAP5 plant model used for this calculation is described in Reference 6. Feedwater was assumed to be restored in these calculations at two times between secondary dryout and core melting. After feedwater was assumed to be recovered, the flow rate was controlled so that the steam generator secondary was filled to, and maintained at a level to cover the steam generator tubes. A maximum feedwater flow that corresponds to the flow raie of the turbine driven auxiliary feedwater pump [44 L/s (700 gpm)] was used. 22 The assuined recovery times for the feedwater were based on core exit thermocouple indications. In the first calculation, the feedwater was initiated when the upper plenum vapor temperature exceeded the saturation temperature by $3 \mathrm{~K}\left(5^{\circ} \mathrm{F}\right)$. This deviation from saturation temperature would indicate the onset time of core heatup. In the second calculation, feedwater was initiated when the upper plenum vapor temperature reached $810 \mathrm{~K}$ $\left(1000^{\circ} \mathrm{F}\right)$. In the RELAPS calculation, the upper plenum vapor temperature corresponds approximately to the average core exit thermocouple reading. However, the maximum core exit thermocouple reading would actually be higher than $810 \mathrm{~K}\left(1000^{\circ} \mathrm{F}\right)$ for two reasons. First, the RELAP5 core was modeled as a single channel with core-average power and an average bumup 
from the end of equilibrium cycle. That is, assemblies of different power and burnup were not accounted for. The maximum temperature above these assemblies would be higher than $810 \mathrm{~K}$ $\left(1000^{\circ} \mathrm{F}\right)$. Second, although the core exit thermocouple location is in the upper plenum volume of the RELAP5 model, this upper plenum temperature corresponds to the vapor temperature at the volume axial center, which is about 0.3 meter $(1 \mathrm{ft})$ higher than the thermocouple location. Therefore, it is estimated that a hot channel thermocouple would read about $920 \mathrm{~K}\left(1200^{\circ} \mathrm{F}\right)$ when the average upper plenum vapor temperature is $810 \mathrm{~K}\left(1000^{\circ} \mathrm{F}\right)$. Table 5 lists the feedwater recovery time and the assumptions used in the two calculations.

The primary and secondary system pressures for the two calculations are plotted in Figure 33. When auxiliary feedwater was initiated at about $9700 \mathrm{~s}$ (162 min) in calculation 1 and at about $10,500 \mathrm{~s}(175 \mathrm{~min})$ in calculation 2 , the primary system depressurized rapidly to about $8.0 \mathrm{MPa}$ (1160 psi) as primary fluid condensed on the inside of the steam generator tubes. The steam generator fluid conditions indicate that the injected water initially boiled on the secondary side. This boiling is evidenced by the secondary pressure fluctuation, which show that the secondary PORVs were cycling. The depressurization rate slowed when the primary system saturation temperature was equal to the inside wall temperature of the tubes and condensation of primary fluid ceased. The secondary system pressures then began to decrease because cold feedwater was still being added to the secondary side. The primary system pressures decreased also, following the secondary system pressure decrease. At about $14,500 \mathrm{~s}$ (242 $\mathrm{min}$ ) in calculation 1 , the pressures rose again because injection of auxiliary feedwater was stopped when the steam generator tubes were covered. Calculation 2 was terminated before the steam generator tubes were covered. Therefore, a similar pressure increase was not seen.

Figure 34 represents the steam generator secondary collapsed liquid level. Dryout of the secondaries was calculated at about $5000 \mathrm{~s}$ (84 min) and heat transfer from the primary to the secondary system ceased until feedwater was injected. Initially, the level did not increase because the injected liquid boiled as heat was removed from the primary system. However, the level began to rise when the primary fluid had been cooled to the same temperature as the steam generator tubes and condensation of primary system liquid ceased. By the termination of the calculations, the steam generator tubes were covered in calculation 1 and nearly covered in calculation 2 .

The effect of feedwater on the core can be seen in Figures 35, 36, and 37. Figure 35 displays the void fractions at the top of the core. Boiling began in the core at about $7500 \mathrm{~s}$ (125 min) in both calculations when the saturation temperature was reached. The void fraction reached 1.0 in the upper part of the core at about $9500 \mathrm{~s}$ (158 $\mathrm{min})$. When feedwater was injected, the core void fractions decreased to $<25 \%$. The additional liquid that reduced the void fraction came from several sources as discussed later.

Table 5. Feedwater addition calculations

\begin{tabular}{|c|c|c|}
\hline Calculation & Feedwater Initiation & Assumptions \\
\hline 1 & $\begin{array}{l}\text { Upper plenum vapor temperature } \\
\text { exceeds saturation }\end{array}$ & Core heatup begins \\
\hline 2 & $\begin{array}{l}\text { Upper plenum vapor temperature } \\
\text { of } 810 \mathrm{~K}\left(1000^{\circ} \mathrm{F}\right)\end{array}$ & $\begin{array}{l}\text { Core exit thermocouples } \\
\text { read } 900 \mathrm{~K}\left(1200^{\circ} \mathrm{F}\right)\end{array}$ \\
\hline
\end{tabular}




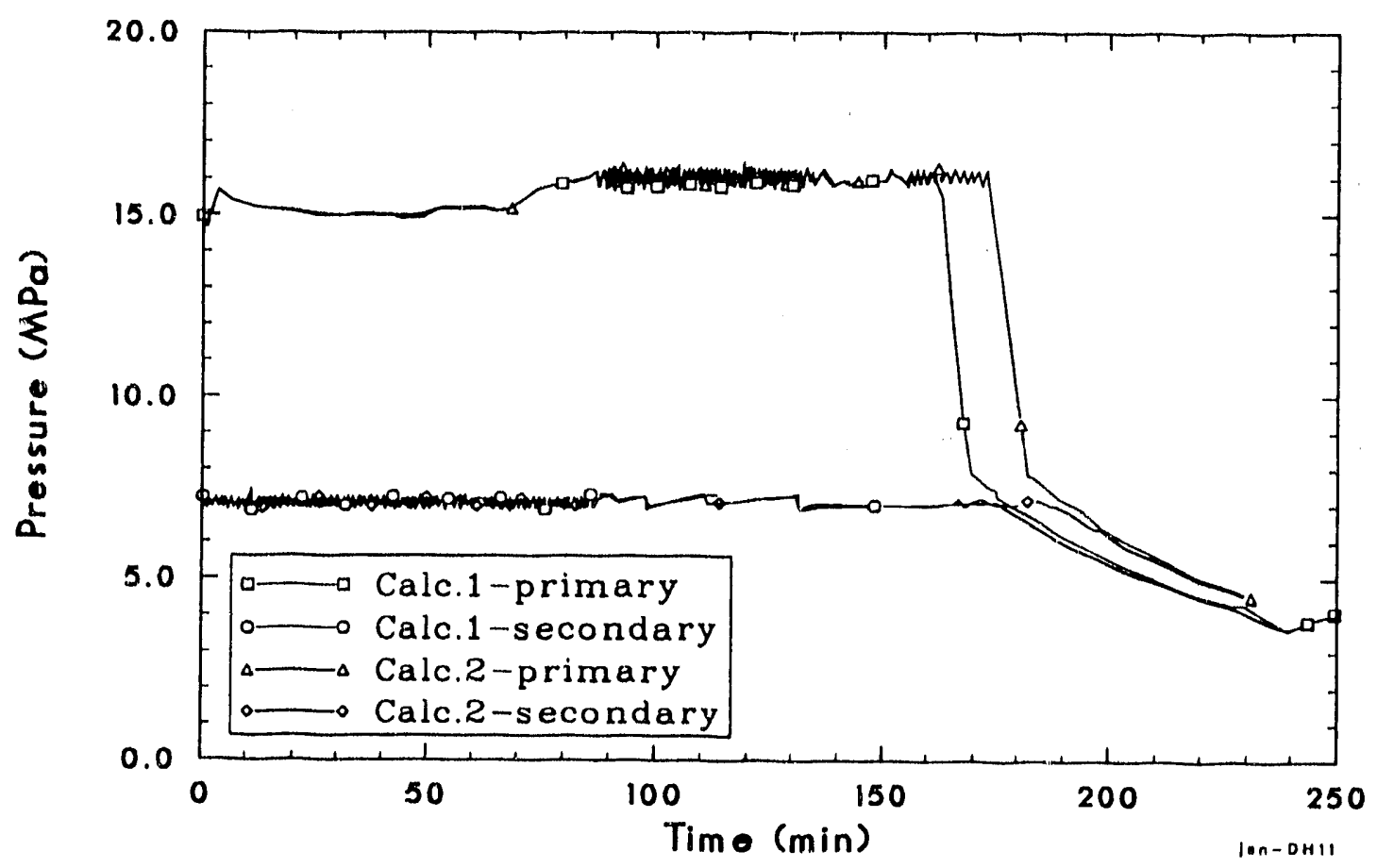

Flgure 33. Primary and secondary system pressures for calculations 1 and 2.

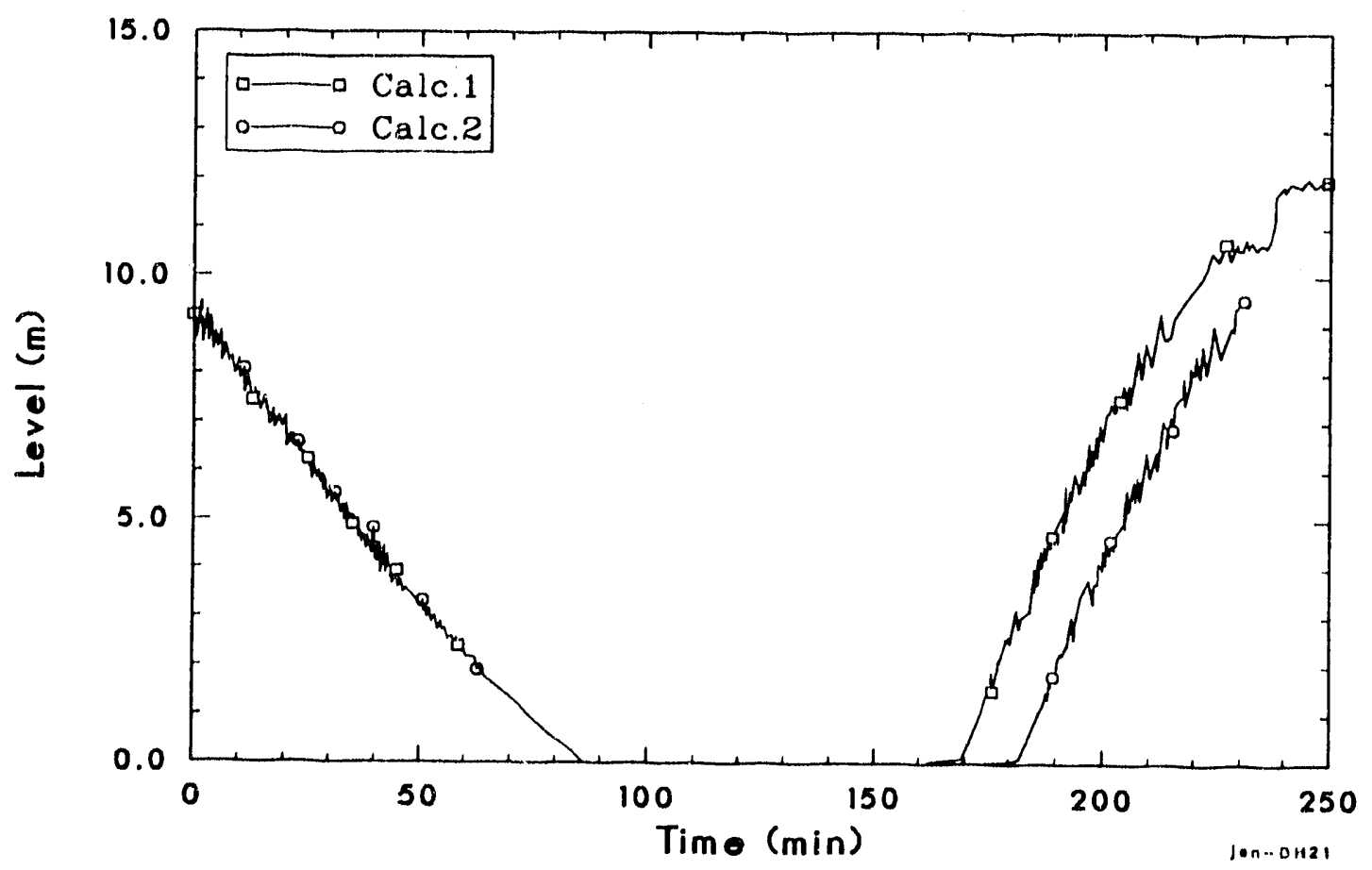

Figure 34. Comparison of steam generator liquid level for calculations 1 and 2. 


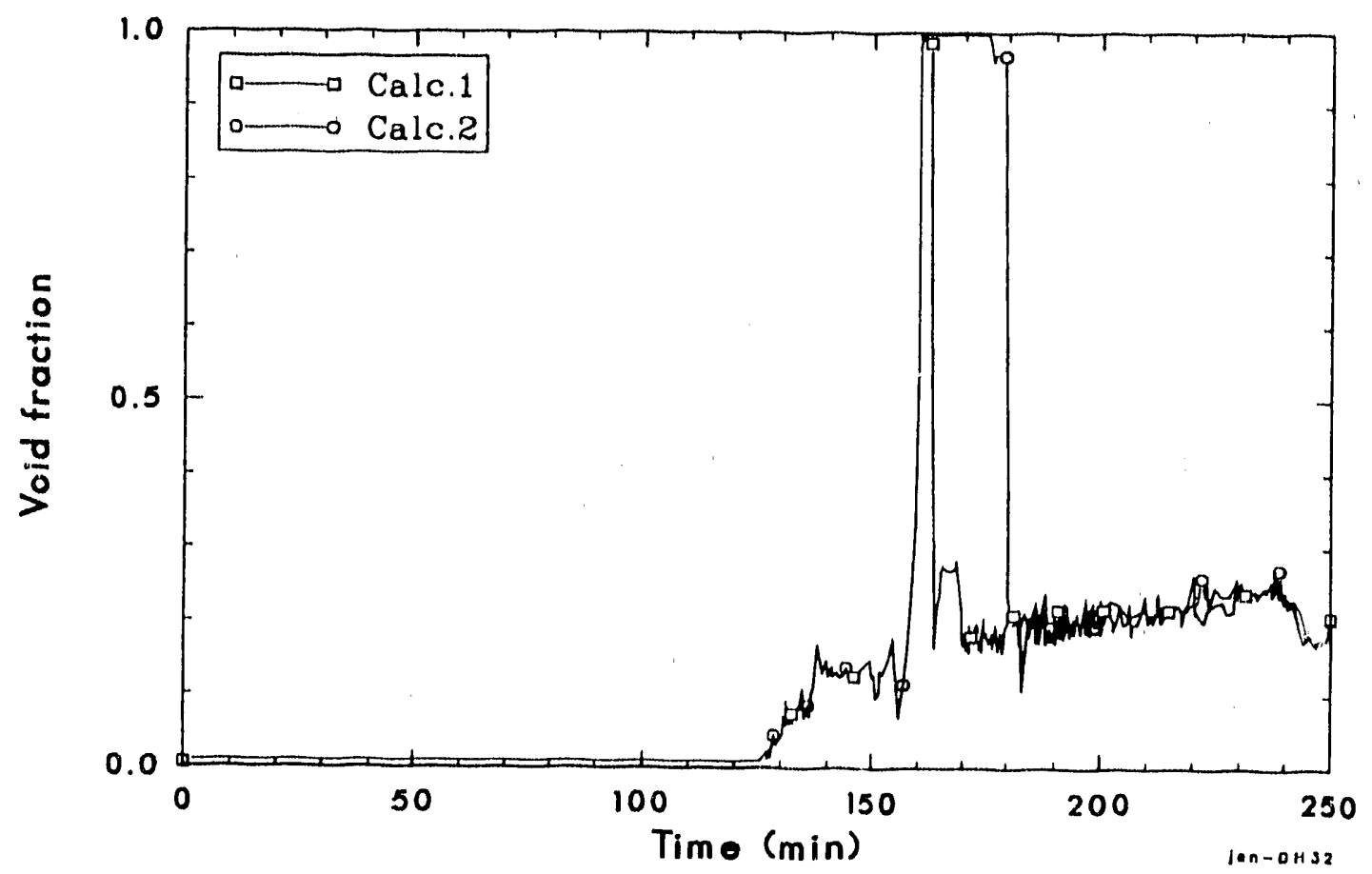

Figure 35. Comparison of void fraction at top of core for calculations 1 and 2.

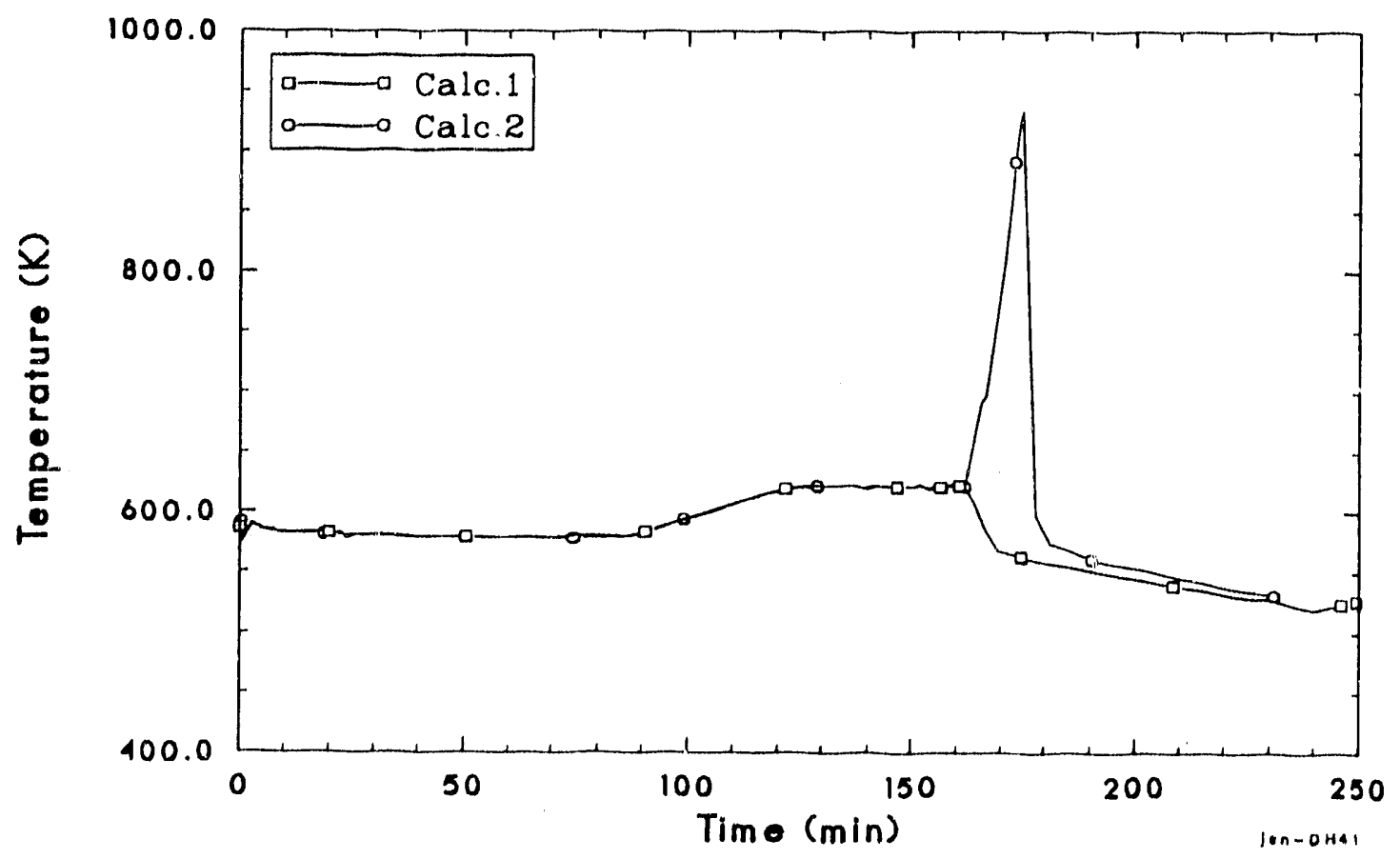

Flgure 36. Comparison of cladding surface temperature at top of core for calculations 1 and 2. 


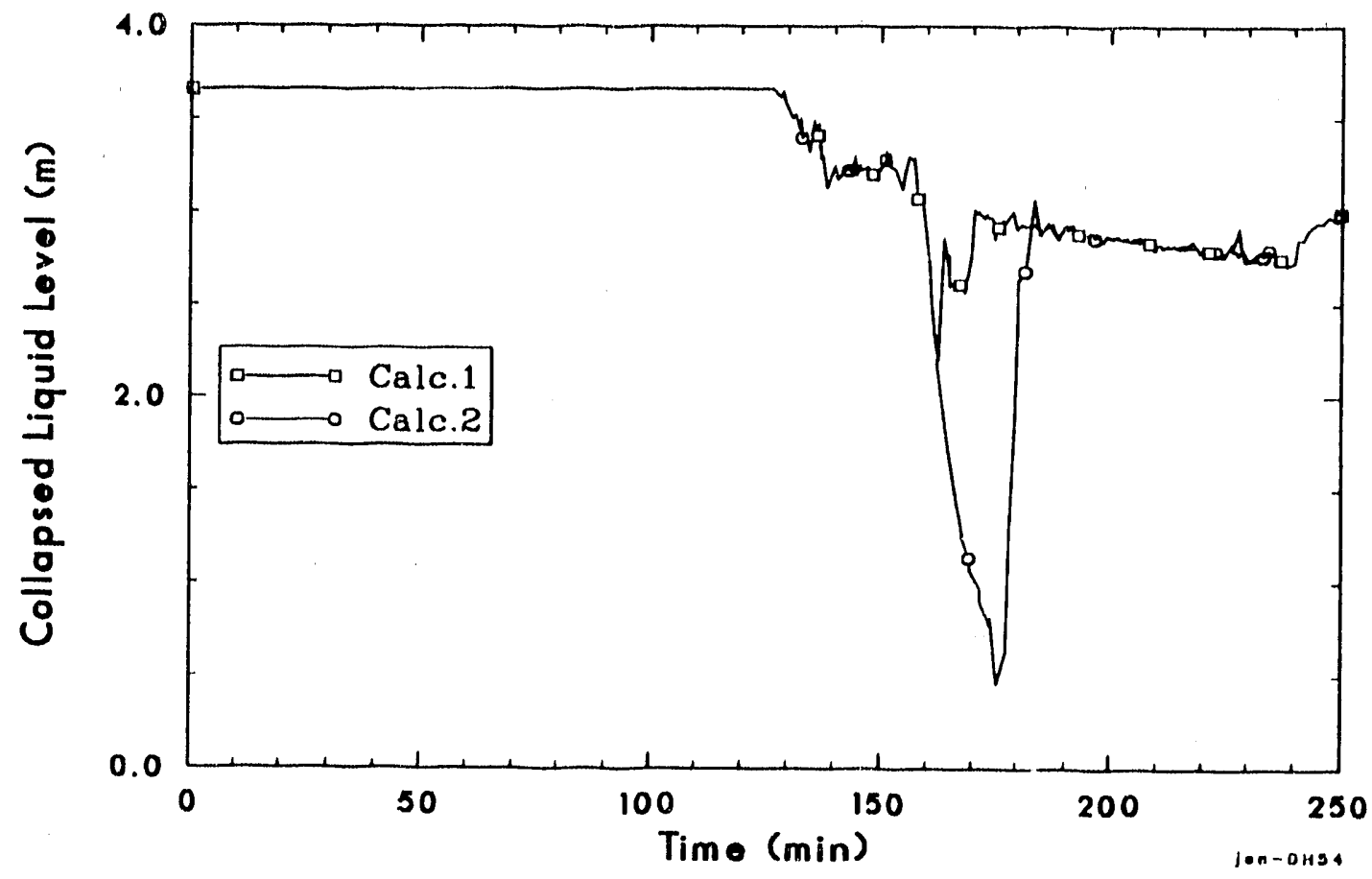

Figure 37. Comparison of collapsed core liquid level for calculations 1 and 2.

The fuel rods were cooled when feedwater was injected into the steam generator secondary system. The cladding surface temperatures at the top of the core are plotted in Figure 36. Because feedwater was started at the onset of cladding heatup in calculation 1, only a small temperature increase was calculated at this elevation. The core heatup had not yet begun at lower elevations. However, in calculation 2, the cladding surface temperature rose to about $920 \mathrm{~K}\left(1200^{\circ} \mathrm{F}\right)$ before feedwater was initiated. If the feedwater had not been recovered at that time, the cladding surface temperature would soon have exceeded $1000 \mathrm{~K}$ $\left(1340^{\circ} \mathrm{F}\right)$, a temperature at which some severe accident codes begin calculating exothermic cladding oxidation. If cladding temperatures had reached 1200 to $1300 \mathrm{~K}\left(1700\right.$ to $\left.1880^{\circ} \mathrm{F}\right)$, the cladding may have ballooned, causing the core geometry and heat transfer characteristics to change. That is, at the heatup rate shown in Figure 36, damage could occur within 600 to $1200 \mathrm{~s}$ (10 to $20 \mathrm{~min}$ ) in the average fuel rod-and sooner in higher-powered rods.
The core liquid level, shown in Figure 37, decreased slightly in calculation 1 . However, in calculation 2, the level decreased to below $0.5 \mathrm{~m}$ $(1.6 \mathrm{ft})$, but was quickly restored after auxiliary feedwater was initiated. Part of the additional liquid came from the pressurizer. The pressurizer liquid level is plotted in Figure 38. The injection of auxiliary feedwater resulted in condensation of steam in the primary system, and draining of liquid from the pressurizer, and loops into the core.

At about $13,500 \mathrm{~s}(225 \mathrm{~min})$ in calculation 1, the accumulators began injecting when primary system pressures dropped below 4.24 MPa (615 psi). At the end of the calculation, about $90 \%$ of the original fluid volume remained in the accumulators. Calculation 2 was terminated at 2 pressure of $4.68 \mathrm{MPa}(680 \mathrm{psi})$-before the pressure reached the injection setpoint for the accumulators. If the pressure were to be reduced to the accumulator setpoint, accumulator injection would help cover the core and keep the fuel rods cool. 


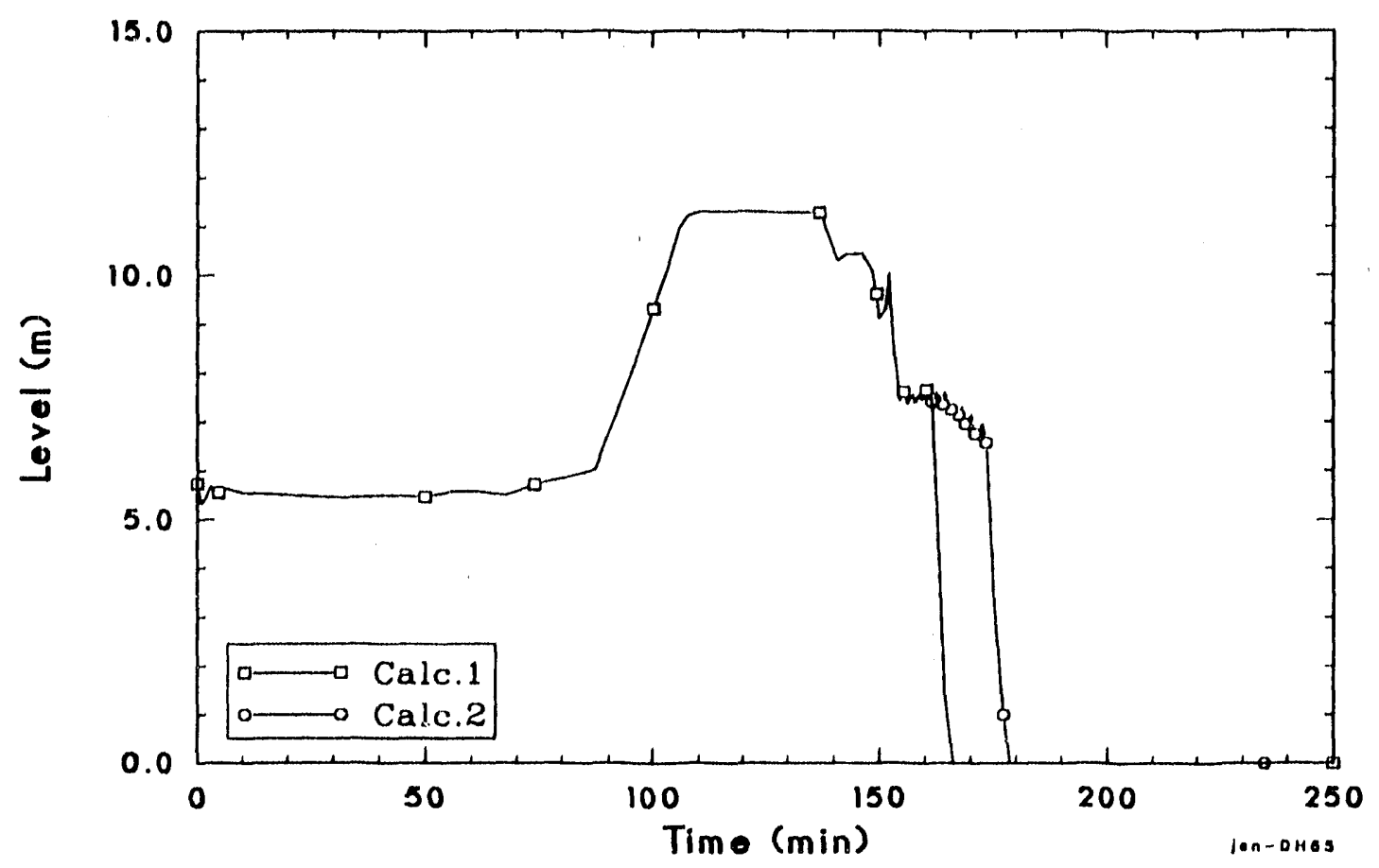

Figure 38. Comparison of pressurizer liquid level for calculations 1 and 2.

\subsection{Operational Performance for Feedwater Addition}

Methods for restoring auxiliary and other sources of feedwater are included in the EOPS and in plant training programs. If electrical power is restored prior to the initiation of RCS depressurization, there is a high likelihood that the steam generators will be available to remove energy from the RCS. However, for the TMLB' sequence, the electrically driven auxiliary feedwater is unavailable and the turbine-driven auxiliary pumps are also assumed to become unavailable, for various reasons, as the sequence progresses. If auxiliary feedwater is not recovered, alternate strategies for providing feedwater will be attempted. Implementation of these strategies would rely on the operating crew to determine what other water sources and motive forces may be available and to initiate actions necessary to locate and actuate valves to provide the correct lineup to feed the steam generators. One of the most likely alternate strategies during a TMLB' sequence would be to use the diesel-driven fire pumps to supply water to the steam generators.

An analysis was performed to estimate the HEPs for an alternate feedwater strategy at Surry that utilizes the diesel-driven fire pumps. Discussions were held with Surry plant personnel to obtain the information used in this analysis. At Surry, this strategy includes dispatching an auxiliary operator to a remote area of the plant where the operator would open three valves to provide the proper lineup to the steam generator. The auxiliary operators who would perform this task at Surry are trained in the necessary tasks, but there are no written procedures for them to refer to as they carry out the strategy.

The order in which the three valves aligning the firewater system to the steam generator must be opened is unimportant at Surry, although there 
are no annunciators or alarms to indicate an incorrect lineup. Identification of the valves and access to them is facilitated, since all three valves are painted red (because they are part of the firewater system) and there are no locks on the valves (which could complicate operating them). Plant personnel estimated that it would take between 5 to $10 \mathrm{~min}$ to reach the valves from the control room, although the operators could dispatch people to the area more rapidly using the plant communication system. Because the emergency diesel firewater pump is in the automatic mode in the event of a loss of site power (LOSP), the auxiliary operators would not have to energize this pump.

Three cases were considered in a scoping evaluation of human error probabilities associated with using the diesel firewater pumps to feed the steam generators. These cases are intended to show the relative change in risk for this activity as a function of a the use of procedures and independent verification of actions performed. The first case considers the current situation where there are no procedures for the personnel performing the necessary actions and assumes there is no recovery resulting from independent verification since only one person is carrying out the action. Case 2 assumes adequate procedures and training are in place, but there is no independent verification. Case 3 assumes adequate procedures and training and that independent verification of actions would allow recovery from errors. All estimates of human error probability are derived from ASEP in a manner similar to that discussed in Section 3.3. Table 6 summarizes the HEP results for the three cases.

For Case 1, a nominal HEP of 1.0 was determined from Table 7-3 of ASEP based on the activity "Perform a required action outside of control room." This screening HEP indicates the tasks will not be correctly implemented and since there is no credit assumed for recovery, the proba- bility of failure is one. As developed, the HEP provides a conservative upper bound on the failure rate because there is insufficient detailed information about the activities performed outside the control room, without a procedure, annunciators, or a second person to verify correct performance.

The second case evaluates the situation where the critical tasks are covered by procedures and are therefore considered to be rule-based actions. Although the actions would still occur outside the control room, the effect of this separation was assumed to have a negligible effect for this case, to facilitate an evaluation of the impact that a set of proceduralized instructions has on the overall reliability. The HEP for this situation was based on ASEP results. No recovery credit was assumed. The reduction in failure probability resulting from use of procedures is shown to be significant, about a factor of 7 lower than Case 1.

Case 3 is an extension of the Case 2 but provides credit for recovery. The HEP was determined from ASEP assuming a rule-based procedural task performed under moderately high stress with a second person verifying the correctness of the valve lineup activities performed by the auxiliary operators. As such, it relies on optimistic assumptions, as compared to the current conditions that exists at Surry, for performing the required actions to achieve emergency firewater injection into the steam generator(s). It is intended to show the relative reduction in failure probability, based on ASEP results, including credit for using a second person to verify the actions of the original performer. Based on these results, reasonable assurance of success for addition of feedwater using the diesel-driven fire water pumps could be achieved if procedures were in place and means of monitoring and verifying actions were included. 
Table 6. ASEP nominal HEPs for actions to utilize emergency diesel firewater pumps to feed the steam generators

\begin{tabular}{|c|c|c|c|c|c|}
\hline & \multicolumn{5}{|c|}{ Median } \\
\hline & $\begin{array}{c}\text { Action } \\
\text { HEP } \\
\end{array}$ & $\begin{array}{c}\text { Recovery } \\
\text { Factor } \\
\end{array}$ & $\begin{array}{c}\text { Failure } \\
\text { Probability } \\
\end{array}$ & $\underline{L C B}$ & $\mathrm{UCB}^{\mathrm{b}}$ \\
\hline Case 1 & 1.0 & N/A & 1.0 & 1.0 & 1.0 \\
\hline Case 2 & 0.05 & N/A & 0.142 & 0.068 & 0.51 \\
\hline Case 3 & 0.05 & 0.5 & 0.096 & 0.059 & 0.28 \\
\hline \multicolumn{6}{|c|}{ Failure probability lower confidence bound. } \\
\hline \multicolumn{6}{|c|}{ Failure probability upper confidence bound. } \\
\hline
\end{tabular}




\section{UNCERTAINTIES}

Uncertainties in calculations, the performance of equipment, and operator performance all have the potential to affect the capability to intentionally depressurize the RCS. The following subsections discuss important uncertainties in each of these three areas.

\subsection{Calculation Uncertainties}

Uncertainties in the calculations have been reviewed based on their potential effect on the system response, with emphasis on the RCS pressure response. For the purposes of discussion, the important uncertainties associated with the calculations are classed as being related to either thermal-hydraulics or core damage progression. The uncertainties in the thermal-hydraulic models that appear to be important and are discussed further include: accumulator flow and its effect on system response, transport of noncondensables and their effect on system response, critical flow through the PORVs, and reactor vessel inventory. The uncertainties in core damage progression that appear to be important include the effects of oxidation during water addition to the core, core melt progression and debris behavior, the quantity and time span of molten pool relocation, and the possibility of rapid and energetic fuel-coolant interactions (steam explosions).

\subsubsection{Thermal-Hydraulic Uncertaintles.}

The calculated flow from the accumulators and the calculated system response to accumulator injection each had a significant effect on the calculated core temperatures for late depressurization and the amount of cladding oxidation for early depressurization. Flow from the accumulator is governed by the pressure difference between the accumulator and the cold leg and by the resistance to flow in the connecting piping. SCDAP/ RELAP5 models the accumulators as a lumped parameter component. The model assumes the following: (a) the gas in the gas dome can be modeled as an ideal gas with constant specific heat; (b) the liquid can be modeled as an isothermal system based on the heat capacity of a large mass of water; and (c) natural convection coefficients are adequate to model the heat transfer from the walls, and heat and mass transfer from the liquid. The model for liquid flow includes inertia, wall friction, form loss, and gravity. ${ }^{4}$ The model specifically includes factors that affect volume, mass, and temperature of the gas dome. Based on the current morlels, it is judged that uncertainties in the model for calculating the accumulator pressure are negligible compared to other uncertainties in the analyses. The other pressure influencing the flow calculation is the cold leg pressure, which is driven by the overall system response. The system response appears to be initially driven downward by condensation at the time of accumulator water injection, followed by a sharp pressure rise caused by vapor generation from flashing caused by the initial pressure decrease and increased heat transfer in the core. In general, RELAP5 has been assessed during high flowrate accumulator injection. However, the code has not been assessed against data for a relatively slow, long-term accumulator injection similar to that predicted in these analyses. Although this uncertainty is not well characterized, it would be expected to influence the timing of the transient but should not significantly affect the RCS pressure when the lower head fails.

Another influence of uncertainties on the accumulator injection flow rate is the back flow of non-condensables (hydrogen) from the upper plenum to the cold leg during the early depressurization analysis. It is recognized that the presence of hydrogen in the system will reduce the effectiveness of condensation. Uncertainties arise not from the effect of hydrogen, but rather from the models for hydrogen transport within the RCS. SCDAP/ RELAP5 does not have a separate field for noncondensable gases. Noncondensable gases are transported at the same velocity as calculated for the steam phase. Uncertainties in the concentration of hydrogen in the cold leg adds uncertainty to the calculation of pressure for the early depressurization calculation between the first and second accumulator injection cycles. This uncertainty may affect the timing but should not significantly affect the pressure at the time of lower head failure 
owing to the large amount of time between the initial accumulator cycles and lower head failure.

The system conditions at the time of accumulator injection (in particular the RPV liquid level) appear to strongly influence the core heat transfer response during accumulator water injection. Therefore, uncertainties in the RCS inventory and in-vessel water level may have an important influence on the predicted core steam generation rate and the core temperature. RCS inventory is a function of the mass lost through the PORVs. The calculated inventory is then a function of the critical flow model for both two-phase and singlephase vapor flows. In late depressurization, the PORVs are latched open based on what is essentially an RCS coolant inventory criteria (core uncovery as defined by the core exit temperature). The pressure just before the PORVs are latched open will be between 15.7 and $16.2 \mathrm{MPa}(2280$ and $2350 \mathrm{psia}$ ), the close and open setpoints for the PORVs. Thus, the conditions for latching open the PORVs are based on fixed conditions that are independent of the code calculations. Therefore, uncertainties in the critical flow model up to latching open the PORVs are insignificant to the calculated results with regard to pressure and the calculated response caused by the first accumulator injection.

The rate of pressure decrease and mass removal from the RCS between the time of core uncovery and the time that water reaches the bottom of the downcomer is primarily determined by the steam flow rate out the PORVs and the rate at which steam is generated in the core. When the PORVs are latched open, the exit flow is single-phase vapor. The critical flow model for single-phase vapor is based entirely on equality of the vapor and sonic velocities. This is a theoretically sound mod$\mathrm{el}$, and no known issue exists as to the accuracy of the critical flow model for single-phase vapor. The rate at which steam is generated in the core is a function of the decay heat and water level, or the steam generation rate is equal to the decay heat below the water level divided by the latent heat of evaporation. Thus, the uncertainties in the calculatiuns of pressure and mass inventory (level) are insignificant between core uncovery and lower plenum uncovery.

From core uncovery to the first accumulator injection, the calculated pressure and liquid levels are primarily a function of the steam flow rate through the PORVs and the rate of steam generation by flashing in the lower plenum and cold leg loop seals. The rate of flashing is a function of the heat input from the vessel, pipe walls, and the rate of depressurization. The rate of depressurization is a function of RCS pressure, steam flow rate out the PORVs, steam mass, and volume. The calculation of level cannot be isolated to a single parameter and is dependent on many models in the code solution. SCDAP/RELAP5 has been assessed for a wide range of basic thermalhydraulic phenomena, although there may be no specific assessment of liquid levels as a function of flashing. Uncertainties in this calculation are not expected to result in major uncertainties in the RCS pressure response.

The uncertainties in RCS inventory for the early depressurization calculation are different from the late depressurization in that the PORVs are latched open prior to core uncovery, which results in a period of two-phase flow at the PORVs prior to core uncovery. While the system inventory is the same at core and lower plenum uncovery, uncertainties in the two-phase critical flow model imply that the uncertainties in pressure up to the first accumulator injection are more significant than in the late depressurization calculation. When the first accumulator injection occurs, the phenomenology of the transient becomes much more complex. There is condensation of vapor on the injected liquid, decreasing RCS pressure, followed by rapid flashing of liquid in the RCS increasing RCS pressure, clearing of the cold leg loop seals, and refilling of the loop seals in early depressurization. While SCDAP/ RELAP5 has been assessed for accident thermalhydraulics, it has not been assessed for this specific set of conditions. The predicted cyclic response appears to be quite reasonable, based on fundamental reasoning as described above. The solutions are probably correct in the trend and relative magnitudes of the quantities calculated by the code. The uncertainties in absolute 
- maprinudes for quandities such as peak pressure during the time $c$ an injection cycle might be considered large becalse there are no spectitic experimearial datiz at hese plant conditions to verity wodel pertomance during accurablator injection.

\subsubsection{Core Damage Progression Uncer-} taintles. Unacertinaties in the vesssel water levels and sccumulation injection resu'o in uncertainties in the trating and anoumt of thadding oxidation furing the early phase of core destudation for both calculustions. For the eanty depressumustion calculation, conniculation of cladding oxidation at the time of axcumulator tajection appears to be quite reasomithle as a resuli of the low llow: The indfow tron the accumulators is on average about $10 \mathrm{~kg} / \mathrm{s}$, which is sutficient to renove about 13 MW of decty hear. Becuse mis is about 10 MW less thin decey heat, the code is consis. tere in esculating partial recovering of the cors and contandation of oxidation. The sessastion of clatuding oxidartion upon actuniulator injection durng late depressistration is sontwe what more uncerting There is strong evidento trom the TMI-2 sesthent that when the B loop RCS purup was rumed on ar 174 arin, the tow injevted buto the sore (while sooling the preriphery of the core) creared an enveronaten that resulied in rapid oxidanon in the aper regions of the core. The oxi. darion energy resulted in a pressure increase of abons $5 \mathrm{MP}$ s It is important to note char conditions in the TMI-2 wore at the inte of the purap transitent inclused a central blo iage and temperatures spproshing twel melang in the uppor regions ot the sore.

Aldrougt rks core condinons tor the late depressurication callation are quite ditteren trom the TMI-2 core conditions the re is the possibility that the SCDAP/RELAPS oxidation arodel is not wresty predicting oxidation durng intlow trom the actumulator it the prediction is not wrmes, there could bx a sugutican uncerain. by ta the energy adjition rate during the bate

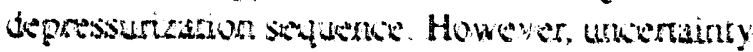
in the oxidarion model may not be stgutican w the ealculegon of pressure over the long term of thas seyuence.
For a bounding case, assume that the rate of oxidation is calculated incorrecty during the first injection cycle. As a result, oxidation continues and a pressure spike of 5 MPad occurs, in addition to the smaller pressure increase currendy calcu. lated. At this time in the sequence the calculated depressurization rate is about $0.5 \mathrm{MPa} / \mathrm{min}$, as stown in Figure 18. Thus, about 10 min more would be required to reach the second accumula. tor cycle. An additional 10 min for depressuriza. tion is insignificant compared to the available time of depressurization.

Because there is a lack of detailed experimenral data on the late phase of core relacation. uncertainties in the SCDAP/RELAP5 calcu. lations of core auelt progression and debris behavior must be considered to be large. The approach discussed in Section 2.3 recognized the potential for large uncertainties during this period and was intended to provide results that would bound the eore damage progression and system pressure responste. Conseyuently, the effect of the major core darage uncertainties on the pressure at the time of lower head failure should be accounted for in the results presented, with one important excepcion, rapid fuel-colart interactions (steam explosions).

There are currendy uncertainties associated with the magnitude and effects of steam explosions as the core relocates to the lower plenum. Because the probability of steam explosions is higher af low-systern pressure, depressurieation followed by relocarion of core material to the lower plenum atay increase the potential for a vessid failure caused by steam explosions. Analy. ses are currendy planned by the NRC to deteraine the intensity and eftect of steam explosions ar conditions similar to those expected during depressurization.

\subsection{Equipment Uncertainties}

Several uncertainties assciciated with equipaxent may be important in determining the capability to intentionally depressurize the RCS. The principal uncertainties are: (a) the capability of the PORVs to remain operational when the temperature of the huid howing through the valves is 
substantially higher than the qualification temperature of the valves, and (b) the capability of the air and de power systems to provide longterm suppont for the PORVs during an extended TMLB' sequence.

PORVs in nuclear power plants are generally qualified for fluid conditions similar to other components and piping in the RCS, $616 \mathrm{~K}$ $\left(650^{\circ} \mathrm{F}\right)$ and $17.2 \mathrm{MPa}(2500 \mathrm{psi})$. The calculated temperature of the fluid passing through the PORVs for the early and late depressurization strategies are shown in Figure 28. These temperatures reach values that are substantially higher than the specified valve qualification limits for extended periods of time.

As discussed in Section 3.2, the PORV's exceed their qualification limits for extended periods of time. Exceding these qualification limits causes uncertainty in the capability of the PORVs to remain functional after they experience the high temperature environment. The effect of this uncertainty is difficult to quantify because there is no experimental data for valves under similar transient high-temperature conditions. During the early depressurization calculation the fluid temperatures at the top of the pressurizer exceeded $1200 \mathrm{~K}\left(1700^{\circ} \mathrm{F}\right)$ for about $1000 \mathrm{~s}$. This very high temperature over an extended time would make the continued proper pertormance of the PORVs more uncertain than for the late depressurization calculation, where the fluid temperatures were appreciably lower and the duration of high temperature conditions shorter. The fluid temperature entering the PORV for the late depressurization sequence ar Surry was similar to the fluid temperature calculated to be entering the Seabrook PORVs for a study performed by Pickert, Lowe and Garrick, Inc. ${ }^{20}$ Results from a detailed heat transfer analysis of the PORV at the Seabruol: Plant for this temperature transient indicated that the body of the FORV was about $110 \mathrm{~K}\left(200^{\circ} \mathrm{F}\right)$ below the qualification temperature of $616 \mathrm{~K}\left(650^{\circ} \mathrm{F}\right)$. Because the valve designs are different for the two plants and the Surry nuid temperatures remain high over a longer perion, an extrapolation of the Seabrook results is not possible. However, the Seabrook results do provide enough informa- tion to indicate that the Surry valve body temperatures should not sabstantially exceed the qualification temperatures for long periods of time. Additional testing or use of higher temperature materials, particularly in the packing, would be necessary to reduce cument uncertainties.

Uncertainties in the capability of the support systems to provide sufficient air and electrical power to hold the valves open would be very plant specific and would depend on the system design and the operational strategies. It appears that provisions would be needed at Surry to ensure that the batteries would continue to be operational for the extended period of the intentional depressurization sequences. The air supply required to open the valves could also be depleted over this long period of time, depending on the system behwvior prior to larching open the PORVs and the leakage from the valve operator during the extended period of time that the valve is latched open. The largest uncertainties would occur during the late depressurization sequence because the PORVs experience a large number of opening cycles prior to the time the PORVs are latched open. Depending on the design of the valve and the rate of air leakage while holding the valve open. additional air supply may be required for the late depressurization sequence for Surry.

\subsection{Operational Uncertainties}

Specific uncertainties in the capability of the operators at Surry to intentionally depressurize are difficult to asceriain because there are no specific depressurization procedures to evaluate. Current procedures at Surry are not designed to use the PORVs for depressurization during a TMLB' sequence. It appears that modifications to the procedures are possible that would provide the steps necessary to allow intentional depressurization during a TML B' sequence. Early depressurization would have less operational uncertainty because there would be additional time for diagnosis and actions to be taken. The uncertainties for late depressurization would be larger because there is less time for the plant personnel to make the decision to depressurize and there would be less time to carry out necessary actions. 


\section{CONCLUSIONS AND RECOMMENDATIONS}

A systematic evaluation of the capability to intentionally depressurize the Surry nuclear power plant during a station blackout transient has been conducted. This analysis examined the phenomenological behavior, equipment performance, and operational performance for two strategies that were believed to have the potential to reduce $R C S$ pressure below a value where direct containment heating would be mitigated. Conclusions and recommendations from this analysis are specific to the Surry Plant. Their applicability to other nuclear power plants is discussed in the final conclusion in this section.

1. Intentional depressurization using the PORVS and upper head vent has the potential to initigate $\mathrm{DCH}$ by reducing the RCS pressure to within about $1 \mathrm{MPa}$ (145 psi) of the containment pressure.

Phenomenological analyses for both the early and late depressurization strategies indicated that the RCS pressure could be reduced to within about $1 \mathrm{MPa}$ of containment pressure. Based on information currently available, this value for RCS pressure would be sufficiently low that DCH could be mitigated. However, there are human factor and equipment issues that could affect the capability to succtssfully implement intentional depressurization. Several of the following conclusions discuss these issues.

2. Current Surry Emergency Operating Procedures would not initiate RCS depressurization for the TMLB' sequence. A human factors evaluation indicates that if modifications were made to the procedures, there is a high likelihood that the plant personnel could successfully initiate depressurization strategies.
During a TMLB' sequence, the current Surry Emergency Operating Procedures would not provide an entry point into the Functional Restoration Procedure that initiates RCS depressurization using the PORVs. Becaure the Surry procedures are consistent with the Westinghouse Emergency Procedure Guidelines (EPGs), other Westinghouse plants that followed the EPGs would also be expected to lack guidance in their EOPs to depressurize during a TMLB' sequence.

A human factors evaluation identified two important factors that could affect the performance of the plant personnel in implementing depressurization strategies: (1) the capability of plant personnel to recognize that a depressurization strategy should be implemented and (2) the capability of the personnel to implement the necessary depressurization actions in the available time. A review of existing instrumentation iudicates there would be adequale information for plant personnel to recognize initiation conditions for either the early depressurization strategy (initiated when the steam generators dry out) or the late depressurization strategy linitiated when the core exit thermocouples reach $922 \mathrm{~K}$ $\left(1200^{\circ} \mathrm{F}\right)$ ].

A human reliability analysis (HRA) was performed to estimate the likelihood that personnel could implement depressurization based on possible changes that could be made to the EOPs. Implementation was separaled in to two components: diagnosis of the need to depressurize and the actions necessary to complete system depressurization. Because specific prosedures were not available, the time required to diagnose the need to depressurize was difficult to determine 
and its effect on the failure probabilities was evaluated using a sensitivity study. The HRA results estimate that the probability of the failure to depressurize is $<0.08$ ( $>0.92$ probability of success) if there is more than twenty minutes available to perform diagnosis. This result would indicate that there is a relatively high likelihood of proper implementation of early depressurization because there is adequate time for implementation. However, for late depressurization, the results indicate that cautions would need to be included in the procedures to alert the operator that the conditions for implementation of late depressurization were being approached. The objective of these cau. tions would be to ensure a high likelihood of successful implementation of late depressurization in a minimum amount of time after the $922 \mathrm{~K}$ $\left(1200^{\circ} \mathrm{F}\right)$ initiation point is reached. Minimizing this time is important because significant delays in implementation would allow core temperatures to reach unacceptably high values.

3. Modifications to plant equipment at Surry would be necessary to ensure that intentional depressurization would be successful.

Based on Draft NUREG-1150 results, there is a relatively high probability ( 0.3 conditional probability per demand) that a block valve on one of the PORV lines will be closed as a result of leakage. Because these block valves operate using only ac power, it would be impossible to open a closed block valve during a TMLB' sequence. The effect of a closed block valve wuald be to significantly slow RCS depressurization. Placing the block valves on emergency battery power would allow closed block valves to be opened during a station blackout which would ensure that the strategies could be successfully implemented.

Both dc power and a supply of pressurized air are needed to force the PORVs to remain in an open position during RCS depressurization. At Surry, it is unlikely that the current systems could continue to supply their necessary functions over the eight to ten hour time period between when depressurization is initiated and the vessel fails for the TMLB' sequence. Additional capacity for both of these systems would be needed for intentional depressurization using the PORVs to be successful at Surry.

4. A strategy that depressurizes the RCS after the core begins to uncover (late depressurization) is preferred to the early depressurization strategy.

While the analyses predict a similar RCS pressure response for both the early and late depressurization cases, there are significant differences in the timing and the extent of core damage during the early stages of the TMLB' sequence. For early depressurization, latching open the PORVs removes large quantities water from the RCS early in the sequence which accelerates the onset of core heatup by about 46 minutes, when compared to late depressurization. By the time the pressure is sufficiently low that the emergency core cooling accumulators inject additional coolant, the temperature of some of the fuel rods have exceeded the threshold for oxidation of zircaloy. Accumulator injection therefore causes significant cladding oxidation and relocation and is not effective in controlling further core damage. 
For late depressurization, core heatup begins at a later time because the water inventory in the RCS is not depleted as rapidly during the early portion of the sequence when the PORVs are cycling at their setpoints, rather than being latched open. When the PORVs are intentionally latched open late in the sequence, the inventory of water remaining in the RCS is relatively small and the RCS depressurizes rapidly to the pressure at which the accumulators inject. The temperatures in the core at the time of accumulator injection are generally below the threshold for rapid zircaloy oxidation. The accumulators initially discharge at higher rates than calculated for early depressurization, because of the higher initial depressurization rate and the inventory distribution in the RCS. Because temperatures are lower and the accumulator injection rates are higher, the core cooling during the period of accumulator injection is relatively effective and delays substantial core damage until the accumulators are empty. Thus, from a phenomenological standpoint, it is concluded that late depressurization is preferable to early depressurization because core heatup and significant core damage are delayed.

The only major difference in the demands on equipment needed to intentionally depressurize for the two strategies would be in the capacity of the air supply. The late depressurization strategy would use more air to operate the PORVs because they would cycle many more times at their setpoints. Cycling requires much more air than does maintaining the valve in its open position. However, this difference is not considered to be significant because it is anticipated that the air supply system would require additional capacity for either strategy.
From an operational standpoint, late depressurization would maximize the time available for the operator to recover ac power and auxiliary feedwater. However, cautions and anticipatory actions should be included in the procedures to assure immediate action when the initiation conditions were reached because some fuel rod temperatures at the upper core levels would be relatively high [ $>922 \mathrm{~K}$ $\left.\left(1200^{\circ} \mathrm{F}\right)\right]^{\circ}$.

5. Failure of the pressurizer surge line could cause the RCS to rapidly depressurize prior to failure of the reactor vessel lower head.

Hot steam and gases exiting the core heat the plant structures as they flow toward the PORVs. The calculation for early depressurization indicates that the pressurizer surge line would reach temperatures that are high enough to cause creep rupture failure during the time period when the accumulators are injecting. Because the temperature of the flow from a rupture would remain high, it is expected that the rupture area would be sufficiently large to rapidly depressurize the RCS. The calculation for late depressurization also indicates high sunge line temperatures, but not sufficiently high to cause a failure prior to vessel failure. Surge line failure was also calculated when no operator action was taken to depressurize. Although failure of the surge line appears to be effective in depressurizing the system, strategies to intentionally depressurize are preferred because they control the accident conditions without relying on the failure of system components.

6. The effect of in-vessel steam explosions during the relocation of molten core material on the integrity of the RCS needs to be assessed. 
There is significant uncertainty in the effect on the reactor pressure vessel of a steam explosion resulting from core-coolant interactions when a molten core relocates during a severe accident. Because steam explosions are more likely at low pressures, use of an intentional depressurization strategy may increase the possibility of vessel damage from a steam explosion. To determine the influence of steam explosions on risk to the public, additional analysis will be needed to assess the potential for steam explosions at various pressure levels and to evaluate the potential for vessel failure.

7. The conclusions on the effectiveness of intentional depressurization strategies are specific to Surry and their extrapolation to other plants must be considered carefully.

A detailed evaluation of the applicability of the Surry results to other plants was not within the scope of this program. However, a preliminary assessment of some important considerations was performed to provide insight as to the possible behavior of other plants under similar transients and initial conditions. Plant differences that could strongly influence the success of intentional depressurization would be associated with the plant hardware or with the plant operations.
Although the effect of plant operations can be very important, this effect was not evaluated because detailed procedures were not available for a reasonable cross section of plants and discussions with the operations staff to evaluate their use of the procedures was beyond the scope of this program. It is recognized that procedural changes could be made to ensure the success of intentional depressurization if plant specific analysis indicated that current procedures were not adequate. Hardware parameters that were considere 1 to be important influences on intentional depressurization include: (a) PORV characteristics, (b) pressurizer, surge line, and relief valve piping characteristics, (c) plant support system capabilities, (d) accumulator setpoints, and (e) containment type. As an example, containment type may be important because the generation of large quantities of hydrogen was calculated during intentional depressurization. Some containment types may require additional equipment that is capable of recombining this hydrogen over a time frame that will prevent detonation and containment failure. It is recognized that other plant characteristics such as steam generator type and core characteristics (control rod material, power profile, etc.) may also influence depressurization. The potential effects of these differences will be assessed and discussed in a later report. 


\section{REFERENCES}

1. M. Silberberg, J. A. Mitchell, R. O. Myer, and C. P. Ryder, Reassessment of the Technical Bases for Estimating Source Terms, NUREG-0956, July 1986.

2. U.S. Nuclear Regulatory Commission, Reactor Risk Reference Document, NUREG-1150, Draft for Comment, February 1987.

3. U.S. Nuclear Regulatory Commission, Severe Accident Risks: An Assessment for Five U.S. Nuclear Reactors, NUREG-1150, Second Draft for Peer Review, June 1989.

4. C. M. Allison et al., SCDAP/RELAP5/MOD2 Code Manual, I, II, III, NUREG/CR-5273, EGG-2555, September 1989.

5. P. D. Bayless, Analyses of Natural Circulation During a Surry Station Blackout Using SCDAPI RELAP5, NUREG/CR-5214, EGG-2547, October 1988.

6. R. Chambers, W. J. Galyean, and W. E. Gilmore, Accident Management of Surry Direct Containment Heating by Depressurization of the Reactor Coolant System - Progress Report, EGG-SSRE-7854, September 1987.

7. D. W. Golden et al., "Summary of the TMI-2 Analysis Exercise," Nuclear Technology, 87, 1, August 1989.

8. W. Camp, J. Tomkins, T. Heames, and J. Dearing, "Physical Modeling of the In-Vessel Phases of Severe Reactor Accidents - The Melprog/Trac Computer Code," International Symposium on Severe Accidents in Nuclear Power Plants, IAEA-SM-296/97, Sorrento, Italy, March 21-25, 1988.

9. J. O. Henrie and A. K. Postma, Lessons Learned from Hydrogen Generation and Burning During the TMI-2 Event, GEND-061, May 1987.

10. P. Kuan, Assessment of TMI-2 Plenum Assembly Damagi, EGG-TMI-8020, April 1988.

11. D A. Petti, Z. R. Martinson, R. R. Hobbins, C. M. Allison, E. R. Carlson, D. L. Hagrman, T. C. Cheng, J. K. Hartwell, K. Vinjamuri, and L. J. Siefken, PBF Severe Fuel Damage Test $1-4$ Test Results Report, NUREG/CR-5163, EGG-2542, February 1989.

12. R. J. Ackermann, S. P. Garg, and E. G. Rauh, "High-Temperature Phase Diagram for the System $\mathrm{Zr}-0$, , Journal of the American Ceramic Society, Vol. 60, No. 7-8, July-August 1977.

13. T. M. Chung and T. F. Kassner, Embrittlement Criteria for Zircaloy Fuel Cladding Applicable to Accident Situations in Light Water Reactors, NUREG/CR-1344, ANL-79-48, January 1980.

14. R. Chambers, D. J. Hanson, R. J. Dallman, F. Odar, "Depressurization To Mitigate Direct Containment Heating," Transactions of the Sixteenth Water Reactor Safety Information Meeting, Gaithersburg, Maryland, October 24-27, 1988.

15. J. E. Kelly, "Advances in MELCOR Modeling and Analysis," Transactions of the Sixteenth Water Reactor Safety Information Meeting, NUREG/CP-0096, October 1988.

16. Virginia Power Company, Surry Power Station Updated Final Safety Analysis Report, Docket 05000280, July 16, 1982. 
17. T. Auble and J. Hosler, EPRI PWR Safety and Relief Valve Test Program, Safety and Rellef Valve Test Report, April 1982.

18. TMI-2 Lessons Learned Task Force Status Report and Short-Term Recommendations, NUREG-0578, July 1979.

19. Clarification of TMI-2 Action Plan Requirements, NUREG-0739, November 1980.

20. Karl N. Fleming et al., Risk Management Actions to Assure Containment Effectiveness at Seabrook Station, Pickard, Lowe and Garrick, Inc., PLG-550, July 1987.

21. A. D. Swain, Accident Sequence Evaluation Program Human Reliability Procedure, NUREG CR-4772, February 1987.

22. Virginia Power Company, Surry Power Station Updated Final Safety Analysis Report, Docket 05000280, 05000281, July 16, 1982. 


\section{APPENDIX A}

TRANSIENT SEQUENCES AND STRATEGIES 


\section{APPENDIX A}

\section{TRANSIENT SEQUENCES AND STRATEGIES}

This appendix presents an overview of the accidents sequences that influence the frequency of core damage for Surry Unit 1. The Surry nuclear power station is comprised of two Westinghouse 3-loop pressurized water reactors (PWRs) with core thermal power of $2441 \mathrm{MW}$ and subatmospheric dry containments. It was chosen for study because it is representative of Westinghouse 3-loop reactors and because it is one of the reference plants used in the risk analysis and source term assessments for NUREG-1150, ${ }^{\mathrm{A}-1}$

Core damage frequencies (CDFs) based on the emergency operating procedures at Surry Unit 1 are given in a draft revision ${ }^{\mathrm{A}-1}$ of the analysis of internally initiated events conducted as part of the initial NUREG-1150A-2 effort. This draft version was used for this evaluation because it was all that was available when the program was initiated.
The final draft of NUREG-1150A-3 showed that the risk associated with DCH was smaller than calculated for the initial draft, but DCH continued to be important. Core damage is defined in the draft analysis as the occurrence of a significant core uncovery, with reflood of the core not imminently expected.

Tables A-1 and A-2 summarize the point estimate $\mathrm{CDF}$ for the various risk-dominant sequences and sequence groups. ${ }^{A-1}$ The total for all accident sequences was a point-estimate core damage frequency of $3.28 \mathrm{E}-5$. The contributions to this CDF by the various accident sequences are summarized in Table A-1. Figure A-1 shows the core damage frequency by sequence groups. The dominance of the station blackout sequences (64.2\% of the total CDF) is evident. Attention in this intentional depressurization study has been

Table A-1. Risk dominant sequences by sequence and sequence group

\begin{tabular}{|c|c|c|c|c|}
\hline Sequence & Initiator & $\begin{array}{l}\text { Sequence } \\
\text { Group } \\
\text { Percent } \\
\text { of Total } \\
\end{array}$ & $\begin{array}{c}\text { Sequence } \\
\text { Percent } \\
\text { of Total }\end{array}$ & $\begin{array}{c}\text { Sequence } \\
\text { Point Estimate } \\
\text { Core Damage } \\
\text { Frequency } \\
\text { (reactor-yr) }\end{array}$ \\
\hline SBO-L(TMLB') & Station blackout & 64.2 & 1.6 & $0.51 \mathrm{E}-6$ \\
\hline SBO-QS-L early & & & 4.2 & $1.39 \mathrm{E}-6$ \\
\hline SBO-QS-L late & & & 8.4 & $2.75 \mathrm{E}-6$ \\
\hline SBO-Q & & & 5.1 & $1.66 \mathrm{E}-6$ \\
\hline SBO-Q-QS & & & 1.6 & $0.51 \mathrm{E}-6$ \\
\hline SBO-SL & & & 13.7 & $4.50 \mathrm{E}-6$ \\
\hline SBO-OD-SL & & & 0.5 & $0.15 \mathrm{E}-6$ \\
\hline SBO-QS-SL & & & 5.5 & $1.81 \mathrm{E}-6$ \\
\hline SBO-BATT & & & 17.4 & $5.70 \mathrm{E}-6$ \\
\hline SBO-QS-BATT & & & 6.2 & $2.02 \mathrm{E}-6$ \\
\hline A-D5 & Large LOCA & 6.0 & 2.6 & $0.85 \mathrm{E}-6$ \\
\hline A-D6 & (6 to $29 \mathrm{in.}$ ) & & 1.4 & $0.47 \mathrm{E}-6$ \\
\hline A-H1 & & & 2.0 & $0.67 \mathrm{E}-6$ \\
\hline S1-D1 & Medium LOCA & 9.4 & 2.5 & $0.81 \mathrm{E}-6$ \\
\hline S1-D6 & ( 2 to 6 in.) & & 2.9 & $0.94 \mathrm{E}-6$ \\
\hline S1-H1 & & & 4.0 & $1.30 \mathrm{E}-6$ \\
\hline
\end{tabular}


Table A-1. (continued)

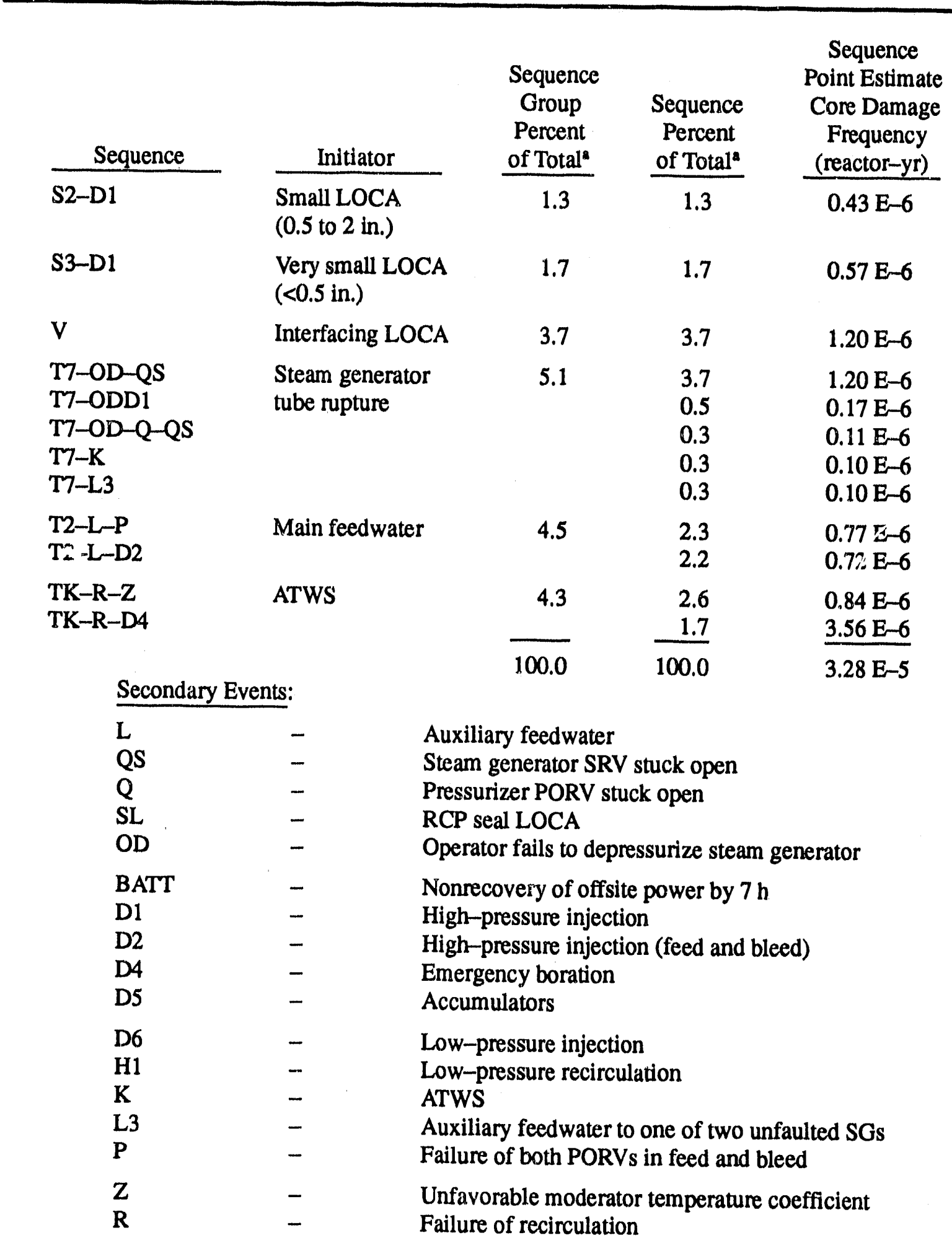

a. Given as percent of total for risk-dominant references (those with point estimate frequencies greater than 1.E-7 per reactor-year). The additional contribution of nondominant sequences was to be $4.4 \mathrm{E}-7$ per reactor-year. 


\section{Core Damage Frequency}

(Percent for Secondary Failure)

\begin{tabular}{|c|c|c|c|c|}
\hline LOCA & $\begin{array}{l}\text { HPI } \\
\underline{D}_{1}\end{array}$ & $\begin{array}{c}\text { ACCUM } \\
\mathrm{D}_{5} \\
\end{array}$ & $\begin{array}{l}\text { LPI } \\
\mathrm{D}_{6} \\
\end{array}$ & $\begin{array}{l}\text { LPR } \\
\mathrm{H}_{1} \\
\end{array}$ \\
\hline A large (6 to 29 in. dia.) & NA & 2.6 & 1.4 & 2.0 \\
\hline$S_{1}$ medium (2 to $6 \mathrm{in}$.) & 2.5 & 0 & 2.9 & 4.0 \\
\hline$S_{2}$ small (1/2 to 2 in.) & 1.3 & 0 & 0 & 0 \\
\hline$S_{3}$ very small $(<1 / 2$ in.) & 1.7 & 0 & $\underline{0}$ & $\underline{0}$ \\
\hline Total & 5.5 & 2.6 & 4.3 & 6.0 \\
\hline
\end{tabular}

Secondary Failure Definitions:

$D_{1}$ HPI $\quad-\quad$ Less than 1 of 3 HPI pumps taking suction from RWST and injecting into one of three cold legs.

$D_{5}$ ACCUM - For A: Less than 2 of 2 accumulators injecting into associated cold legs.

For $S_{1}$ : Less than 2 of 3 accumulators injecting into associated cold legs.

D $_{6}$ LPI $\quad-\quad$ Less than 1 of 2 LPI trains taking suction from RWST and injecting to 1 of 3 RCS cold legs.

$\mathrm{H}_{1}$ LPR $\quad$ - Less than 1 of 2 LPI pumps taking suction from the sump and injecting to MOV or charging pump suction. Also, for $A$ and $S_{1}$, switch to hot leg recirculation at $16 \mathrm{~h}$.

LOCA Assumptions:

$\begin{array}{lll}\text { A } & - & \text { One accumulator discharge is lost out the break. } \\ S_{1} & - & \begin{array}{l}\text { Accumulators required in absence of analysis to prove } \\ \text { otherwise. }\end{array} \\ S_{2} & - & \text { Includes non-isolatable stuck-open PORV with LOSP. } \\ S_{3} & - & \text { Includes local faults in one RCP seal. }\end{array}$




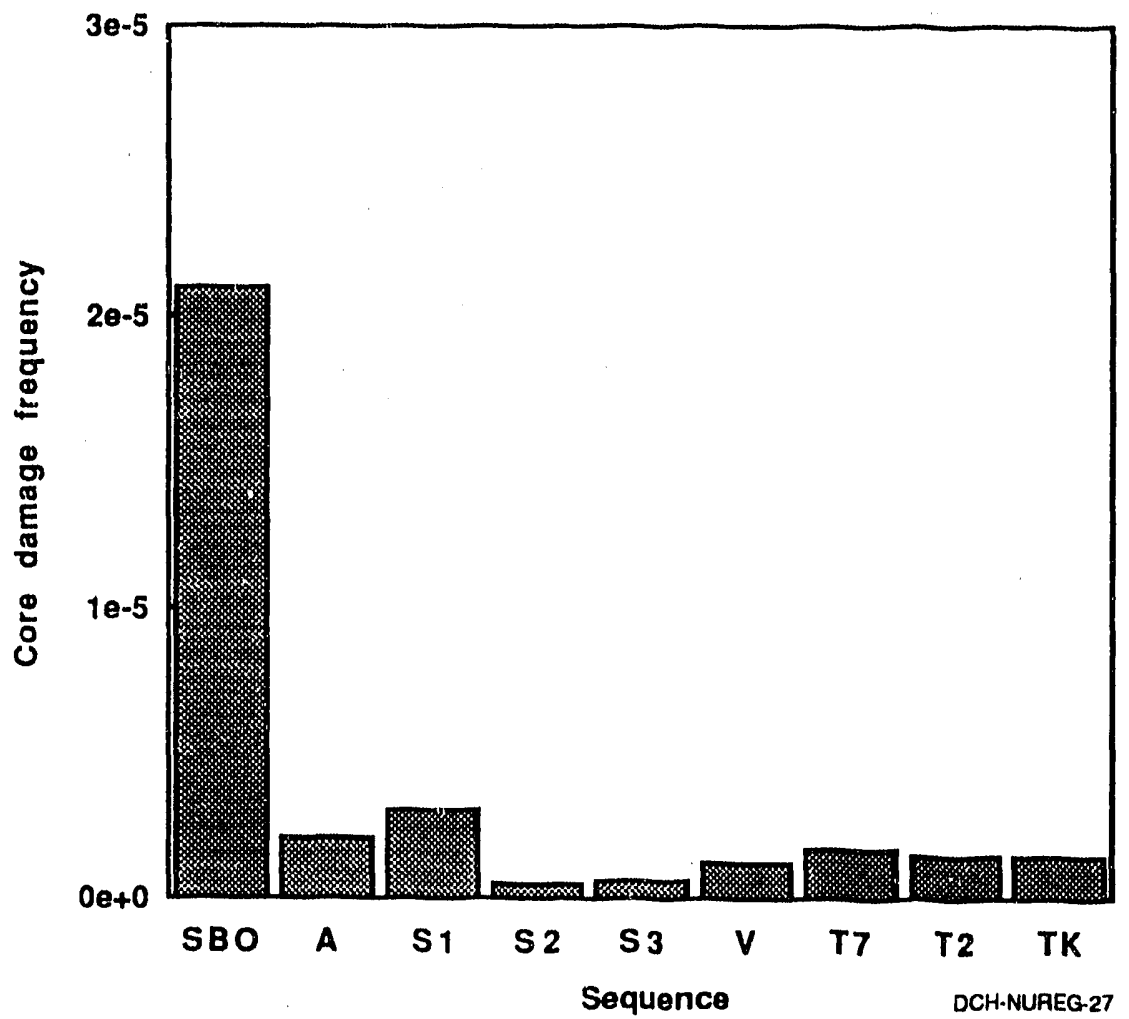

Figure A-1. Core damage frequency shown by sequence group.

directed to those sequences because improvements in station blackout risk can obviously improve the risk profile of the plant by a significant amount.

\section{A-1. Influence of Depressurization on Sequences}

To assess the potential influence of intentional depressurization on the core damage frequency at Surry, the sequences were reviewed to determine whether depressurization would be expected to reduce the risk. Four categories were developed and each sequence was assigned to a category depending on the potential for a reduction in core melt frequency based on the influence of depressurization. The four categories of sequences are: (a) low-pressure sequences in which the accident sequence itself results in an RCS pressure at vessel melt-through that may be below the DCH cutoff pressure; (b) sequences in which the RCS pressure cannot be reduced by opening the pressurizer PORVs; (c) sequences in which the assessment of CDF is not sufficiently defined to permit determining the effect of additional intentional depressurization; and (d) sequences that currently would lead to high-pressure melt ejection and which could be depressurized using the pressurizer PORVs. Table A-3 shows the assignment of the sequences to these categories.

As shown in Table A-3, the low-pressure category includes the large and medium LOCAs, which together constitute $15.4 \%$ of the total CDF. Another 3.7\% of the total CDF placed in this category is Event $V$, in which check valve failures result in the rupture of low-pressure piping outside containment. While early cooling is provided, the core is eventually uncovered at low RCS pressure because of the failure in the low pressure recirculation system. A final $2.6 \%$ of the total CDF is added to the low-pressure category by the ATWS manual scram-unfavorable moderator sequence in which the pressure cannot be 
Table A-3. CDF for sequences subject to preventive modification or depressurization

\begin{tabular}{|c|c|c|c|c|c|}
\hline \multirow[b]{2}{*}{ Sequence $^{\circ}$} & \multicolumn{5}{|c|}{ Current CDFa for Sequences by Depressurization Status } \\
\hline & Initiator & $\begin{array}{l}\text { Event Causes } \\
\text { Depressurization }\end{array}$ & $\begin{array}{c}\text { Operator } \\
\text { Depressurization } \\
\text { Not Possible } \\
\end{array}$ & $\begin{array}{c}\text { Operator } \\
\text { Depressurization } \\
\text { Not Applicable } \\
\end{array}$ & $\begin{array}{c}\text { Operator } \\
\text { Depressurization } \\
\text { Is Possible } \\
\end{array}$ \\
\hline \multirow{5}{*}{$\begin{array}{l}\text { SBO-L(TMLB') } \\
\text { SBO-QS-L early } \\
\text { SBO-QS-L late } \\
\text { SBO-Q } \\
\text { SBO-Q-QS }\end{array}$} & Station blackout & - & - & - & 1.6 \\
\hline & - & - & - & - & 4.2 \\
\hline & 一 & - & - & - & 8.4 \\
\hline & - & - & - & - & 5.1 \\
\hline & - & - & - & - & 1.6 \\
\hline \multirow{5}{*}{$\begin{array}{l}\text { SBO-SL } \\
\text { SBO-OD_SL } \\
\text { SBO-QS-SL } \\
\text { SBO-BATT } \\
\text { SBO-QS-BATT }\end{array}$} & - & - & - & - & 13.7 \\
\hline & - & - & - & - & 0.5 \\
\hline & - & - & - & - & 5.5 \\
\hline & - & - & - & - & 17.4 \\
\hline & - & - & - & - & 6.2 \\
\hline \multirow{5}{*}{$\begin{array}{l}\text { A-DS } \\
\text { A-D6 } \\
\text { A-H1 } \\
\text { S1-D1 } \\
\text { S1-D6 }\end{array}$} & Large LOCA & 2.6 & - & - & - \\
\hline & - & 1.4 & - & - & - \\
\hline & - & 2.0 & - & - & - \\
\hline & Medium LOCA & 2.5 & - & - & - \\
\hline & - & 2.9 & - & - & - \\
\hline \multirow{5}{*}{$\begin{array}{l}\text { S1-H1 } \\
\text { S2-D1 } \\
\text { S3-D1 } \\
\text { V } \\
\text { T7-OD-QS }\end{array}$} & - & 4.0 & - & - & - \\
\hline & Small LOCA & - & - & - & 1.3 \\
\hline & Very small LOCA & - & - & - & 1.7 \\
\hline & Interfacing LOCA & 3.7 & - & - & - \\
\hline & SG tube rupture & - & - & - & 3.7 \\
\hline \multirow{5}{*}{$\begin{array}{l}\text { T7-OD-D1 } \\
\text { T7-OD-Q-QS } \\
\text { T7-K } \\
\text { T7-L3 } \\
\text { T2-L-P }\end{array}$} & SG tube rupture & - & - & - & 0.5 \\
\hline & SG tube rupture & - & - & - & 0.3 \\
\hline & SG tube rupture & - & - & 0.3 & - \\
\hline & SG tube rupture & - & - & 0.3 & - \\
\hline & Main feediwater & - & 2.3 & - & - \\
\hline \multirow{3}{*}{$\begin{array}{l}\text { T2-L-D2 } \\
\text { TK-R-Z } \\
\text { TK-R-D4 }\end{array}$} & Main feedwater & - & - & - & 2.2 \\
\hline & ATWS & 2.6 & - & - & - \\
\hline & ATWS & $=$ & 1.7 & - & - \\
\hline \multicolumn{2}{|l|}{ Total } & 21.7 & 4.0 & 0.6 & 73.9 \\
\hline \multicolumn{6}{|c|}{ a. Percent of lotal of point-estimate frequencies for risk dominant sequences (point estimate frequency greater than 1.B-7 per reactor ycar). } \\
\hline \multicolumn{6}{|l|}{ b. Por sequences 8} \\
\hline \multicolumn{6}{|c|}{ c. Secondary events described in Table 1 . } \\
\hline
\end{tabular}


relieved and the RCS envelope fails. The sum for the low-pressure category is $21.7 \%$ of the total CDF.

The second category (pressure cannot be reduced with the pressurizer PORV/s) includes the main feedwater, AFW, and PORVs unavailable sequences, with $2.3 \%$ CDF. Also included in this category is the ATWS-manual seram-boration sequence, with $1.7 \%$ CDF. Because full RCS pressure is maintained, the charging pumps cannot deli er makeup and $t^{3}$, PORV s are insulficient to rejuce the RCS pressure. The sum for this caregory is $4.0 \%$ of the total CDF.

The third category ixcludes two steam generator tube rupture events. Depressurization in called for in the procedures for these events but here is uncertainty in accident progression for the continuation of depressurization below the secondary side pressure. Calculations were not performed for this condition. The thind category has a total CDF of $0.6 \%$.

The fourth caregory, sequeuces leading to high-pressure melt ejection which could be depressurized, includes $73.9 \%$ of the total CDF. As discussed in subsequent secions, sucuesfiul depressurization would delay core damage and would reduce RCS pressure at vessel meltthrough to a level that may prevent DCH. In the case of the Station Blackout sequences in this group (64.2\% of total CDF), it is also possible that depressurization would delay core damage for enough time that a recovery of ac power would occur is sufficient time that there would be minimal core damage. Because the station blackout category is predominant, the capability to depressurize for these sequences was chosen for evaluation. 


\section{REFERENCES}

A-1. R. C. Bertuito and J. A. Julius, Anabysis of Core Damage Frequency: From Insernal Events: Surry. Unit 1, NUREG/CR-4550, Revision 1, Volume 3, (Draft), September 1988.

A-2. U.S. Nuclear Regulatory Commission, Reactor Risk Reference Document, NUREG-1150, (Draft), Februsin' 1987.

A-3. U.S. Nuclear Regulatory Commission, Severe Accident Risks: An Assessment for Five U.S. Nuclear Reactors, NUREG-1150, (Second Draft), June 1989. 
APPENDIX B

DEPRESSURIZATION STRATEGIES

B-1 


\section{APPENDIX B}

\section{DEPRF.SSURIZATION STRATEGIES}

The possible strategies that might be used to depressurize the reactor coolant system (RCS) to prevent core heatup or mitigate the effects of direct containment heating (DCH) are summarized in this appendix. An understanding of the capabilities and limitations of a specific depressurization strategy can be gained by examining the phenomena that control RCS pressure. Any process that either removes mass and/or removes energy from the RCS faster than it is being generated will reduce RCS pressure. Possible strategies to accomplish this are secondary feed and bleed, primary feed and bleed, and intentional depressurization (blowdown) of the steam generator secondary or the RCS. If no action is taken by plant personnel, there may also be a high probability of an RCS pressure boundary failure of sufficient size to depressurize the system. The strategies are summarized in Table B-1.

Preventative depressurization strategies require that the energy flow out of the system be equal to or greater than decaly heat and, if there is mass flow out of the reactor coolant system, that the mass be replaced by the safety injection system or charging pumps. Secondary feed and bleed has, by design, the capacity to remove decay heat, and therefore control RCS pressure. The rate at which pressure is reduced is determined by the net rate of energy removal from the RCS and by whether the energy removal is by condensation or decreasing the average liquid temperature in the RCS. To remove energy from the RCS, the secondary temperature must be less than the RCS temperature. Thus for secondary feed and bleed, the lowest pressure to which the RCS can be reduced is the secondary side saturation pressure.

The Severe Accident Sequence Analysis (SASA) Program analyzed nuclear plant transients likely to lead to a severe accident. For a station blackout, all ac power except that derived from battery-driven inverters is lost. In the station blackout transient sequence, safety injection is not available and feed and bleed cannot be established. Analyses of station blackout sequences performed at the Idaho National Engineering Laboratory (INEL) ${ }^{l}$ under SASA's sponsorship provide a basis to conclude that if auxiliary feedwater is avallable or is recovered from about 10 to $28 \mathrm{~min}$ (a function of the plant analyzed) prior to core uncovery, or if ac power is restored 14 to $38 \mathrm{~min}$ prior to core uncovery (interpreted as no core damage), feed and bleed operations can be performed and core damage can be prevented. ' Because energy removal from the RCS prevents core heatup, piessure control is maintained, and no loss of RCS coolant inventory occurs, secondary feed and bleed would be the preferred method for controlling RCS pressure during an abnormal transient.

Primary feed and bleed has the capacity to remove decay heat and reduce pressure given that (a) the energy flow rate out the power operated relief valves (PORVs) is greater than decay heat and (b) the inflow from safety injection is sufficient to maintain the RCS coolant inventory. The depressurization rate is primarily a function of the total PORV flow area, the magnitude of the system pressure, the temperature of the RCS fluid, the amount of fluid remaining in the RCS, and the rate of energy addition from the core. It aiso depends on whether the flow out the PORVs is all steam or a two-phase mixture. A possible limit on the capability to depressurize using primary feed and bleed is the magnitude of the secondary pressure. If RCS pressure and temperature decreases to less than secondary pressure, then energy will be transferred from the secondary to

a. In both cases described, the analyses are plantspecific. While a broad interpretation about feed and blead may be generally appropriate, there may be specific plants that could require much earlier initiation of feed and bleed or unusual procedures to initiate feed and bleed. Also, Combustion Engineering's Systenı 80 plants, which do not have PORVs, are incapable of feed and bleed or direct primary system depressurization. 

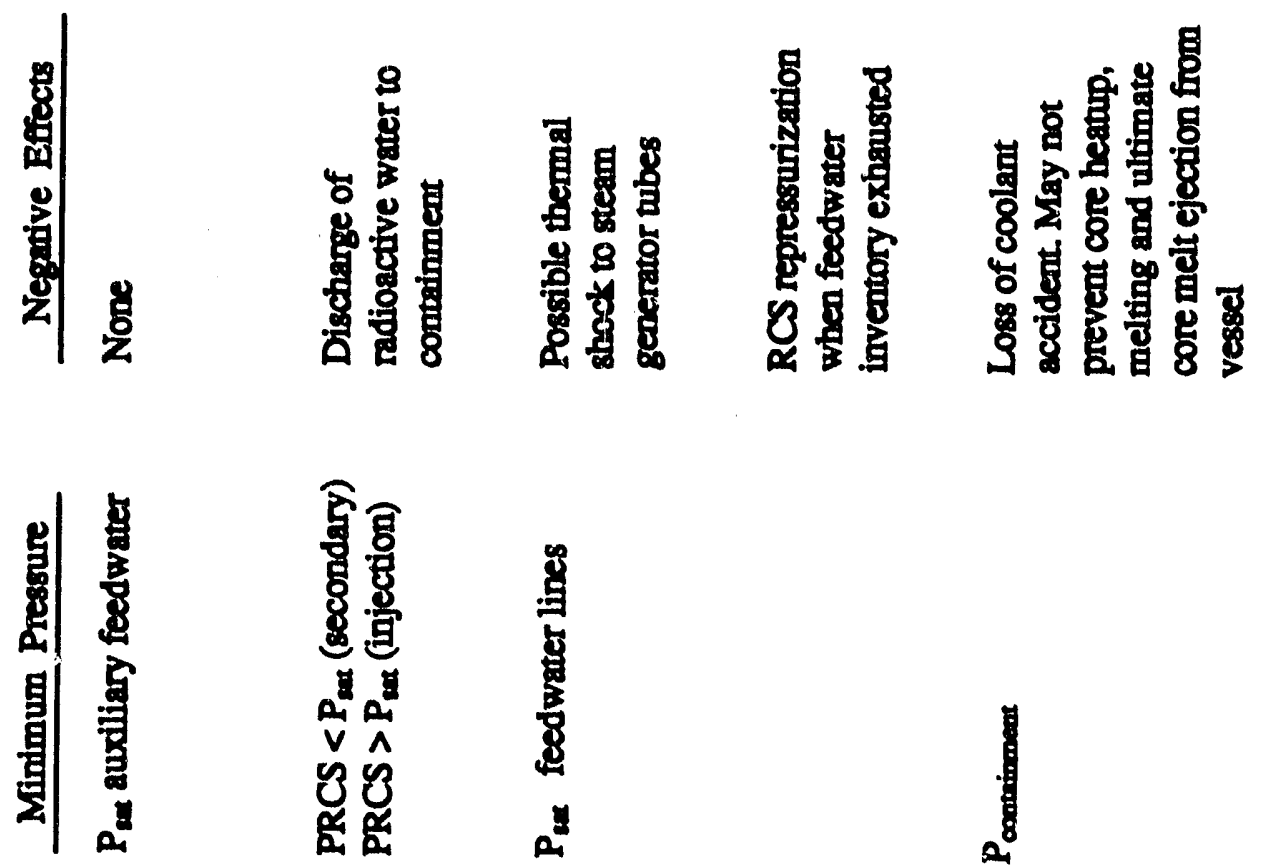

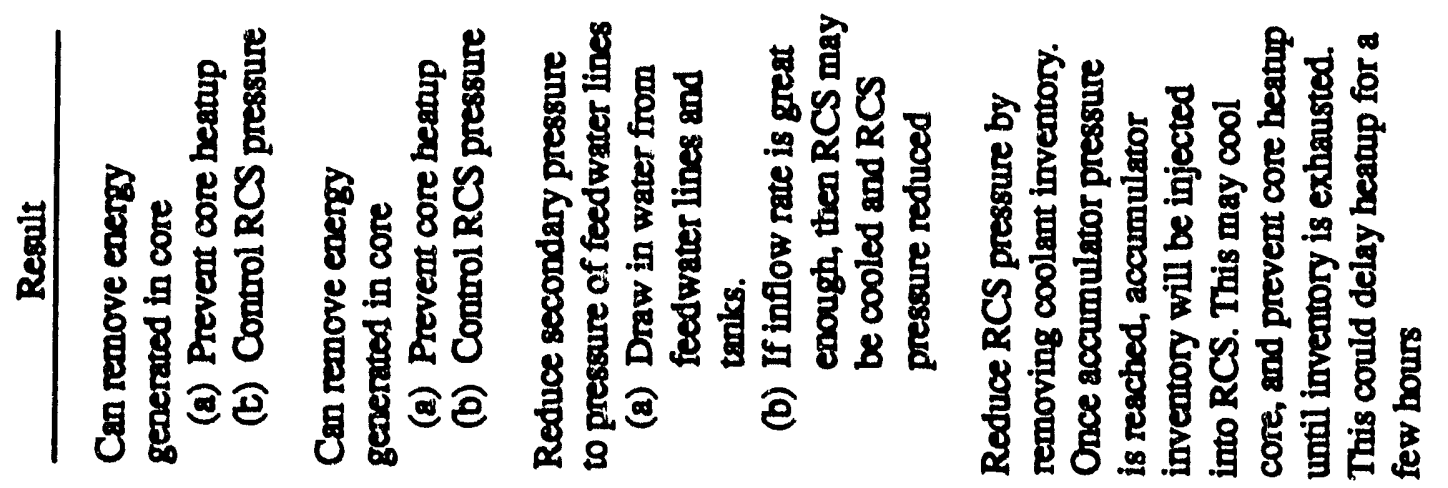

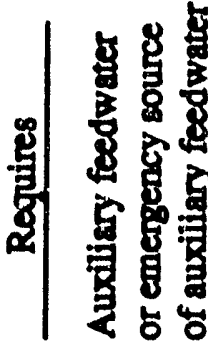
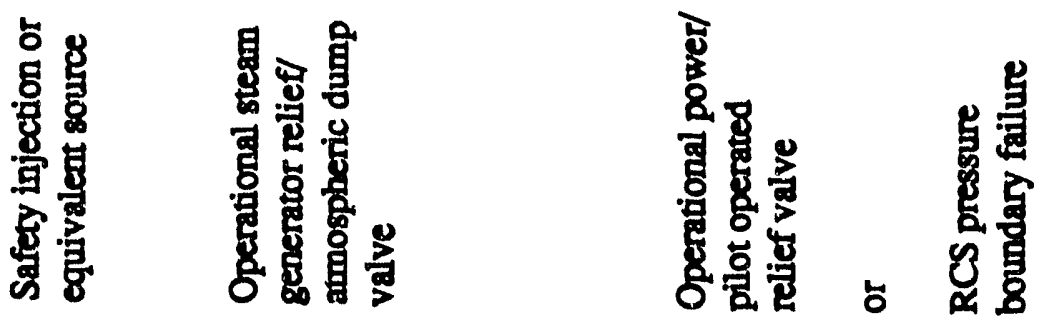

容

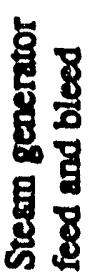

8
8
8
8
8
8
8

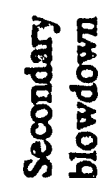

:
8
0
0
0
0
0 
the primary. The rate of heat transfer will depend on secordary conditions, such as water level and the availability of auxiliary feedwater. If the energy removal rate through the PORVs is less than the total energy input from the core and steam generators, then it is expected that RCS pressure will stabilize at a value betasy sicondary pressure. If the energy removal sht through the PORVs is large enough that depressirization continues, then the next possible limit is the saturation pressure of the RCS coolant. Thus, the minimum pressure is the saturation pressure at the minimum possible average RCS temperature. There has been extensive research conducted by the U.S. Nuclear Regulatory Commission (NRC) regarding the effectiveness of feed and bleed of the primary system. Loomis and Cozzuol ${ }^{2}$ reviewed research involving both experiments and calculations for primary system feed and bleed and concluded that this strategy is a viable technique to maintain control of primary system pressure and temperature. While primary feed and bleed has been estimated to be quite capable of preventing core heatup and capable of controlling RCS pressure, it is probably less desirable than secondary feed and bleed. (Large quantities of radioactive RCS coolant may need to be processed).

Intentional depressurization (blowdown) of the steam generator(s) may be useful, if auxiliary feedwater and primary feed and bleed are not available. Once the blowdown results in a steam generator pressure that is less than the pressure of the coolant remaining in the feedwater system, then that coolant may be drawn into the steam generators. The effectiveness of this strategy is dependent on: (a) the capability of the atmospheric dump valves or other valves to remove energy from the steam generator(s) in an amount equivalent to core decay heat levels; (b) the quantity of noncondensable gases that are flowing through or have accumulated in the steam generator U-tubes (these gases would cause degradation of steam generator heat transfer); and (c) the inventory of the coolant in the steam generator that is available to remove coro-generated energy. The minimum RCS pressure that can be attained corresponds to the minimum secondary pressure. This pressure is established by the saturation pressure for the coolant remaining in the feedwater system. Repressurization of the RCS will occur once the secondary coolant inventory has been exhausted if coolant cannot be added to the secondary.

Depressurization of the steam generators would not only remove energy from the RCS, but it could also provide the opportunity to feed the steam generators using pumps with low head capabilities. An example would be fire water pumps which generally produce a head of $:$ ' put $1 \mathrm{MPa}$ (145 psi). Because these pumps are diesel driven, they would be available for a wide variety of severe accident sequences. With the capability to direct the flow of these pumps to the secondary sides of the steam generators, they could be used to supply water as long as the secondary pressure remained low.

Intentional RCS depressurization (blowdown) using the PORVs has been calculated, using various codes, to be an adequate means of depressurizing the RCS. This strategy is discussed in detail in the body of this report.

If there are no actions taken by plant personnel, the RCS pressure boundary could fail during a severe accident. One potential failure mechanism would be high temperatures at the pump which could cause failure of the pump seal. Also,

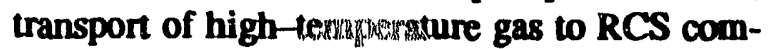
ponents, such as the pressurizer surge line, could lead to creeveruptaxtite or melting of these components. The effex these types of failure on the overall plant risi will be evaluated in a study currently being sponsored by the Nuclear Regulatory Commission. 


\section{REFERENCES}

B-1. R. D. Schultz, C. D. Fletcher, and T. R. Charlton, "Station Blackout in U.S. Light-Water Reactors, Nuclear Safety, 25, 4, July-August 1984.

B-2. G. G. Loomis and J. M. Cozzuol, "Decay Heat Removal Using Feed-and-Bleed for U.S. Pressurized Water Reactors," NUREG/CR-5072, EGG-2526, June 1988. 


\section{APPENDIX C}

\section{SCDAP/RELAP5 CODE DESCRIPTION}




\section{APPENDIX C}

\section{SCDAP/RELAP5 CODE DESCRIPTION}

The computer code used in the depressurization analysis was the SCDAP/RELAP5 code. ${ }^{\mathrm{C}-1}$ Although specific code models and modeling uncertainties were presented in Sections 3 and 4 of this report, a brief general description of the code is presented below.

SCDAP/RELAP5 is a light water reactor transient analysis code capable of analyzing plant transients, such as large- and small-break lossof-coolant accidents (LOCAs) and station blackouts (SBOs). The thermal-hydraulics portion of the code (RELAP5) ${ }^{\mathrm{C}-2}$ uses a one-dimensional, nonequilibrium hydrodynamic model. Each of the two phases, liquid and vapor, is represented by three equations (energy, momentum, and continuity) for each control volume. Heat transfer between the coolant and solid structures, such as pipe walls, fuel rods, and steam generator tubes, is modeled as a source within the control volume. One-dimensional conduction is used to model heat transfer within solid structures. Specific models are included for plant components, such as valves, accumulators, turbines, and control systems.

The severe core damage analysis package $(\mathrm{SCDAP})^{\mathrm{C}-3}$ models the energy generation and mechanical degradation of the fuel rods during a severe core damage accident sequence. SCDAP includes models for the following:

- Fuel rod ballooning and rupture

- Cladding oxidati on for both fuel and control rods and control rod guide tubes

- Double-sided oxidation of cladding if the fuel rod has ballooned and ruptured

- Candling of fuel rods
- Dissolution of fuel by molten cladding

- Formation of resolidified crusts

- Formation of molten pools

- Formation of rubble debris beds caused by fracture of embrittled cladding

- Failure of supporting crusts and relocation of molten corium to the lower plenum

- Heatup and failure of the lower head due to creep rupture or melting using a two-dimensional, finite-element heat conduction analysis.

As indicated by the above list of capabilities, SCDAP is capable of modeling many of the phenomena associated with core degradation during a severe accident sequence. Also, a flow area change caused by ballooning or fuel rod candling is fed through to the hydraulics calculation. Thus, an integrated severe accident and thermalhydraulics calculation can be performed.

In addition to the thermal-hydraulics and severe core damage analysis capabilities, the TRAP-MELT ${ }^{\mathrm{C}-4}$ fission product transport models have been integrated into the code. However, the fission product transport models were not utilized in the transient analysis.

The versions of the code used in the transient analysis were SCDAP/RELAP5/MOD0 cycle 62, SCDAP/RELAP5/MOD1 cycles 5 and 10, and SCDAP/RELAP5/MOD2 cycle 341 with updates. The updates were required to correct coding errors. The symptoms of the errors were water property table failures occurring in the RELAP5 code. The cause of the water property errors were related to energy transfer between SCDAP ard RELAP5. Error corrections have been included in subsequent versions of the code. 


\section{REFERENCES}

C-1. C. M. Allison et al., SCDAP/RELAP5/MOD2 Code Manual, I, II, III, NUREG/CR-5273, EGG-2555, September 1989.

C-2. V. H. Ransom et al., RELAP5/MOD2 Code Manual, $I$ and 2, NUREG/CR-4312, EGG-2396, August 1985.

C-3. G. A. Berna, C. M. Allison, and L. J. Siefken, SCDAP/MOD1/V0: A Computer Code for the Analysis of LWR Vessel Behavior During Severe Accident Transients, IS-SAAM-83-002, Rev. 1, July 1984.

C-4. H. Jordan, J. A. Giesk, and P. Baybutt, TRAP-MELT2 User's Manual, NUREG/CR-4205, BMI-2124, May 1985. 
APPENDIX D

INPUT MODELS

D-1 


\section{APPENDIX D}

\section{INPUT MODELS}

The SCDAP/RELAP5 input model of the plant includes all of the major components necessary to perform the analysis of intentional depressurization of the RCS during a station blackout sequence (SBO). It was assumed that the plant has sufficient battery and air bottle capacity for operation of the PORVs and that the F ORVS would function in a cyclic manner for the number of cycles required by the analysis. The input models were described in detail by Bayless. NO TAG The nodalization diagrams for the plant model are shown in Figures D-1 and D-2. The radial and axial power profiles are shown in Figures D-3 and D-4. For these calculations, hot leg countercurrent natural circulation was not considered to be a significant energy transport mechanism with the PORVs open and controlling flow in the RCS. Thus, fission product transport was not modeled in the depressurization calculations.

A 16 control volume model (see Figure D-5) of the Surry containment has been built to run with the MELCOR computer code. The model includes 35 flow connections between, and 52 separate heat structures within, those control volumes.

The majority of data used in this model was collected from a containment model built by Sandia National Laboratories (SNL) as input for the HECTR computer code. The data that were used in the SNL modei were supplied by Stone and Webster, the designer and constructor of the plant. The data included plane and crosssectional views of the facility, plus tables of data presenting control volume, flow path, and heat structure information. Scaled drawings were supplied by Surry plant personnel. Upon review of all of this information, some control volume size and flow connection alterations were made to the HECTR model.
The MELCOR nodalization differs from the HECTR model in one respect; an extra control volume was added by separating the reactor cavity and instrument tunnel into two separate cells. This will not affect the calculation for this particular accident sequence but might be important for a different sequence more directly involving the reactor cavity. The authors anticipated the possibility of using this sarne model for further containment response analysis.

Modeling was conducted on several more flow paths than were present in the HECTR model (35 opposed to 28). Several were found through examining the technical drawings of the Surry plant. Flow paths were added to model the drain gratings in the bottom of each steam generator room, doorways that were not previously modeled, and the extra requirements due to an additional control volume. All of the flow path loss coefficients came from the HECTR model. The values of these loss coefficients seemed quite high ( 0.1 to 1.8$)$ but may very well be appropriate.

Most of the heat structure data came from the tabulated values. All internal walls were modeled to one-half their actual thickness and a symmetry boundary condition. External walls were modeled at full thickness and also with a symmetry boundary condition; this could be changed to either a constant temperature on the outer surface or a convective boundary condition if an environment were modeled. Currently, the model has no heat transfer between control volumes nor heat losses from the facility via conduction through the heat structures. MELCOR will model heat structures with multiple compositions as one heat structure (e.g., concrete dome with steel liner), and this application was implemented. 


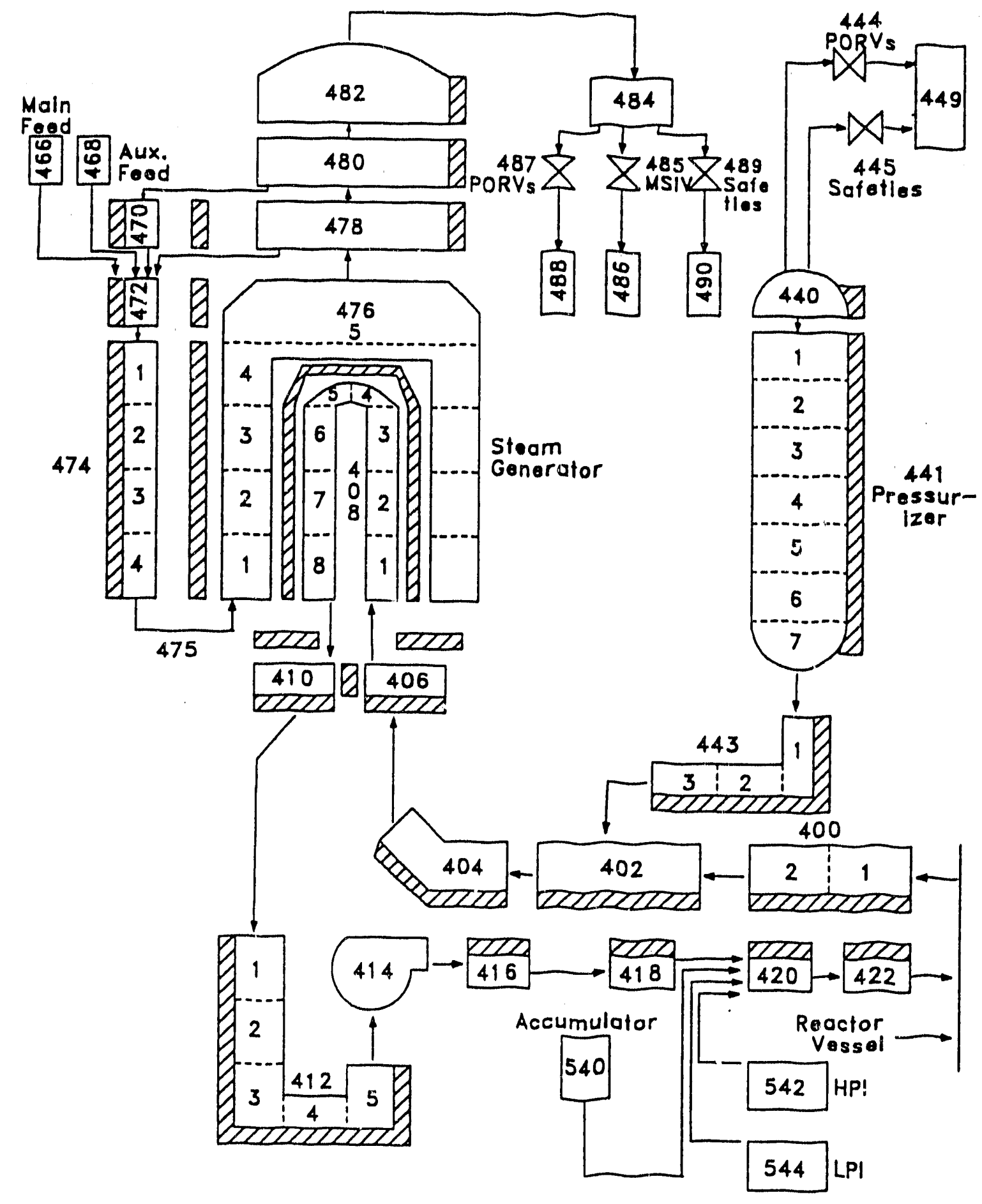

P428 5T-0245-01

DCH.NUREG.34

Figure D-1. Nodalization of the pressurizer loop for the SCDAP/RELAP5 calculations. 


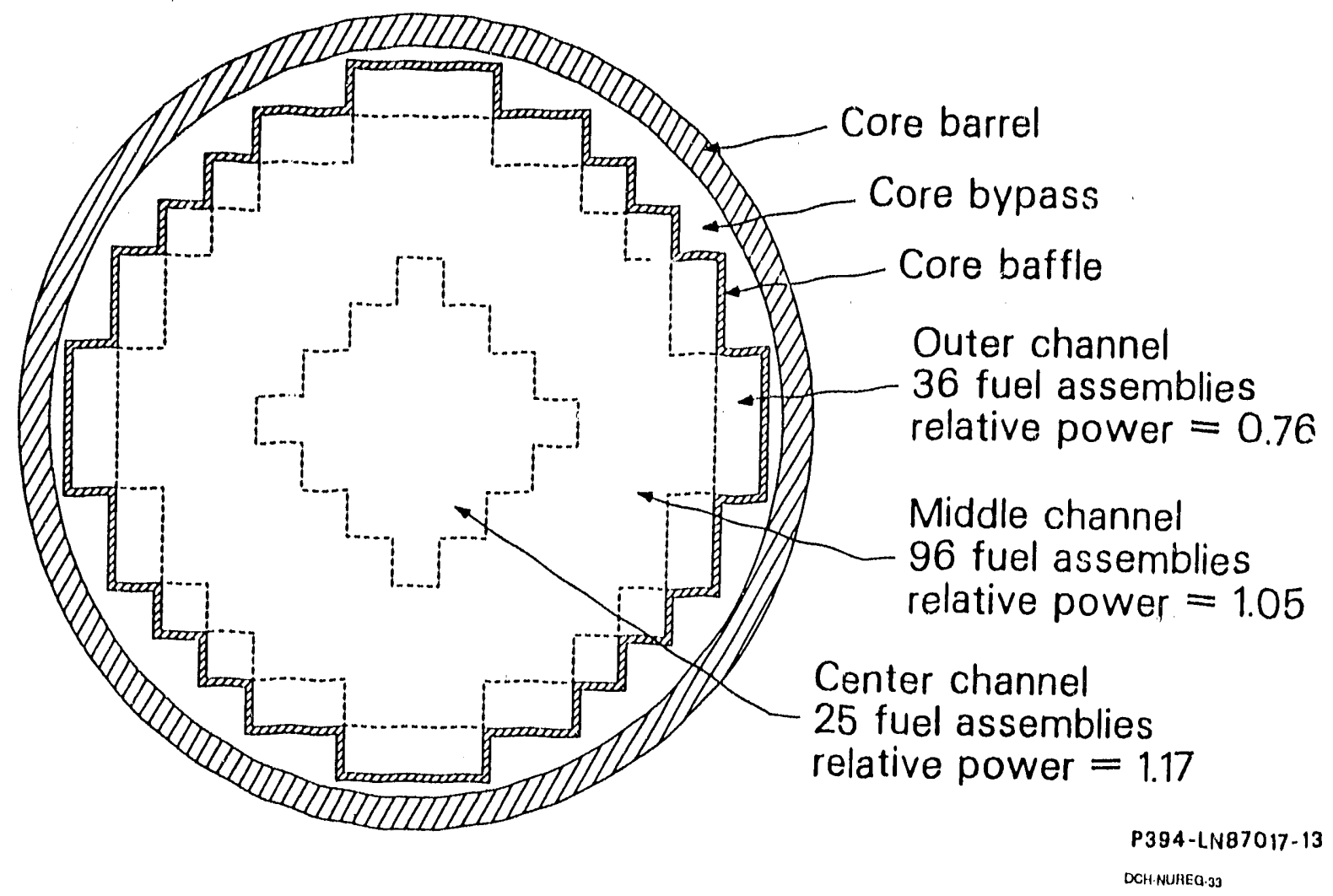

Figure D-3. Cross section of the core region.

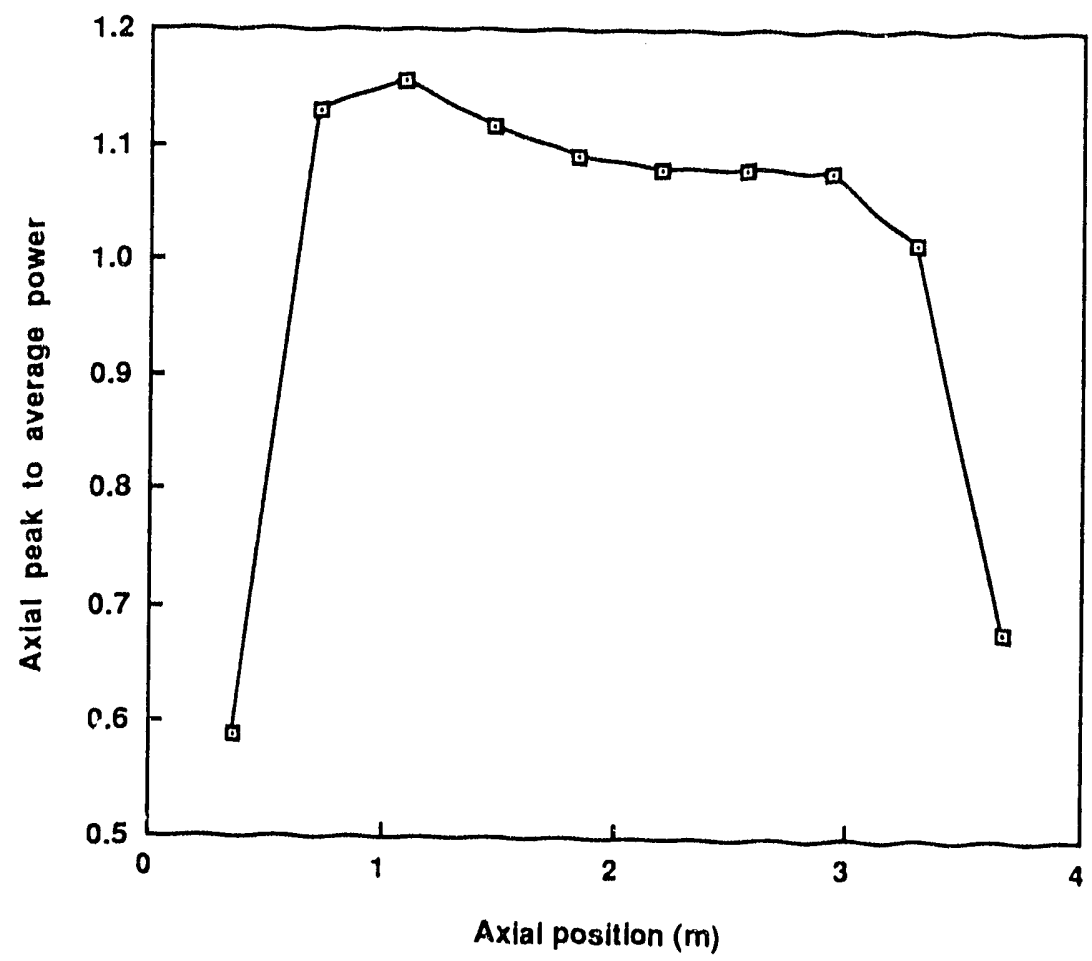

Figure D-4. Axial peaking factors used in the SCDAP/RELAP5 analysis. 


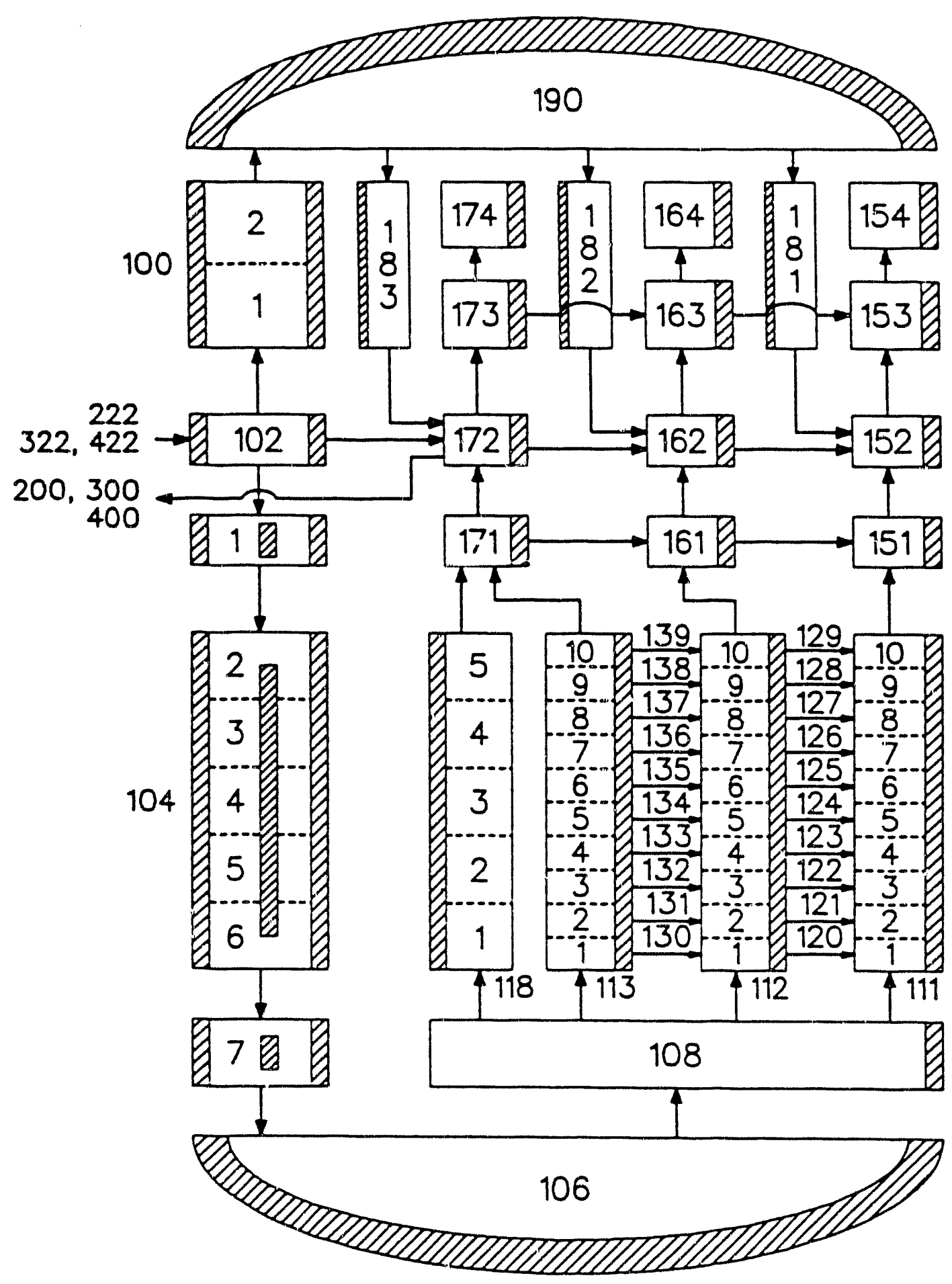

P394-LN87017-1

DCH.NUREG-3S

Figure D-2. Nodalization of the reactor pressure vessel for the SCDAP/RELAP5 calculations. 


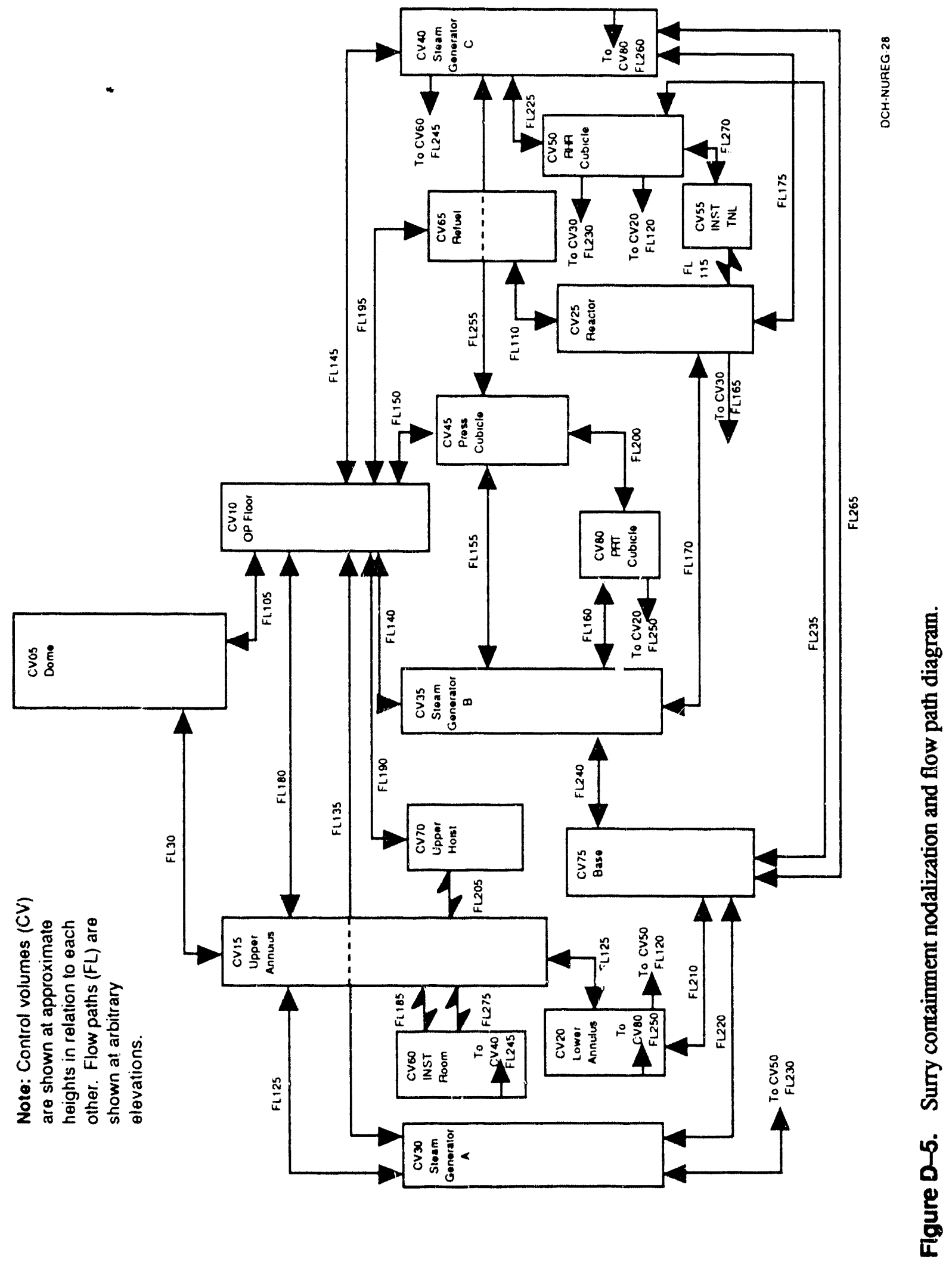




\section{REFERENCES}

D-1. P. D. Bayless, Analyses of Natural Circulation During a Surry Station Blackout Using SCDAP/ RELAP5, NUREG/CR-5214, EGG-2547, October 1988. 


\section{APPENDIX E}

CORE MELT PROGRESSION 


\section{APPENDIX E}

\section{CORE MELT PROGRESSION}

The following two strategies have the capability to intentionally depressurize the RCS: (a) feed and bleed of the steam generators and (b) use of the RCS power operated relief valves and reactor vessel upper head vent lines. The use of the steam generator feed and bleed would be preferred over other mitigative depressurization strategies if it could be implemented and was effective during an accident. This strategy could have limited effectiveness if the inventory of the RCS was mostly depleated or if the effectiveness of the heat transfer from the RCS to the steam generator was restricted. An example of a heat transfer restriction would be the accumulation of relatively large quantities of hydrogen or other noncondensable gases inside the steam generator tubes.

Extensive research sponsored by the NRC and others on feed and bleed confirms the use of this straiegy as a viable technique to prevent core uncovery. The research results also provide a data base to assess the adequacy of code models that are intended to predict plant thermal-hydraulics during feed and bleed. Experiments conducted in the Loss of Fluid Test Facility (LOFT), Semiscale, MIST, OTIS, and ROSA-IV form the assessment data base for analytical tools such as RELAP5 ${ }^{\mathrm{E}-1, \mathrm{~B}-2}$ and TRAC. ${ }^{\mathrm{B}-3}$ Loomis and $^{\mathrm{B}}$ Cozzoul' $\mathrm{s}^{\mathrm{B}-4}$ review of feed and bleed included a review of code comparisons for both RELAP5 and TRAC to the experimental data. They concluded that the codes predicted the phenomenology of feed and bleed but did not match event timing as well.

The analyses presented in this report consider depressurization by opening the PORVs. It is expected that the flow through the PORVs will be choked (limited to sonic or critical velocity) until the RCS pressure is nearly equal to the containment pressure. Therefore, the performance of the critical flow model in SCDAP/RELAP5 is of particular importance. The SCDAP/RELAPS critical flow model calculates the velocity of sound in a two-phase, two-component mixture based on the equation of state. ${ }^{\mathrm{B}-5}$ The critical flow model at low quality has been identifi(xd by tie International Code Assessment Program (ICAP) ${ }^{\mathrm{B}-6}$ as one of the three main code deficiencies. The discrepancy was found to be most notable for a small break with low-quality, saturated flow that occurred over an extended period of time. At the time the PORVs are assumed to be latched open, it is expected that the pressurizer will rapidly drain or will have already drained. A saturated, lowquality flow will exist at the PORVs for at most a brief time. Therefore, the uncertainties associated with the critical flow model should not have a significant effect on the results.

The first damage to a fuel rod that is likely to occur is rod ballooning. ${ }^{\mathrm{B}-7}$ Ballooning is identified by a localized increase in the cladding outer diameter. This enlargement can appear as a localized blister or as a more generalized increase in the outer diameter. For ballooning to take place, the cladding temperature must be above about $900 \mathrm{~K}$ and the internal pressure of the rod must be greater than the RCS coolant pressure. As cladding temperature increases, the cladding mechanical strength decreases and can stretch outward (balloon) away from the fuel pellets, depending on the internal pressure of the rod and circumferential temperature gradients. By the time cladding temperature reaches $1200 \mathrm{~K}$, it is likely that the cladding will have ruptured in the ballooned region. The extent to which the cladding stretches before rupture (total circumferential elongation) is primarily a function of the zircaloy crystal phase (temperature), heating rate, difference in pressure between the fuel rod and the RCS coolant, and the circumferential temperature difference at the start of ballooning. High heating rates or large circumferential temperatune differences (as litule as about $5 \mathrm{~K}$ around the cladding) will limit ballooning to the formation of a blister. With low heating rates and essentially zero circumferential temperature difference, it may be possible to form large balloons that stretch over some 
length of the fuel rod (sometimes called sausage balloons). The presence of balloons will alter flow patterns within the core and alter the heat transfer rate from the fuel pellet to the ballooned region of cladding.

The second state of fuel rod damage is oxidation of the zircaloy cladding. ${ }^{\mathrm{E}-7, \mathrm{~B}-8}$ At temperatures above about $1200 \mathrm{~K}$, the presence of oxygen (steam) in the coolant results in exothermic oxidation of the cladding. The cladding temperature then rapidly escalates. Control rod material will melt and fail the stainless steel cladding at the melting temperature of stainless steel $(1720 \mathrm{~K})$. Metallic zircaloy melts at about 2100 to $2200 \mathrm{~K}$ but is retained by the outer layer of oxidized cladding. The metallic zircaloy has the capability to dissolve at least some of the fuel and oxidized zirculoy, forming a U-Zr-O (corium) mixture. The temperature of the cladding continues to escalate; eventually, the oxide shell fails and the molten mixture flows down the the outside of the fuel rod, much like molten wax flows down the side of a candle. Hence, the process at this point is often called candling of the fuel rods. The candling corium will resolidify at some point down the fuel rod once sufficient heat has been transferred either to the coolant or the fuel rod. Freezing tends to occur at or near the water line within the core or at cold spacer grids. Freezing of the candling flow will eventually cause the flow channel to be blocked to both the downward flow of candling corium and the upward flow of coolant. At this time, the core consists of highly oxidized cladding in the upper regions and a solid crust lower in the core, depending on the water level and temperature distribution within the core. Below the water level fuel rods are essentially undamaged. The crust can act as a vessel to contain molten material. Thus, a molten pool can be formed and contained within the core region of the RPV. Also, the injection of water into the upper region of the core can cause the oxidized cladding to cool sufficiently to become embrittled and fail due to mechanical and/or thermal shock. Thus, a rubble debris bed can be formed in the upper region of the core. Formation of a rubble debris bed increases the surface-area-tovolume ratio of the cladding and fuel and may make more metallic cladding surface available for oxidation, increasing the energy input through the coolant. Ultimately, the crust may fail, causing the flow of molten corium downward to the lower plenum. With molten material resting on the RPV lower head, the lower head may heatup and fail. During the TMI-2 accident, all of these events, except lower head failure, occurred and the scenario for their occurrence is described in Reference E-9. While the TMI-2 accident was a severe accident with the features described above, it may not be typical of all severe accident scenarios; there remains some uncertainty as to what constitutes a typical severe accident.

A datum for sequences leading to late-phase core melt progression (formation of a molten pool in the core region and relocation of molten material to the lower plenum) is represented by the TMI-2 accident. The TMI-2 accident was a small-break LOCA through the stuck-open PORV without adequate safety injection. (The operators bypassed safety injection early in the accident.) Eventually, the core uncovered and approximately $50 \%$ of the core melted. About 20 tons of the molten material flowed to the lower plenum. The RPV did not fail, and the molten material in the reactor vessel was cooled after safety injection was established by the operators. Since the accident embodies many of the possible events in a severe accident and is a unique datum for LWRs, the TMI-2 analysis is being conducted through the sponsorship of the Committee on the Safety of Nuclear Installations (CSNI) to benchmark severe accident analysis codes. ${ }^{\mathrm{B}-10}$ User: and developers of many of the severe accident analysis codes, including SCDAP/RELAP5 and MELPROG/TRAC, ${ }^{\mathrm{E}-11}$ are participating in the analysis exercise.

Up to the time of initial core melting, most of the codes match the recorded plant data-such as RCS pressure-reasonably well. Preliminary results from the various codes have a relatively wide spread beyond initial core melting, while generally following the trend of the recorded RCS pressure. This was particularly evident in the calculations of total hydrogen generation. The calculated total hydrogen at $174 \mathrm{~min}$ (the end time of the first two phases of the analysis 
exercise) varied from about 100 to $460 \mathrm{~kg}$. This compares to an estimated release of about $300 \mathrm{~kg}^{\mathrm{B}-12, \mathrm{~B}-13}$ at $174 \mathrm{~min}$. Similar variances occurred for other calculated quantities. It is noted that some of the boundary conditions, particularly the high-pressure injection rate, may have large uncertainties due to the lack of recorded flow measurements. Because an effort has been made to compare the codes based on a common set of boundary conditions, the variations noted are apparently real. Therefore, it is concluded that there are potentially large uncertainties in the core damage progression models that need to be accounted for in an analysis of intentional depressurization.

Because of the significant uncertainties in severe accident calculations, and because the time to reactor vessel breach is many hours, the analytical approach to model late-phase core melt progression attempts to bound the uncertainties in the core melt progression parameters that are believed to affect RCS pressure. The methodology shown in Figure $\mathrm{E}-1$ relies on performing calculations to target core damage states. This methodology is described in Section 2.3 of the report.

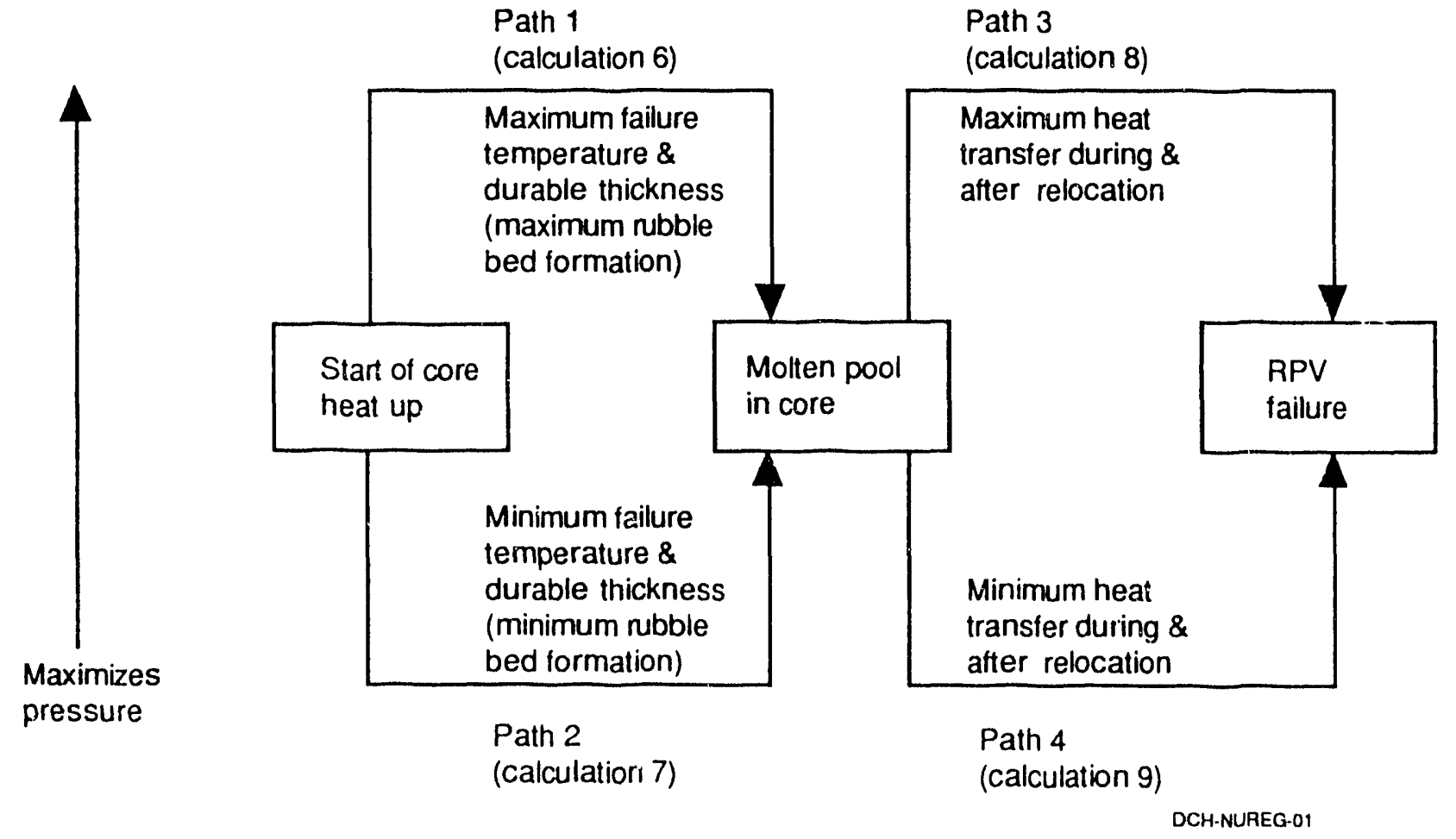

Flgure E-1. Calculation paths used for core damage parameter study. 


\section{REFERENCES}

E-1. V. H. Ransom et al., RELAP5/MODI Code Manual 1: System Models and Numerical Models, NUREG/CR-1826, EGG-2070, November 1980.

E-2. V. H. Ransom et al., RELAP5/MOD2 Code Manual, NUREG/CR-4312, EGG-2396, August 1985.

E-3. D. Liles et al., TRAC-PF1/MOD1, NUREG/CR-3858, LA-1057-MS, July 1986.

E-4. G. G. Loomis and J. M. Cozzuol, Decay Heat Removal Using Feed-and-Bleed for U.S. Pressurized Water Reactors, NUREG/CR-5072, EGG-2526, June 1988.

E-5. V. H. Ransom and J. A. Trapp, "Sound Speed Models for a Noncondensable Gas-Steam-Water Mixture," Proceedings of the Japan-U.S. Seminar on Two-Phase Flow Dynamics, Lake Placid, New York, July 29-August 3, 1984.

E-6. W. E. Driskell and R. G. Hanson, "Summary of ICAP Assessment Results for RELAP5/MOD2," Transactions of the Sixteenth Water Reactor Safety Information Meeting, Gaithersburg, Maryland, October 24-27, 1988.

E-7. J. M. Broughton, D. W. Golden, and D. L. Hagrman, "Analysis of the PBF In-Pile Large Break LOCA Tests Results with FRAP-T6/BALON-2," ASME Paper 82-HT-65, 1982.

E-8. C. M. Allison et al., SCDAP/RELAP5/MOD2 Code Manual, I, II, III, NUREG/CR-5273, EGG-2555, September 1989.

E-9. J. M. Broughton, P. Kuan, D. A. Petti, E. L. Tolman, "A Scenario of the TMI-2 Accident," Nuclear Technology, 87, 1, August 1989.

E-10. D. W. Golden et al., "Summary of the TMI-2 Analysis Exercise," Nuclear Technology, 87, 1, August 1989.

E-11. W. Camp, J. Tomkins, T. Heames, and J. Dearing, "Physical Modeling of the In-Vessel Phases of Severe Reactor Accidents - The MELPROG/TRAC Computer Code," International Symposium on Severe Accident in Nuclear Power Plants, IAEA-SM-296/97, Snrrento, Italy, March 21-25, 1988.

E-12. J. O. Henrie and A. K. Postma, Lessons Learned from Hydrogen Generation and Burning During the TMI-2 Event, GEND-061, May 1987.

E-13. P. Kuan, Assessment of TMI-2 Plenum Assembly Damage, EGG-TMI-8020, April 1988. 
APPENDIX F

EVALUATION OF PORV TEMPERATURE RESPONSE FOR LATE DEPRESSURIZATION 


\section{APPENDIX F}

\section{EVALUATION OF PORV TEMPERATURE RESPONSE FOR LATE DEPRESSURIZATION}

The Surry depressurization strategies require the PORVs to remain fully open from depressurization initiation until RCS failure. The assumption inherent in the depressurization strategies is that the PORVs are operable under the environmental conditions associated with the event. If PORV structure temperature in the vicinit:; of the valve stem packing exceeds the design temperature of the packing material, the packing may fail. Leakage of high pressure steam through the failed packing could potentially fail the valve actuator and cause the PORV to close. To test the validity of the assumption that the PORV would survive the depressurization strategies, a calculation was performed to determine the Surry pressurizer PORV structure temperature during a TMLB' station blackout sequence with late depressurization up to the time of lower head failure. The following describes the assumptions made and analytical methodology used to determine the temperature response of the Surry PORVs for a TMLB' with DCH mitigated using the late depressurization strategy.

The first assumption involved extending the late depressurization calculation to the time of lower head failure. Because the desired result of the calculation is the temperature response of the PORV, time-dependent pressure and temperature in the hot leg at the surge line connection is required. As the extension of the late depressurization calculation would require a substantial amount of computer resources, a decision was made to determine the hot leg pressure and temperature response following core relocation and use it as time-dependent input to a SCDAP/ RELAP5 model of the Surry surge line, pressurizer, and relief valves. The final assumption concluded that the core relocation into the lower plenum calculated for the early depressurization calculation would be the same as those calculated for the late depressurization calculation if it were extended.

At the end of the late depressurization calculation, the RCS pressure and lower plenum water inventory were similar to those observed for the early depressurization calculation just prior to the time of core relocation. These two parameters dominate the magnitude and duration of the RCS pressure increase following core relocation, which provides the potential for flow through the PORVs. The most notable difference in the calculated results was the higher RCS pressure in the early depressurization calculation that resulted from the higher calculated containment pressure. The differential pressure from the hot leg to the containment and, therefore, calculated flow through the PORVs were similar in the two calculations. Given the assumption that core relocation and resultant steam production would be similar in the two calculations, the hot leg pressure and temperature history and time to lower head failure relative to the initiation of core relocation for the early depressurization calculation was used to extend the late depressurization calculation.

The next step was to determine when the core relocation would occur in the late depressurization calculation. Based on a comparison of the SCDAP/RELAPS results of the two calculations relative to the extent of core damage and core temperature, it was estimated that the core relocation would occur between 30 and 60 min after the late depressurization calculation was terminated.

Estimates of debris heatup rates for the late depressurization case to the core relocation initiation temperature observed in the early depressurization calculation produced a range of core relocation times from $10 \mathrm{~min}$ earlier to $60 \mathrm{~min}$ later than that calculated for the early depressurization calculation. This variability was related to the amount of cladding oxidation assumed for the late depressurization extension. For the subject analysis, core relocation was assumed to occur at $450 \mathrm{~min}, 40 \mathrm{~min}$ after the late depressurization calculation was terminated. because the RCS was essentially at containment pressure at this time, the flow through the PORVs will be low $[<0.5 \mathrm{~kg} / \mathrm{s}(1.1 \mathrm{lbm} / \mathrm{s})]$ and extending the time to core selocation would have a mininal effect upon 
PORV structure temperatures. The hot leg temperature and pressure calculated at the end of the late depressurization calculation were assumed to remain constant over this period based upon the observed RCS response in the early depressurization calculation.

The SCDAP/RELAP5 model used for the calculation is shown in Figure F-1. The model included the pressurizer surge line, pressurizer, relief valves, and a section of the Loop C hot leg piping at the surge line connection. This part of the model was extracted from the SCDAP/RELAP5 model used for the depressurization calculations. The model was expanded to model the relief piping between the pressurizer and the PORVs. This line consists of $3.78 \mathrm{~m}(12.4 \mathrm{ft})$ of 4 in. and $4.45 \mathrm{~m} 14.6 \mathrm{ft}$ ) of $3 \mathrm{in}$. uninsulated stainless steel pipe. A constant heat transfer coefficient $t^{R_{1}-1}$ of $28.4 \mathrm{~W} / \mathrm{m}^{2}-\mathrm{K}\left(5.00 \mathrm{Btu} / \mathrm{hr}-\mathrm{ft}^{2}-\mathrm{F}\right)$ was applied to the outside surface of the relief piping for heat transfer to containment. This value represents a high natural convection heat transfer coefficient and does not consider radiation heat transfer effects that may occur at high temperatures. The hot leg component was changed to a time-dependent volume to provide the RCS conditions in the hot leg at the surge line connection.

Due to the coarse surge line nodalization, lack of internal pressurizer structures (primarily heaters and support structures), and adiabatic surfaces used in this model, the steam temperature at the PORV would be higher than expected. Because the PORVs are simulated with SCDAP/RELAP5 as junctions, the structure of the PORVs cannot be directly modeled. The PORV structure temperature was simulated with the upstream relief valve piping structure temperature. This approach will slightly overestimate the temperature at the PORV stem packing as the relief valve piping is

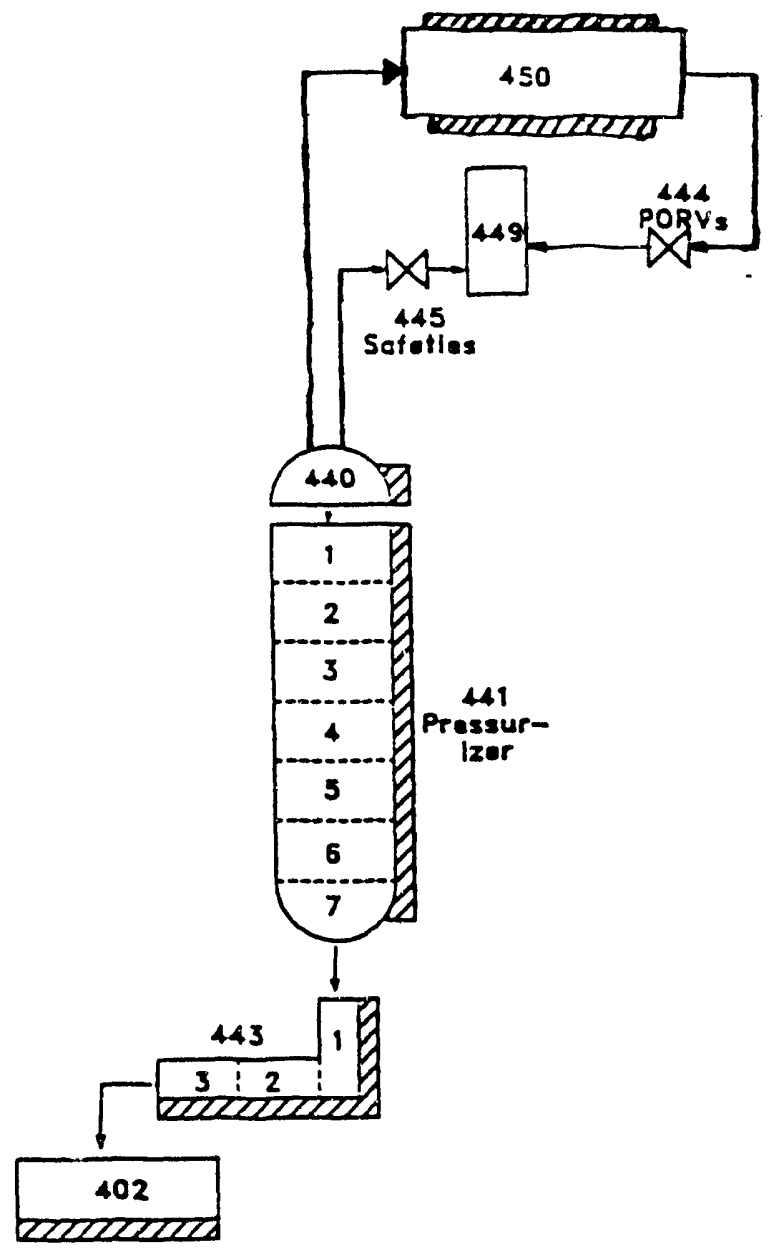

Figure F-1. Nodalization used for the late depressurization ex'ension calculations. 


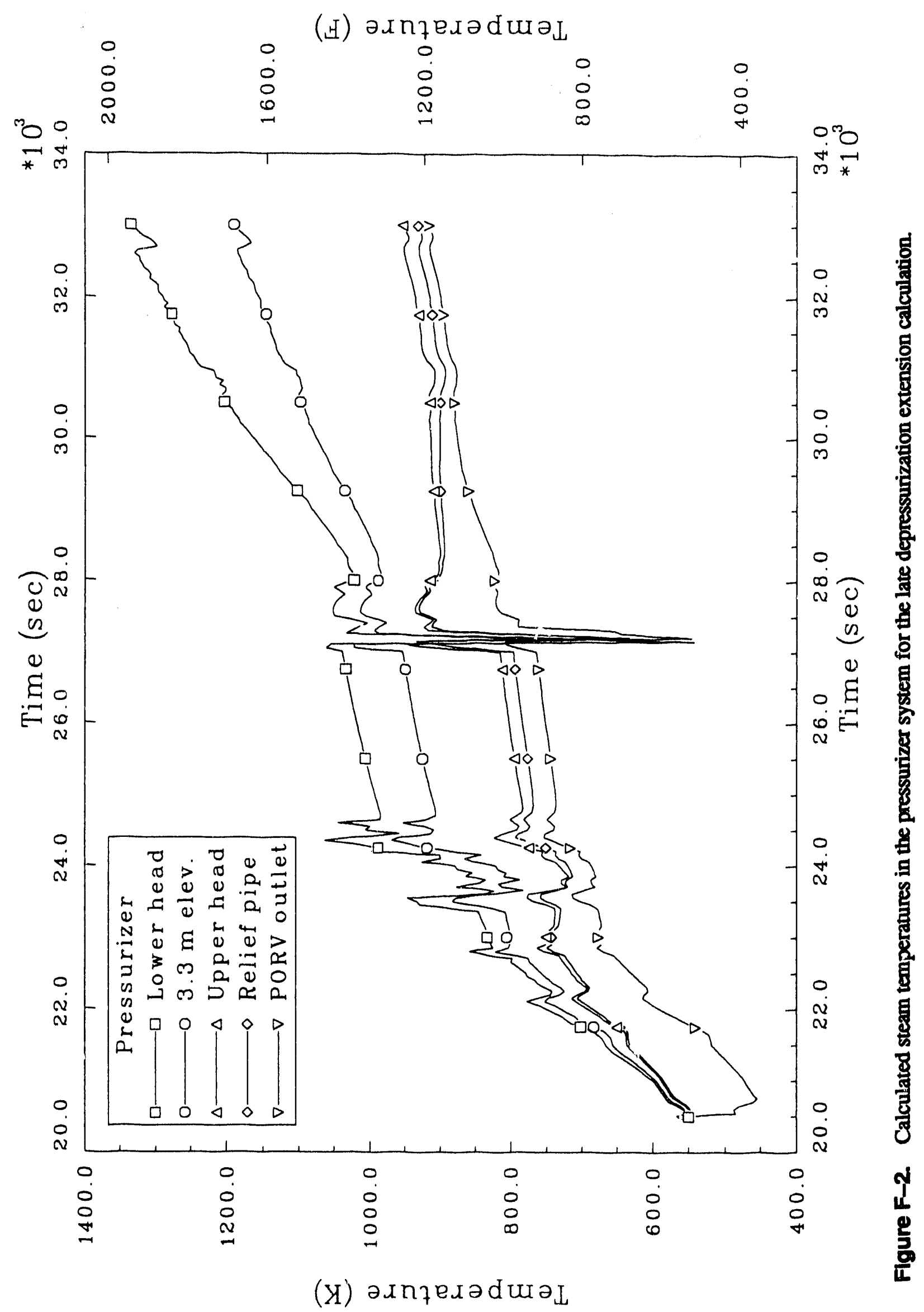


thin walled compared to the PORV stnucture and the upstream steam temperanures are higher than those in the PORV due to heat transfer to containment. The model was initialized to the temperature (fluid and structure) and flow conditions that exist at the end of the late depressurization calculation.

The separate effects SCDAP/RELAPS input deck of the Surry pressurizer system was set up to simulate the core relocation phase of the late depressurization callculation. Hot leg C calcuLationd data was extracted from the two depressurization calculations and provided as timedependent data. The dectr was initialized to the late depressurization calculated results at 20,500 s (341.7 mib) wh are the RCS coolant and anuctures approach samuration temperature. The containment pressure was fixed at $0.6 \mathrm{MPa}$ from transient initiation until the beginning of cor. selocation in reflect the pressure calculated it the Late depressuriz stion calculacion to produce similar PORV flow rates. The pressure was then ranped up to $1.0 \mathrm{MPa}$ to match the value used in the earty depressurization calculation, again to produce similar PORV flow rates. As detriled in the discussion of the early depressurizaxion calculation extension, the lower head failure attributable to creep ruprure was assumed to occur at approximately $33,000 \mathrm{~s}$ (550 min). The calculation was stopped at this time.

The calculated steam temperatures and volume average structure temperatures are shown in Figures F-2 and F-3, respectively. The steam temperatures decrease dramatically at $27,100 \mathrm{~s}$ when the core relocation vaporizes the lower plenum liquid and the vapor is swept out of the PORV. The steam temperature gradient was observed to be large through the pressurizer due to the large thermai mass of the pressurizer structure and low steam velocities. Conversely, the temperanure gradient was small across the surge line and relief live due to the small thermal mass and high velocities. The structure temperatures reflect this behavior. The pressurizer structure temperatures at the end of the calculation are still weil below the steam temperatures. The surge line and relief piping structures are closer to the associated steam temperanures again because of the lower thermal mass of the structures. As shown in Figure F-3, the relief piping temperature remains below $922 \mathrm{~K}\left(1200^{\circ} \mathrm{F}\right)$ for the entire calculation. This, plus the fact thas the pressure in the PORV is essentially contxinmert pressure during most of the calculation, indicates that packing failure and steam leak ge induced failure of the actuator are highly unlikely.

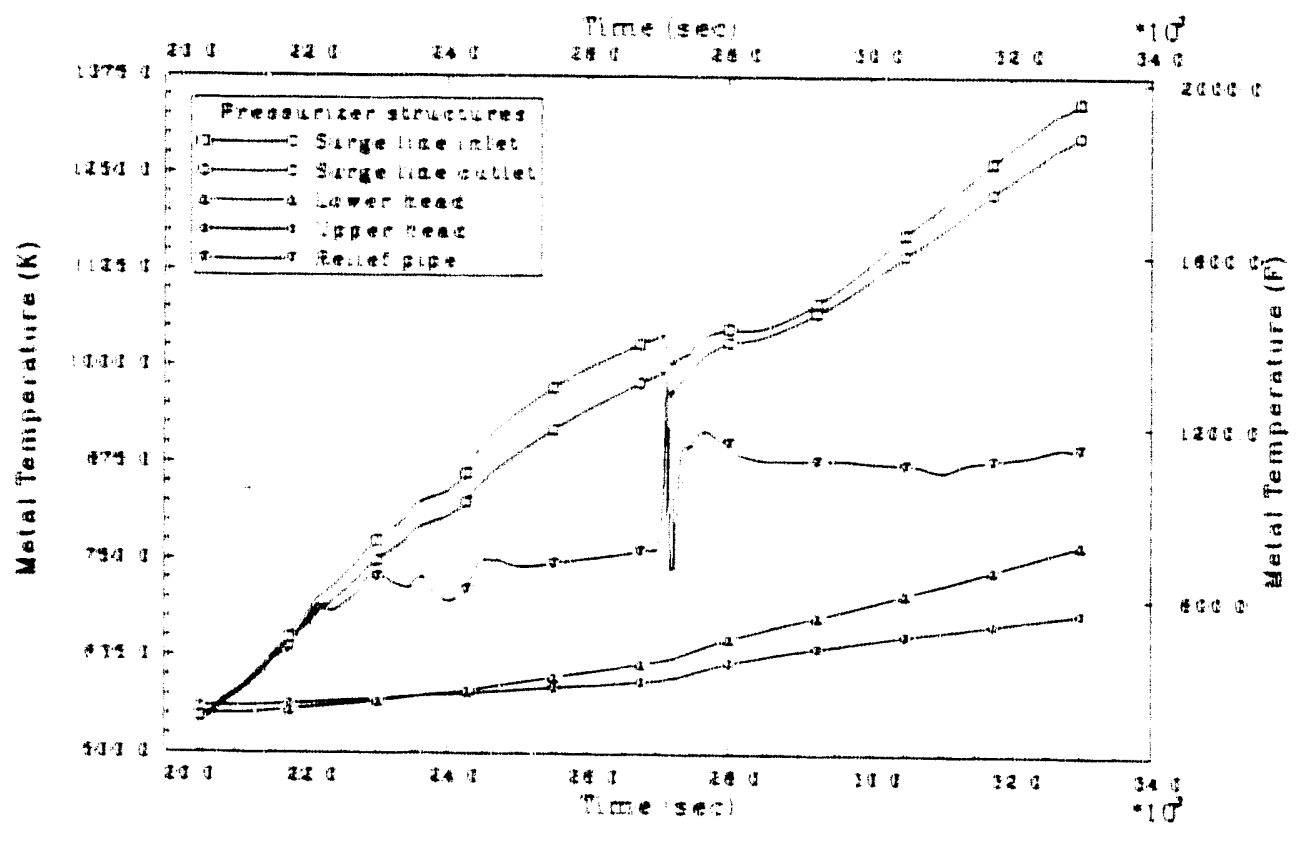

Fgure F-3. Cakculated average metal temperaures in the pressurizer system for the late depressuriation extersion caloulation. 


\section{REFERENCES}

F-1. R. J. Dallman, P. D. Bayless, R. Chambers, and J. T. Han, "Heat Transfer Effects in Severe Accident Integrai Analysis," Proceedings of the 1988 National Heat Transfer Conference - 2, Houston, Texas, July 24-27, 1988. 


\section{APPENDIX G \\ EMERGENCY OPERATING PROCIEDURES}

G-1 


\section{APPENDIX G}

\section{EMERGENCY OPERATING PROCEDURES}

An examination of the Surry Emergency Operating Procedures (EOPs) was performed for a sustained Loss-of-Site Power with corresponding failures of the emergency diesel-generators (EDGs) to energize upon demand, accompanied by a failure of the emergency (auxiliary) feedwater systems (a TMLB' sequence). The tests that the operators would perform and information requirements in the control room are discussed below. The EOP examination also served as the basis for the assumptions made in the HRA.

Once a reactor trip signal is received in the control room, the EOPs, in particular EP-1.00, will be entered by the operating crew. The immediate post-trip actions are typical and uncomplicated. After verifying a successful reactor and turbine trip, the crew will transition from EP-1.00 to ECA 1.00 (loss of all ac power) provided they determine that the ac buses are not energized.

Upon transitioning to ECA 1.00 , the crew is cautioned that the CSFSTs should be monitored for information only. Although the critical plant functions (e.g., heat sink and RCS and core heat removal safety functions in particular) may exceed estabi shed safety function limits, they cannot trá ssition from ECA 1.00 to an appropriate Functional Recovery Procedure (FRP) until power has been restored. This is buause ac power availability is a prerequisite to implementing the FRPs.

The instructions given to the operating crew for transients that normaily result in a challenge to the secondary heat sink would direct them to FRP H.1, Response to Loss of Secondary Heat Sink, which contains the guidance for responding to a challenge resulting from a potential loss of secondary inventory. Transitioning to FRP H.1 would be appropriate for accidents that result in a loss of capability to feed the steam generators coupled with an adequate supply of feedwater to balance the removal of decay heat from the RCS.
Because this accident is further complicated by a loss of ac power, the recovery actions in the procedures indicated by the CSFSTs will not be implemented until ac power has been restored.

While implementing ECA 1.00 , the crew will identify a loss of all feedwater. After identifying the loss of feedwater, the crew will have two objectives of immediate and equal priority: restore ac power ano feedwater to a steam generator. If ac power is restored, they can transition to any FRP berause the equipinent necessary to restore the plant to an acceptable post-trip condition will be available. Thus, they can establish a heat sink via the steam generators or depending on pressure conditions in the RCS when ac power is restored and the capacity (e.g., shutoff head) of the safety injection pumps, feed and bleed the RCS with the HPI pumps.

Based on the assumptions of the TMLB' sequence, the actions of the plant crews to restore ac power will not be successful. Table G-1 presents a list of operator actions to mitigate this transient. Once the operating crew reaches Step 24 of ECA 1.00, they will be directed back to Step 17. This is an intentional do-loop in which they monitor RCS conditions and continue attempts to establish vital power or a heat sink. From this point on, they will either persist in the tasks they are performing or become innuvative (e.g., establish firewater to a steam generator) in order to mitigate the transient.

Based on data gathered at another Westinghouse plant ${ }^{\mathrm{G}-1}$ and interviews with licensed operator examiners at the INEL who are familiar with the operation of Westinghouse plants, it is estimated that the operating crew will reach Step 24 of ECA 1.00 between 15 and $25 \mathrm{~min}$ after the initial reactor trip. Core uncovery with no operator actions is calculated to occur much later (approximately $3 \mathrm{~h}$ after transient initiation). Thus, the time avallable to the operating crew to recover the plant is large enough to 
Table G-1. Operator actions required by Emergency Procedure 1.00

EP-1.00

1

2

3

ECA 1.00

3
Rx Trip/SI

Verify Reactor Trip:

- Trip reactor

- Verify:

- Rod bottom lights lit

- Rod position indicators fully in

- Neutron flux

Verify Turbine Trip:

- Trip main turbine:

- Close turbine stop valves

-- Verify rapid load cecrease

- Open turbine drains

- Reset reheaters

Verify ac Buses Energized:

- ac einergency buses $\mathrm{H}$ and $\mathrm{J}$ voltages Not Normal

- Attempt to restore power to at least one emergency bus. If no einengency bus energized, go to ECA 1.00 loss of a!l ac power, Step 3

Operating Crew/ Transition to ECA 1.00

ECA 1.00 Loss of all ac Power

(proceed to Step 3 following transition from EP 1.00)

Operators Read Note: CSF Status Trees should be monitored for information only. FRPs should now be implemented.

Check RCS Isolation:

- Verify Closed:

-- PZR PORVs

- Letdown isolation valves

- Excess letdown isolation valves

- PZK and head vent valves

- Loop fill isolation valves 
Verify AFW Flow:

- Not greater than $350 \mathrm{gpm}$ (first procedural opportunity tc detect total loss-of-feedwater)

- Turbine-Driven AFW Pump:

- Verify not running

- Manually open steam supply valves

- Verify proper emergency alignment of AFW MOVs

or

- Manually align AFW MOVs

- Cross connect AFW from unaffected unit

Try to Restore Power to any ac Emergency Bus:

- Energize ac emergency buses with Emergency Diesel Generator (EDG); Fails to start

Also Fail:

- Start emergency EDG in exercise

- Manually energize bus

- Initiate backfeed electrical lineup

Check ac Emergency Buses:

- None energized

Try to Cross-Connect from Other Unit:

- Changing

- Instrument Air

- $\mathrm{CCW}$

- Reduce nonessential loads

- Implement Emergency Plan 
Table G-1. (continued)

$\underline{E P-1.00}$

6

7

8

9

10

11

12
Loss of All ac Power

Place in Pull-to-Lock:

- CHG/SI pumps

- Low head SI pumps

- Motor-driven AFW pumps

- $\quad$ CS pumps

- $\quad$ RS pur ups

- $\quad$ CW pumps

Attempt to Locally Restore ac Power:

Initiate AP-17 Restoration and Loading of EDG

Initiate AP-10.1 Loss of Vital Bus

Switch radiation monitoring common cabinet power supply

Check RCP Seal Cooling Established:

Seal injection

or

Thermal barrier CCW

Terminate any Radioactive Effluent Releases

Close CST to Hotwell Isolation Valves (2 valves)

Check SG Isolation:

- Check closed:

- MSTVs and bypass valves

- MFW FCVs and bypass valves

- SG blowdown trip valves

Check Circulating Water Availability:

- Intake canal level normal

- $\quad$ Start emergency SW pumps 
Table G-1. (continued)

EP-1.00

13

14

15

16

17

18
Loss of All ac Power

Check if SGs Are Not Faulted:

- Check SG pressures:

- No SG pressure decreasing in an uncontrolled manner

- No SG completely depressurized

Check if SG Tubes Are Not Ruptured:

- $\quad$ Verify Normal:

- Condenser air ejector radiation

- SG blowdown radiation

- MS line radiation

Check Intact SG Levels:

- Verify narrow range level $>9$ [32]\%

Check dc Bus Loads:

Shed all non-vital loads:

- Break condenser vacuum when turbine stops, then place EOP switch in PTL

- Vent generator hydrogen using 0-HG-7

- When pressure <2 psig, place air side seal oil backup pump switch in PTL

- Electrical department determine battery condition and remaining life

Check ECST LVL $>20 \%$

Depressurize Intact SG(s) to 175 psig:

- $\quad$ Check SG NR levels $>9[32] \%$ in at least one $\mathrm{SG}^{\mathrm{a}}$

a. Because AFW has been lost, it is doubtful that this step will be performed unless either (a) the particular failure mode masks loss of AFW or (b) the crew decides, against their training, to depressurize early. 
Table G-1. (continued)

EP-1.00

19

20

21

22

23

24
Loss of All ac Power

- Depressurize intact SG(s) to 175 psig:

- Locally open MSTV bypass valves and dump steam at max rate:

- Close AS cross-tie valve

- Open MS to AS bypass valve

- Open condenser hogger steam valves

- Verify RCS TC $>315^{\circ} \mathrm{F}$

- Check SG pressures <175 psig

- Manually control steam flow

Check Reactor Subcritical:

- INR zero or negative startup rate

- Source range channels zero or negative

Check SI Signal Status:

If SI has not actuated, GO TO Step 23.

Read Note!

- Reset SI Upon Actuation to Permit Manual Loading of Equipment on an Energized ac Bus

Verify Containment Isolation Valves Closed

Verify Containment Pressure Has Remained $<3$ psia

Verify Containment Radiation $<10 \mathrm{R} / \mathrm{H}$

Check if ac Emergency Power Restored

If it has not, perform the following:

- Continue to control RCS conditions and monitor unit status:

- Check status of local actions:

- ac power restoration

- RCP seal isolation

- dc power supply

- Verify BASTS temp $<135^{\circ} \mathrm{F}$

- If SFP level < circulating pump suction, then fill SFP using fire water

- Retum to Step 17. 
encompass a number of options. Some of these options include obtaining additional support by calling in personnel from offsite, activating the Emergency Operation Facility (EOF), seeking assistance from vendor personnel, etc. However, the options remain uncertain because they are not addressed by the EOPs.

In order to depressurize the Surry RCS to a pressure below that which may result in DCH, a member of the operating crew must open both PORVs and the high point vent valves. The procedural instructions to open the PORVs and high point vent yalves on the primary system are provided in FRP C.1 (Inadequate Core Cooling), Step 22. However, unless the control room crew leave ECA 1.00 against the caution to do so, they will not reach the proper procedural steps to depressurize the RCS.

As the transient progresses, it is likely that some portion of time will be occupied by comniu- nication with the Technical Suppor Center and Emergency Response Center due vo degrading RCS conditions. In additisn, some portion of the operating crew's time may be spent communicating with personnel dispatched to recover ac power and feedwater. It is possible that some of the control room crew may accompany the auxiliary operators to the area(s) of the plant where actions to recover power and feedwater will be conducted, as occurred during the June 9, 1985, loss-of-fcidwater transient at Davis Besse.

However, because no actual or simulator data for the TMLB' sequence at this plant were available, activities that might occur and are not presented in the EOPs were not included as operator actions. Such activities would impose additional demand on crew performance, and this should be recognized. Recognition should also be given to the sequence of operator activities outlined for this event, including, those that would occur but are not presented in the EOPS. 


\section{REFERENCES}

G-1. D. J. Hanson et al., "Evaluation of Operational Safety at Babcock and Wilcox Plants, Voume 1-Results Overview," NUREG/CR-4966, October 1987. 


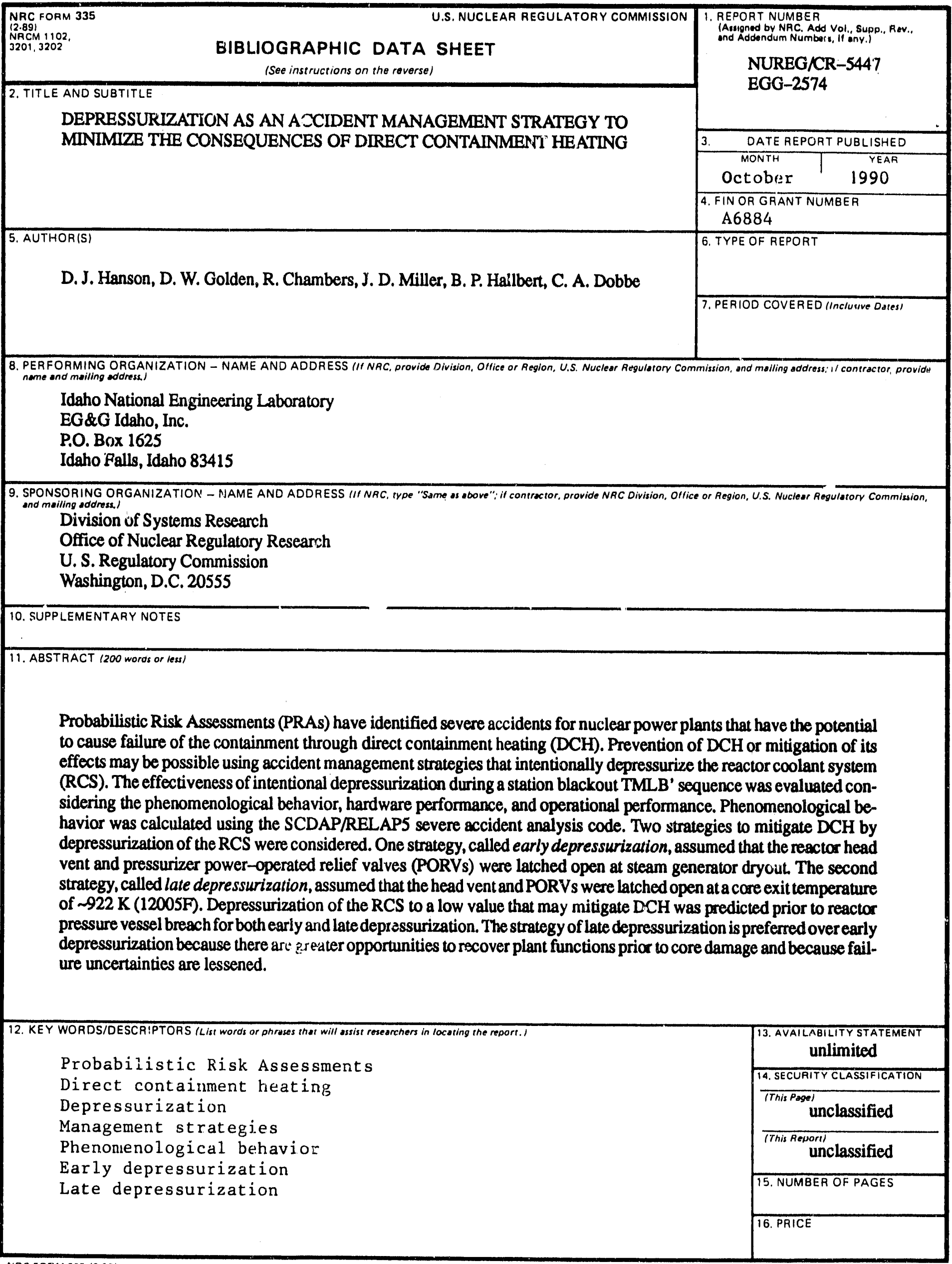



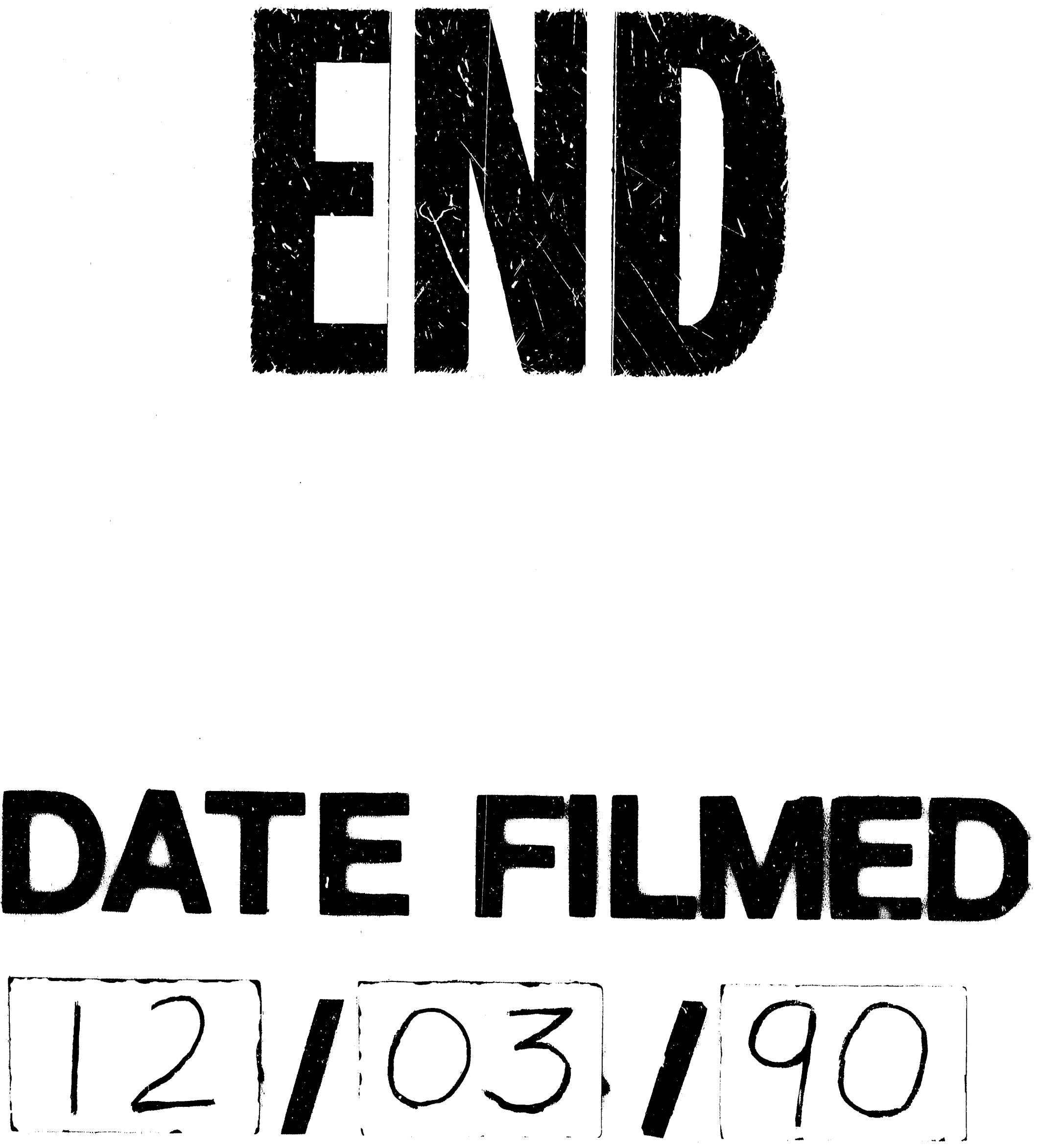
